\title{
AC-AC VOLTAGE REGULATION BY SWITCH MODE PWM CÛK VOLTAGE CONTROLLER WITH IMPROVED PERFORMANCE
}

\author{
by \\ Palash Kumar Banerjee \\ Bachelor of Science in Engineering, DUET, Bangladesh, 1998 \\ A project \\ presented to Ryerson University \\ in partial fulfillment of the requirement for the degree of \\ Master of Engineering \\ in the program of \\ Electrical and Computer Engineering
}

Toronto, Ontario, Canada, 2014

(C) Palash Kumar Banerjee 2014 


\section{AUTHOR'S DECLARATION}

I hereby declare that I am the sole author of this project / thesis. This is a true copy of the project / thesis, including any required final revisions, as accepted by my examiners.

I authorize Ryerson University to lend this project / thesis to other institutions or individuals for the purpose of scholarly research.

I further authorize Ryerson University to reproduce this project by photocopying or by other means, in total or in part, at the request of other institutions or individuals for the purpose of scholarly research.

I understand that my thesis may be made electronically available to the public. 


\begin{abstract}
Title: AC-AC Voltage Regulation by Switch Mode PWM Cûk Voltage Controller With Improved Performance

Degree: Master of Engineering

Year: 2014

Student Name: Palash Kumar Banerjee

Program: Electrical and Computer Engineering

University: Ryerson University, Canada
\end{abstract}

In this research project, an $\mathrm{AC}$ Cûk voltage regulator has been proposed for maintaining constant voltage across the load during wide range of input voltage fluctuations. The proposed AC Cûk voltage regulator made of practical IGBT switches has been investigated for both manual and automatic control circuit. A fraction of the output voltage is taken as the input voltage of the control circuit and produce the error signal if any changes occur in the output voltage. The modified error signal is used to make PWM signals for switching devices as per output voltage of regulator. The PWM controls the ON/OFF time (Duty cycle) of switching devices (IGBTs) of the proposed regulator. As a result the regulator is maintaining a constant voltage across the load during any change in supply voltage. The simulation waveforms and the calculated total harmonics distortion (THD) values are compared with previously studied AC Buck-Boost regulator. The observed simulated waveforms of output voltage, output current and input current and THD values have been improved in case of proposed AC Cûk voltage regulator. 


\section{ACKNOWLEDGEMENTS}

First and foremost, I express my deepest gratitude and appreciation to my supervisor, Dr. Kaamran Raahemifar for his continuous aspiration, enlightenment, valuable instruction, encouragement and exceptional support throughout my studies. Without his continuous guidance and direction, I may not have been able to complete this research project and achieve my Master of Engineering degree.

I would like to express my thankfulness to faculty members and staff of Electrical and Computer Engineering Department of Ryerson University.

My deepest gratitude goes to my parents who have always provided unconditional support.

I also thank my family members, relatives and friends for their helps, support and encouragement.

Last but not least, my special thanks to my wife and two lovely kids for their endless love and encouragement which has enabled me to complete this project and my Master of Engineering program. 


\section{DEDICATION}

\section{To my parents}




\section{TABLE OF CONTENTS}

Author's Declaration $\quad$ ii

Abstract $\quad$ iii

Acknowledgements $\quad$ iv

Dedication $\quad \mathrm{V}$

Table of Contents vi vi

List of Figures $\quad$ ix

List of Abbreviations $\quad$ xiv

\section{Chapter 1: Introduction}

1.1 Introduction 1

1.2 Organization of the Thesis 4

\section{Chapter 2 : Literature Review}

2.1 Review of Related Research 5

2.2 Review of Most Significant Papers Work on AC-AC Voltage Regulator 5

2.2.1 Review of AC-AC Buck Voltage Regulator 5

2.2.2 Review of AC-AC Buck-Boost Voltage Regulator (Manually 11 Controlled)

2.2.3 Review of AC-AC Buck -Boost Voltage Regulator (Auto Controlled) 15

2.3 Objective and Contribution of this Research 17

\section{Chapter 3 : DC Voltage Regulator and AC Voltage Regulator}

3.0 Introduction of Power Conversion Principle 18

3.1 Principle of DC-DC Switch Mode Power Supply (SMPS) 20

3.2 Types of DC-DC Regulator Topologies 22

3.2.1 Buck Regulator 
3.2.2 Boost Regulator 22

3.2.3 Buck-Boost regulator 23

$\begin{array}{ll}3.2 .4 \text { Cûk regulator } & 23\end{array}$

3.3 Switch Mode AC Voltage Regulator 24

\section{Chapter 4 : Development and Analysis of Proposed Switch Mode AC - AC Cûk Voltage Regulator}

4.0 Introduction $\quad 25$

4.1 Operation Principle of Proposed Switch Mode AC Cûk Voltage Regulator 25

4.2 Manually Controlled Proposed AC Cûk Voltage Regulator 29

4.3 Gate Signal Generating Circuit for Manually Controlled Proposed AC Cûk 31 Regulator

4.4 Results of Manually Controlled Proposed AC Cûk Regulator 31

4.5 Automatically Controlled Proposed AC Cûk Voltage Regulator 42

4.6 Results of Proposed Automatic Controlled AC Cûk Regulator 45

4.7 Harmonics Analysis of Proposed Automatic Controlled AC Cûk Regulator 47

4.8 Harmonics Analysis of Automatically Controlled AC Buck-Boost 51 Regulator

4.9 Comparison of Results: Proposed AC Cûk With Reviewed Buck-Boost 55 Regulator

(A) Comparison Based on Input-Output Waveforms as Input Voltage 55 Varies from its Rated Supply Voltage (250V to 350V)

(B) Comparison Based on Harmonics Analysis 55 
Chapter 5 : Conclusion and Recommendation

5.1 Conclusion $\quad 57$

5.2 Recommendation for Future Work 58

$\begin{array}{ll}\text { References } & 60\end{array}$ 


\section{LIST OF FIGURES}

Figure 2.1: AC-AC Buck Converter Schematic (as reported in paper) 6

Figure 2.2: AC-AC Buck Converter (with ideal switches) 6

Figure 2.3: AC-AC Buck Converter (with IGBT switches) 7

Figure 2.4: Input and output voltage waveforms, when input voltage $250 \mathrm{~V}$, load $50 \mathrm{ohm} \quad 8$ and $\mathrm{V}_{\mathrm{dc}}=8.0 \mathrm{~V}$

$\mathrm{V}(\mathrm{V} 5:+)-$ Input voltage $=250 \mathrm{~V}$

$\mathrm{V}(\mathrm{R} 1: 2)-$ Output voltage $=300 \mathrm{~V}$

Figure 2.5: Generated PWM signals for switch 1 and 2 when input voltage=250V 9

Figure 2.6: Input and output voltage waveforms, when input voltage $225 \mathrm{~V}$, load $50 \mathrm{ohm}$ and $\mathrm{V}_{\mathrm{dc}}=4.0 \mathrm{~V}$

$\mathrm{V}(\mathrm{V} 5:+)-$ Input voltage $=225 \mathrm{~V}$

$\mathrm{V}(\mathrm{R} 1: 2)-$ Output voltage $=300 \mathrm{~V}$

Figure 2.7: Generated PWM signals for switch 1 and 2 when input voltage=225V 10

Figure 2.8: AC-AC Buck-Boost Converter Schematic (with IGBT switches) 12

Figure 2.9: Input and output voltage waveforms, when input voltage $250 \mathrm{~V}$, load $50 \mathrm{ohm}$ and $\mathrm{V}_{\mathrm{dc}}=11.8 \mathrm{~V}$

$\mathrm{V}(\mathrm{V} 1:+)-$ Input voltage $=250 \mathrm{~V}$

$\mathrm{V}(\mathrm{R} 7: 2)-$ Output voltage $=300 \mathrm{~V}$

Figure 2.10: Generated PWM signals for switch 1 and 2 when input voltage $=250 \mathrm{~V}$

Figure 2.11: Input and output voltage waveforms, when input voltage $300 \mathrm{~V}$, load $50 \mathrm{ohm}$ and $\mathrm{V}_{\mathrm{dc}}=12.30 \mathrm{~V}$

$\mathrm{V}(\mathrm{V} 1:+)-$ Input voltage $=300 \mathrm{~V}$

$\mathrm{V}(\mathrm{R} 7: 2)-$ Output voltage $=300 \mathrm{~V}$

Figure 2.12: Input and output voltage waveforms, when input voltage $350 \mathrm{~V}$, load $50 \mathrm{ohm}$ and $\mathrm{V}_{\mathrm{dc}}=12.70 \mathrm{~V}$

$\mathrm{V}(\mathrm{V} 1:+)-$ Input voltage $=350 \mathrm{~V}$

$\mathrm{V}(\mathrm{R} 7: 2)-$ Output voltage $=300 \mathrm{~V}$

Figure 2.13: Input and output voltage waveforms, when input voltage $400 \mathrm{~V}$, load $50 \mathrm{ohm}$ 
and $\mathrm{V}_{\mathrm{dc}}=13.0 \mathrm{~V}$

$\mathrm{V}(\mathrm{V} 1:+)-$ Input voltage $=400 \mathrm{~V}$

$\mathrm{V}(\mathrm{R} 7: 2)-$ Output voltage $=300 \mathrm{~V}$

Figure 2.14: AC- AC Buck-Boost converter with automatic feedback control Circuit

Figure 2.15: Input and output voltage waveforms, when input voltage $250 \mathrm{~V}$ and load $50 \Omega$

$\mathrm{V}(\mathrm{V} 6:+)-$ Input voltage $=250 \mathrm{~V}$

$\mathrm{V}(\mathrm{R} 1: 2)-$ Output voltage $=300 \mathrm{~V}$

Figure 2.16: Input and output voltage waveforms, when input voltage $300 \mathrm{~V}$ and load $50 \Omega$

$\mathrm{V}(\mathrm{V} 6:+)-$ Input voltage $=300 \mathrm{~V}$

$\mathrm{V}(\mathrm{R} 1: 2)-$ Output voltage $=300 \mathrm{~V}$

Figure 2.17: Input and output voltage waveforms, when input voltage $400 \mathrm{~V}$ and load $50 \Omega$

V(V6:+) - Input voltage $=400 \mathrm{~V}$

$\mathrm{V}(\mathrm{R} 1: 2)-$ Output voltage $=300 \mathrm{~V}$

Figure 3.1: Linear (dissipative) power conversion circuit

Figure 3.2: Switch mode (non dissipative) power conversion circuit

Figure 3.3: Typical switch mode power conversion circuit

Figure 3.4: Block diagram of Switch Mode Power Supply (SMPS)

Figure 4.1: AC Cûk regulator configuration by using IGBT switches with manual control circuit

Figure 4.2: (a) Circuit operation during positive half- cycle of AC input supply, when IGBT1 is ON (by gate signal) and IGBT-2 is OFF

Figure 4.2: (b) Circuit operation during positive half - cycle of AC input supply, when IGBT-1 is OFF and IGBT-2 is ON (by gate signal)

Figure 4.3: (a) Circuit operation during negative half - cycle of AC input supply, when

IGBT-1 is ON (by gate signal) and IGBT-2 is OFF

Figure 4.3: (b Circuit operation during negative half- cycle of AC input supply, when IGBT-1 is OFF and IGBT-2 is ON (by gate signal)

Figure 4.4: AC Cûk regulator configuration with manual control circuit 
Figure 4.5: Input and output voltage waveforms, when input voltage $300 \mathrm{~V}$, load $150 \mathrm{ohm}$ and duty cycle $\mathrm{D}=0.3$.

$\mathrm{V}(\mathrm{V} 1:+)-$ Input voltage $=300 \mathrm{~V}$

$\mathrm{V}(\mathrm{R} 7: 2)-$ Output voltage $=60 \mathrm{~V}$

Figure 4.6: Input and output voltage waveforms, when input voltage $300 \mathrm{~V}$, load $150 \mathrm{ohm}$ and duty cycle $\mathrm{D}=0.4$

$\mathrm{V}(\mathrm{V} 1:+)-$ Input voltage $=300 \mathrm{~V}$

$\mathrm{V}(\mathrm{R} 7: 2)-$ Output voltage $=120 \mathrm{~V}$

Figure 4.7: Input and output voltage waveforms, when input voltage $300 \mathrm{~V}$, load $150 \mathrm{ohm}$

and duty cycle $\mathrm{D}=0.5$

$\mathrm{V}(\mathrm{V} 1:+)-$ Input voltage $=300 \mathrm{~V}$

$\mathrm{V}(\mathrm{R} 7: 2)-$ Output voltage $=200 \mathrm{~V}$

Figure 4.8: Input and output voltage waveforms, when input voltage $300 \mathrm{~V}$, load $150 \mathrm{ohm}$ and duty cycle $\mathrm{D}=0.6$

$\mathrm{V}(\mathrm{V} 1:+)-$ Input voltage $=300 \mathrm{~V}$

$\mathrm{V}(\mathrm{R} 7: 2)-$ Output voltage $=300 \mathrm{~V}$

Figure 4.9: Input and output voltage waveforms, when input voltage $300 \mathrm{~V}$, load $150 \mathrm{ohm}$ and duty cycle $\mathrm{D}=0.7$

$\mathrm{V}(\mathrm{V} 1:+)-$ Input voltage $=300 \mathrm{~V}$

$\mathrm{V}(\mathrm{R} 7: 2)-$ Output voltage $=450 \mathrm{~V}$

Figure 4.10: Input and output voltage waveforms, when input voltage $300 \mathrm{~V}$, load $150 \mathrm{ohm}$ and duty cycle $\mathrm{D}=0.8$

$\mathrm{V}(\mathrm{V} 1:+)-$ Input voltage $=300 \mathrm{~V}$

$\mathrm{V}(\mathrm{R} 7: 2)-$ Output voltage $=550 \mathrm{~V}$

Figure 4.11: Input and output voltage waveforms, when input voltage $300 \mathrm{~V}$, load $150 \mathrm{ohm}$ and duty cycle $\mathrm{D}=0.9$

$\mathrm{V}(\mathrm{V} 1:+)-$ Input voltage $=300 \mathrm{~V}$ and $\mathrm{V}(\mathrm{R} 7: 2)-$ Output voltage $=625 \mathrm{~V}$

Figure 4.12: Variation of output voltage with Duty Cycle (When input voltage $=300 \mathrm{~V}$ )

Figure 4.13: Input and output voltage waveforms, when input voltage $200 \mathrm{~V}$, load $150 \mathrm{ohm}$

$\mathrm{V}(\mathrm{V} 1:+)$ : Input voltage $=200 \mathrm{~V}$

$\mathrm{V}(\mathrm{R} 7: 2):$ Output voltage $=300 \mathrm{~V}$

Figure 4.14: Input and output voltage waveforms, when input voltage $250 \mathrm{~V}$, load $150 \mathrm{ohm}$ $\mathrm{V}(\mathrm{V} 1:+)$ : Input voltage $=250 \mathrm{~V}$ 
$\mathrm{V}(\mathrm{R} 7: 2):$ Output voltage $=300 \mathrm{~V}$

Figure 4.15: Input and output voltage waveforms, when input voltage $300 \mathrm{~V}$, load $150 \mathrm{ohm}$

$\mathrm{V}(\mathrm{V} 1:+):$ Input voltage $=300 \mathrm{~V}$

$\mathrm{V}(\mathrm{R} 7: 2):$ Output voltage $=300 \mathrm{~V}$

Figure 4.16: Input and output voltage waveforms, when input voltage $350 \mathrm{~V}$, load $150 \mathrm{ohm}$

$\mathrm{V}(\mathrm{V} 1:+):$ Input voltage $=350 \mathrm{~V}$

$\mathrm{V}(\mathrm{R} 7: 2):$ Output voltage $=300 \mathrm{~V}$

Figure 4.17: Input and output voltage waveforms, when input voltage $400 \mathrm{~V}$, load $150 \mathrm{ohm}$

$\mathrm{V}(\mathrm{V} 1:+):$ Input voltage $=400 \mathrm{~V}$

$\mathrm{V}(\mathrm{R} 7: 2)$ : Output voltage $=300 \mathrm{~V}$

Figure 4.18: Switching pulses, when input voltage $250 \mathrm{~V}$, load $150 \mathrm{ohm}$

$\mathrm{V}(\mathrm{Z1})$ : Switching voltage of switch-1 and V(Z3): Switching voltage of switch-2

Figure 4.19: Switching pulses, when input voltage $300 \mathrm{~V}$, load $150 \mathrm{ohm}$

$\mathrm{V}(\mathrm{Z1})$ - Switching voltage of switch-1

$\mathrm{V}(\mathrm{Z3})$ - Switching voltage of switch-2

Figure 4.20: Switching pulses, when input voltage 400V, load $150 \mathrm{ohm}$

$\mathrm{V}(\mathrm{Z} 1)$ - Switching voltage of switch-1

$\mathrm{V}(\mathrm{Z} 3)$ - Switching voltage of switch-2

Figure 4.21: Variation of duty cycle with input voltage to maintain output constant at 300V

Figure 4.22: Proposed Automatically controlled AC Cûk regulator configuration with IGBT switches

Figure 4.23: Input and output voltage waveforms, when input voltage $250 \mathrm{~V}$

$\mathrm{V}(\mathrm{V} 4:+)$ : Input voltage $=250 \mathrm{~V}$

$\mathrm{V}(\mathrm{R} 0: 2)$ : Output voltage $=300 \mathrm{~V}$

Figure 4.24: Input and output voltage waveforms, when input voltage $300 \mathrm{~V}$

$\mathrm{V}(\mathrm{V} 4:+)$ : Input voltage $=300 \mathrm{~V}$

$\mathrm{V}(\mathrm{R} 0: 2)$ : Output voltage $=300 \mathrm{~V}$

Figure 4.25: Input and output voltage waveforms, when input voltage 325V

$\mathrm{V}(\mathrm{V} 4:+)$ : Input voltage $=325 \mathrm{~V}$

$\mathrm{V}(\mathrm{R} 0: 2):$ Output voltage $=300 \mathrm{~V}$ 
Figure 4.26: Input and output voltage waveforms, when input voltage 350V

$\mathrm{V}(\mathrm{V} 4:+)$ : Input voltage $=350 \mathrm{~V}$

$\mathrm{V}(\mathrm{R} 0: 2)$ : Output voltage $=300 \mathrm{~V}$

Figure 4.27: Input current, output current and output voltage waveforms when input voltage $250 \mathrm{~V}$

Figure 4.28: Spectrums of input current, output current and output voltage according to figure 4.27

Figure 4.29: Input current, output current and output voltage waveforms when input voltage $325 \mathrm{~V}$

Figure 4.30: Spectrums of input current, output current and output voltage according to figure 4.29

Figure 4.31: Input current, output current and output voltage waveforms when input voltage $250 \mathrm{~V}$

Figure 4.32: Spectrums of input current, output current and output voltage according to figure 4.31

Figure 4.33: Input current, output current and output voltage waveforms when input voltage $325 \mathrm{~V}$

Figure 4.34: Spectrums of input current, output current and output voltage according to figure 4.33 


\section{LIST OF ABBREVIATIONS}

$\begin{array}{ll}\text { BJT } & =\text { Bipolar Junction Transistor. } \\ \text { EMI } & =\text { Electromagnetic Interference. } \\ \text { IGBT } & =\text { Insulated Gate Bi-polar Junction Transistor. } \\ \text { IEEE } & =\text { Institute of Electrical and Electronics Engineers } \\ \text { MOSFET } & =\text { Metal Oxide Semiconductor Field Effect Transistor. } \\ \text { OPAMP } & =\text { Operational Amplifier. } \\ \text { PWM } & =\text { Pulse Width Modulation. } \\ \text { SMPS } & =\text { Switch Mode Power Supply. } \\ \text { SCR } & =\text { Silicon Controlled Rectifier. } \\ \text { THD } & =\text { Total Harmonics Distortion }\end{array}$




\section{CHAPTER - 1}

\section{INTRODUCTION}

\subsection{INTRODUCTION}

In modern society, power delivery has become a core necessity of our everyday lives. Quality and reliable power delivery is fundamental for a large portion of our lives, from the industries that produce our goods, to hospitals that care for our sick and even to our home refrigerators which preserves our food. Power quality describes the level of voltage and current, and it is one of the important considerations in domestic, industrial and commercial applications [5]. Voltage sag is an important power quality problem in our power supply line. Power lines experience voltage sags largely due to switching lines/loads and faults somewhere in the system. Short-lived voltage sags may also occur because of nearby momentary aperiodic loads, such as welding and operation of building construction equipment. Voltage sags are very common since they can be associated with faults remote from the customer. In some countries, continuous voltage sags are also prevalent in many areas due to inadequate supply and demand situation. Both momentary and continuous voltage sags are undesirable in complex process controls and household appliances as they use precision electronic and computerized mechanisms. Major problems associated with the unregulated long - term voltage sags include equipment failure, overheating and complete shutdown. Tap changing transformers with SCR switching are commonly used as a solution to continuous voltage sags [1]. They require large transformer with many SCRs to control the voltage at the load; however, they lack the facility of adjusting to momentary changes. Some other solutions have been suggested in past years to encounter problems of voltage sag [2 - 4]. Advances in power semiconductor devices are making it possible for utilities to use a variety of power control equipment to raise power quality levels to meet the requirements [3]. Manual and auto AC voltage regulators are also used for low, medium and high power applications for domestic, commercial and industrial use. There are some types of AC /AC converter to regulate the input voltage to a lower or higher output voltage. A winding transformer is 
widely used in voltage regulation fields, such as power system, motor speed control and so on. However, because the winding ratio is changed by servo motor or by manual regulation, it has low regulation speed. There is also other research who use thyristor phase controlled circuit to regulate voltage. These converters have been widely used as a soft-starter and a speed regulator of pumps and fans. Although it has a higher regulating speed than a winding transformer, the low input power factor and the large amount of the low-order harmonic current are the major problems [6].

The area of power line conditioning for sensitive loads is important in power electronics. A wide class of equipment is available, including transient suppressors, line voltage regulators, standby power supplies as well as off-line and online uninterruptible power supplies. Given the proliferation of personal computer loads, the need for economical power conditioners is growing rapidly. The use of isolation is not vitally important in many applications, as the input power supply normally contains a high frequency transformer [7].

Dynamic Voltage Restorer (DVR) is sometimes used to regulate the load side voltage [16-18]. The DVR requires an energy storage device to compensate for the voltage sags. Flywheels, batteries, superconducting magnetic energy storage (SMES) and super capacitors are generally used as energy storage devices. The rated power operation of DVR depends on the size and capacity of energy storage device and thus limits its use in high power applications. In contrast, a switching regulator needs no energy storage devices; therefore, it can be used both in low power and high power applications.

The major developments in the field of power electronics make it possible to improve the electrical power system utility interface [12-13]. The work presented in those papers can be used to solve power quality problems caused by line voltage sags and swells. However, in order to reduce the power loss, control simplicity, cost and reliability with good efficiency, further research and investigation are needed to reduce the number of the switching devices. 
Several AC voltage regulators have been studied as a solution of voltage sags and better quality of power supply [20-25]. In each of these every papers, the proposals that have been presented have their own merits along with significant achievements. In some papers, research has been conducted to reduce the number of switching devices in order to reduce power loss. Different working principles have also been presented to ensure the safety of the converter. The switching patterns are critical, and an alternate path must be established in dead time. DC regenerative snubber capacitor is used to realize the safe commutation and to enhance efficiency. Some valuable and considerable proposals also have been suggested to achieve sinusoidal input-output currents/voltage waveforms, improved power factor, reduced harmonic current, a fast response speed and a smaller input filter size [11]. Moreover, there are various investigation that focused on the different topology of AC to AC converter. Every paper has its own significant achievements as well as its own drawbacks and limitations based on input-output voltage/ current, harmonics (THD), power factor, efficiency, etc.

Therefore, an automatic control AC-AC voltage regulator is still in the research and development stage. In order to achieve constant output voltage during the input voltage fluctuation with better performance an automatic control AC- AC Cûk voltage regulator by using PWM switch mode technique has been employed in this project work. 


\subsection{ORGANIZATION OF THE THESIS}

\section{The structure of this project is as follows:}

Chapter-2 includes the literature review of related works. It also highlights a brief summary of the two most significant papers as related to the development of AC-AC voltage regulator and its drawbacks. Objectives of this research are also integral to this chapter.

Chapter-3 includes the description of theory of DC voltage regulator and AC voltage regulator.

Chapter-4 includes the detailed study of proposed switch mode AC Cûk voltage regulator. AC Cûk voltage regulator with IGBT switch implementation has been proposed and studied. Manually controlled AC Cûk voltage regulator with its operation, gate signal generating circuit and results of the AC voltage regulator is included. This chapter also incorporates proposed automatic controlled AC Cûk voltage regulator implemented by practical IGBT switches and its results. Harmonics analysis and total harmonics distortion (THD) calculation are taken into account. The comparison of results of input-output waveforms of voltage/current and THD value of this AC regulator with Buck-Boost AC regulator are also discussed.

Chapter-5 concludes this work with a summary and recommendation for future work. 


\section{CHAPTER - 2}

\section{LITERATURE REVIEW}

\subsection{REVIEW OF RELATED RESEARCH}

With the growth of applications of power electronics, a large number of studies have investigated its application to the power system and its further development (including industries, commercial and domestic consumers). Most of these studies explored the use of switch mode converter topologies that are used in DC-DC conversion. Conversely, some studies have modified these DC regulators to use AC-AC conversion by using pulse width modulation (PWM) technique.

Moreover, among all of these studies for AC-AC conversion, some significant proposals have already been made to control output voltage during input voltage fluctuation by using a switch mode $\mathrm{AC}$ voltage regulator with improved power quality $[5,8]$. The following sections will provide a detailed review of these studies.

\subsection{REVIEW OF MOST SIGNIFICANT PAPERS WORK ON AC-AC VOLTAGE REGULATOR}

\subsubsection{REVIEW OF AC-AC BUCK VOLTAGE REGULATOR}

A switch mode voltage regulator based on Buck conversion principle with a step up injection transformer at its output has been proposed by Steven M. Hietpas and Mark Naden [5]. The converter incorporates fast -switching insulated gate bipolar transistor (IGBT) technology and controls involving pulse width modulation (PWM) techniques.

The AC to AC Buck Converter as reported [5] is shown in fig-2.1. This buck converter can be implemented as shown in fig 2.2 and fig 2.3 by using ideal switches and IGBT switches respectively. The input-output waveforms are shown in fig.2.4 for input voltage of $250 \mathrm{~V}$. 


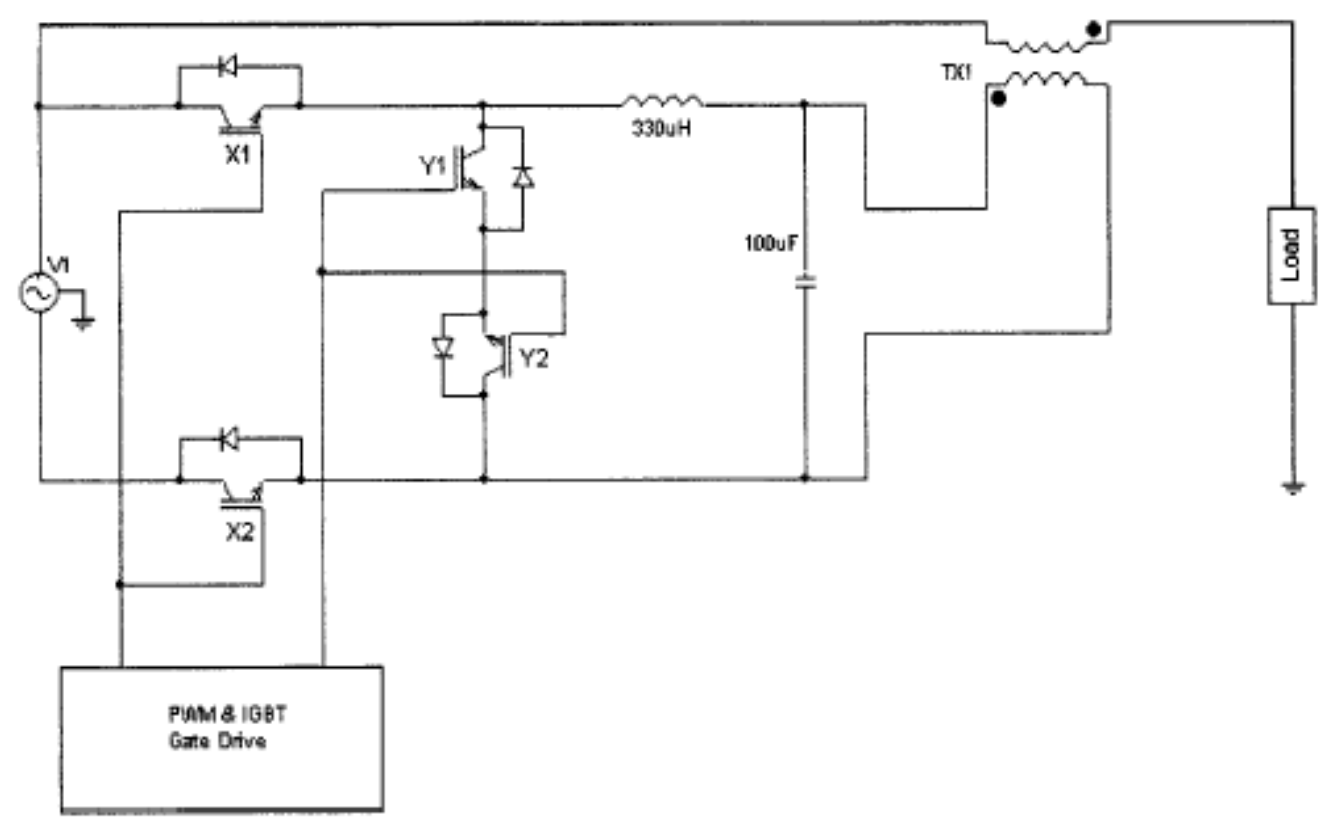

Fig.2.1: AC-AC Buck Converter (as reported in paper)

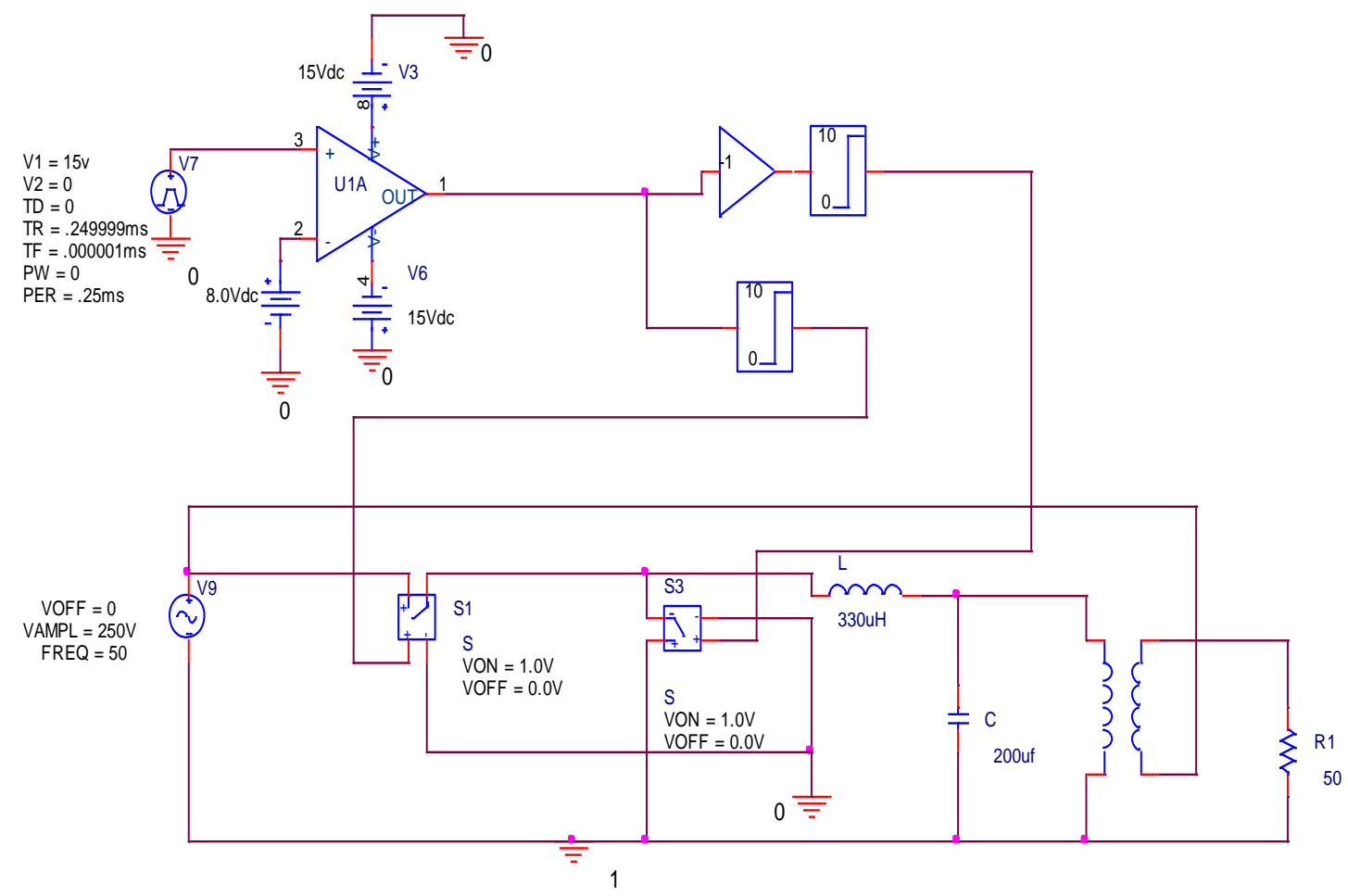

Fig.2.2: AC-AC Buck Converter（with ideal switches) 


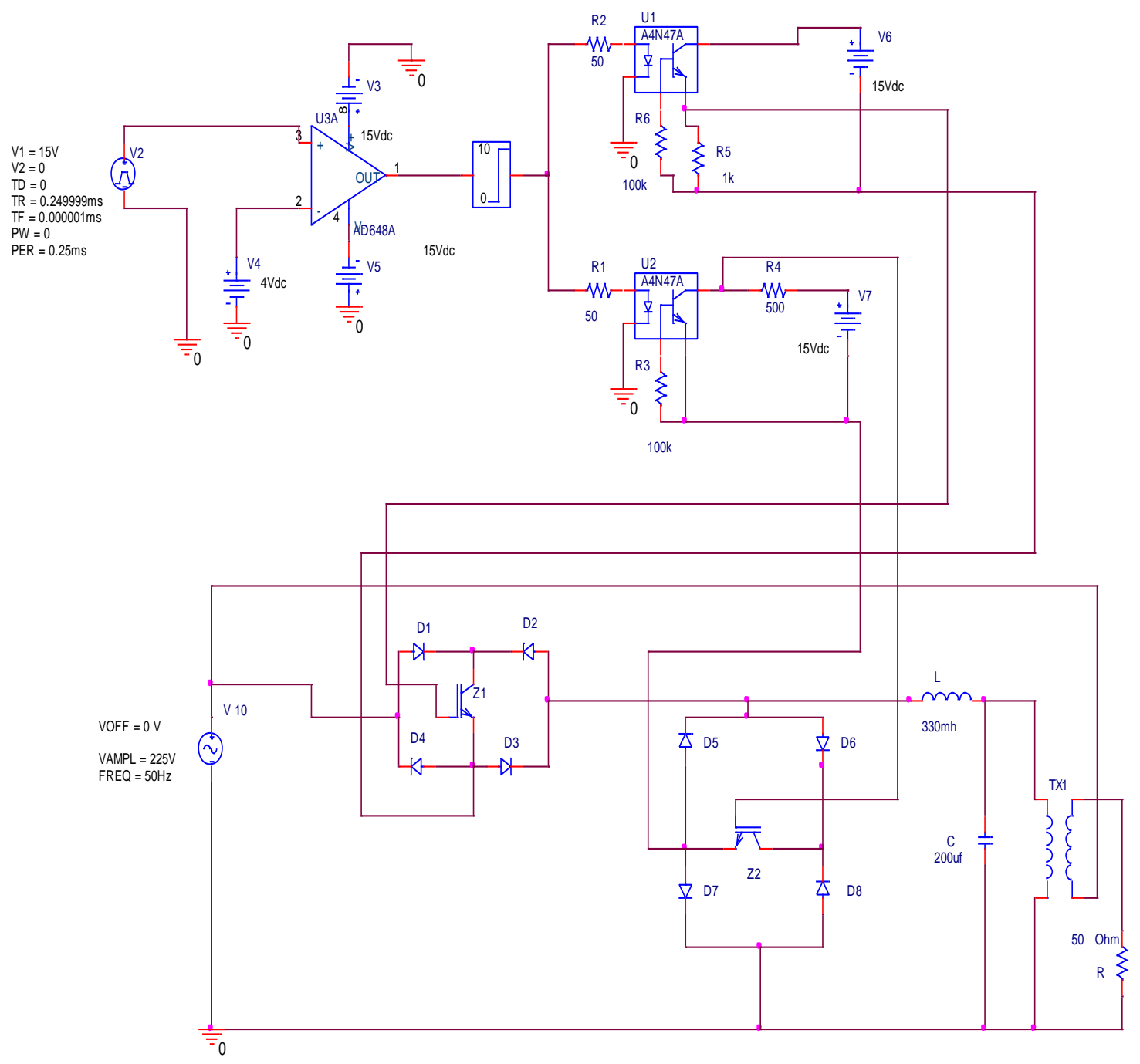

Fig.2.3: AC-AC Buck Converter (with IGBT switches)

When input voltage is $250 \mathrm{~V}$ then output voltage is $300 \mathrm{~V}$. The voltage induced in the transformer secondary $\left(\mathrm{E}_{\mathrm{b}}\right)$ is added with input voltage $\left(\mathrm{V}_{\mathrm{in}}=250 \mathrm{~V}\right)$ and maintains the desired constant voltage $(300 \mathrm{~V})$ across the load instead of decreasing its supply input voltage. The input voltages of OPAMP'S and its output voltage pulse (which is PWM signals for switch 1 and 2) are shown in fig.2.5. To maintain output 300V the input DC voltage of OPAMP'S is required to be $8 \mathrm{~V}$.

If the input voltage is decreased again to $225 \mathrm{~V}$ then output voltage remains $300 \mathrm{~V}$, which is shown in fig.2.6. The input voltages of OPAMP'S and its output voltage pulse (which 
is PWM signals for switch 1 and 2) are shown in fig.2.7. To maintain output $300 \mathrm{~V}$ the input DC voltage of OPAMP'S is required to be $4 \mathrm{~V}$. In this way, pulse width variation controls the duty cycle and output remains constant with the variation of input voltage.

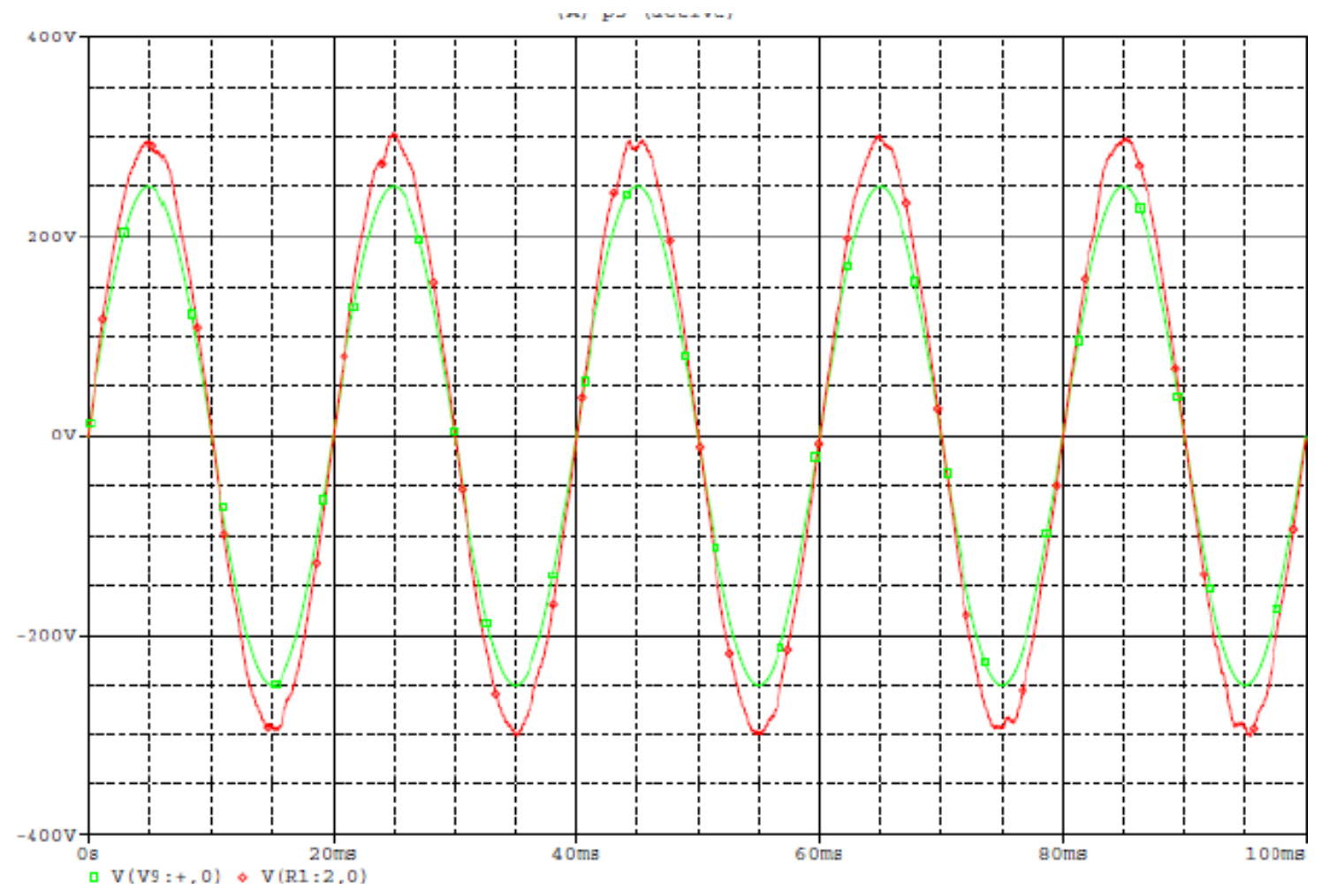

Fig-2.4: Input and output voltage waveforms, when input voltage $250 \mathrm{~V}$, load $50 \mathrm{ohm}$ and $\mathrm{V}_{\mathrm{dc}}=8.0 \mathrm{~V}$ $\mathrm{V}(\mathrm{V} 5:+)-$ Input voltage $=250 \mathrm{~V}$ $\mathrm{V}(\mathrm{R} 1: 2)-$ Output voltage $=300 \mathrm{~V}$ 


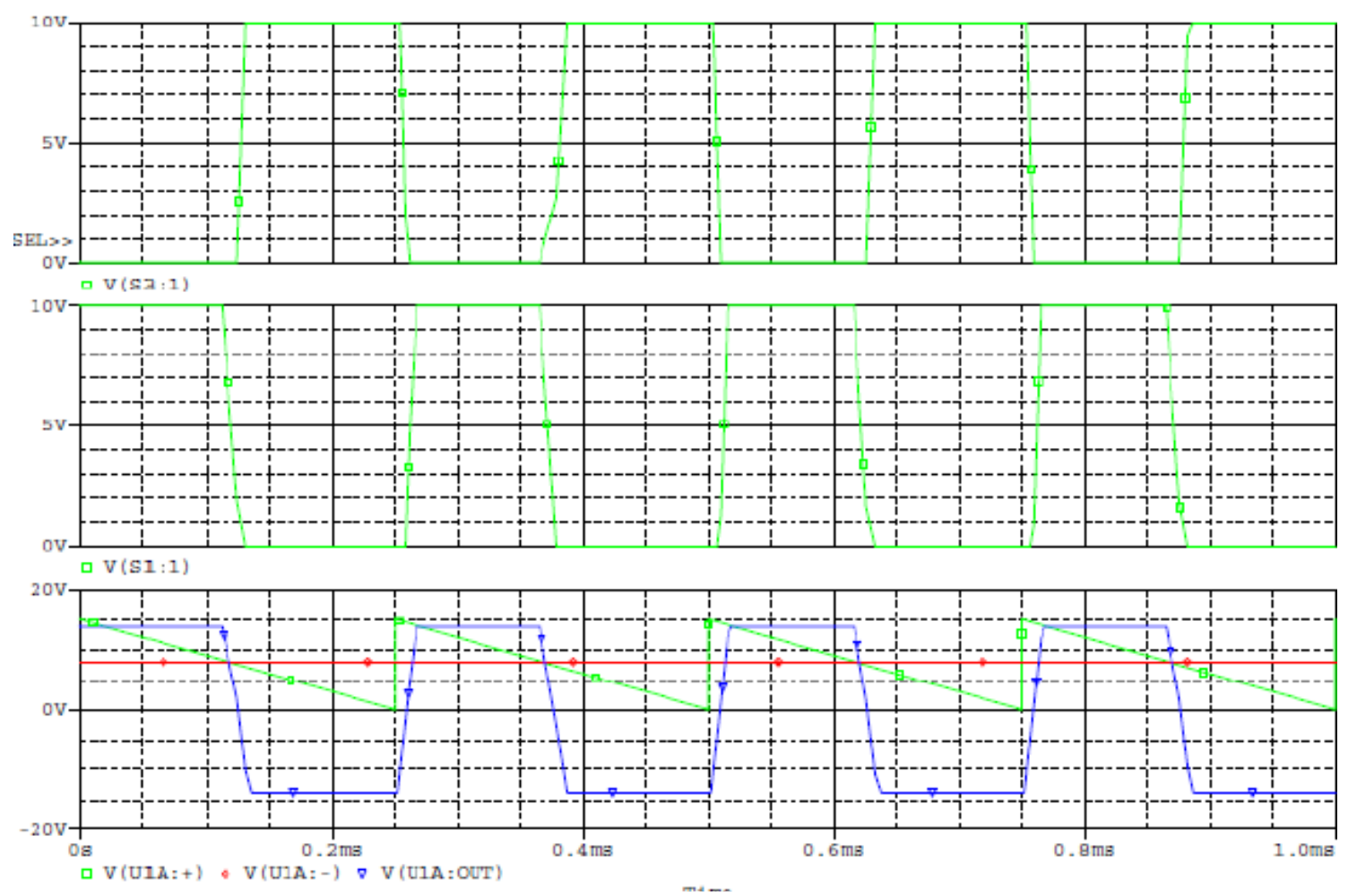

Fig.2.5: Generated PWM signals for switch 1 and 2 when input voltage $=250 \mathrm{~V}$

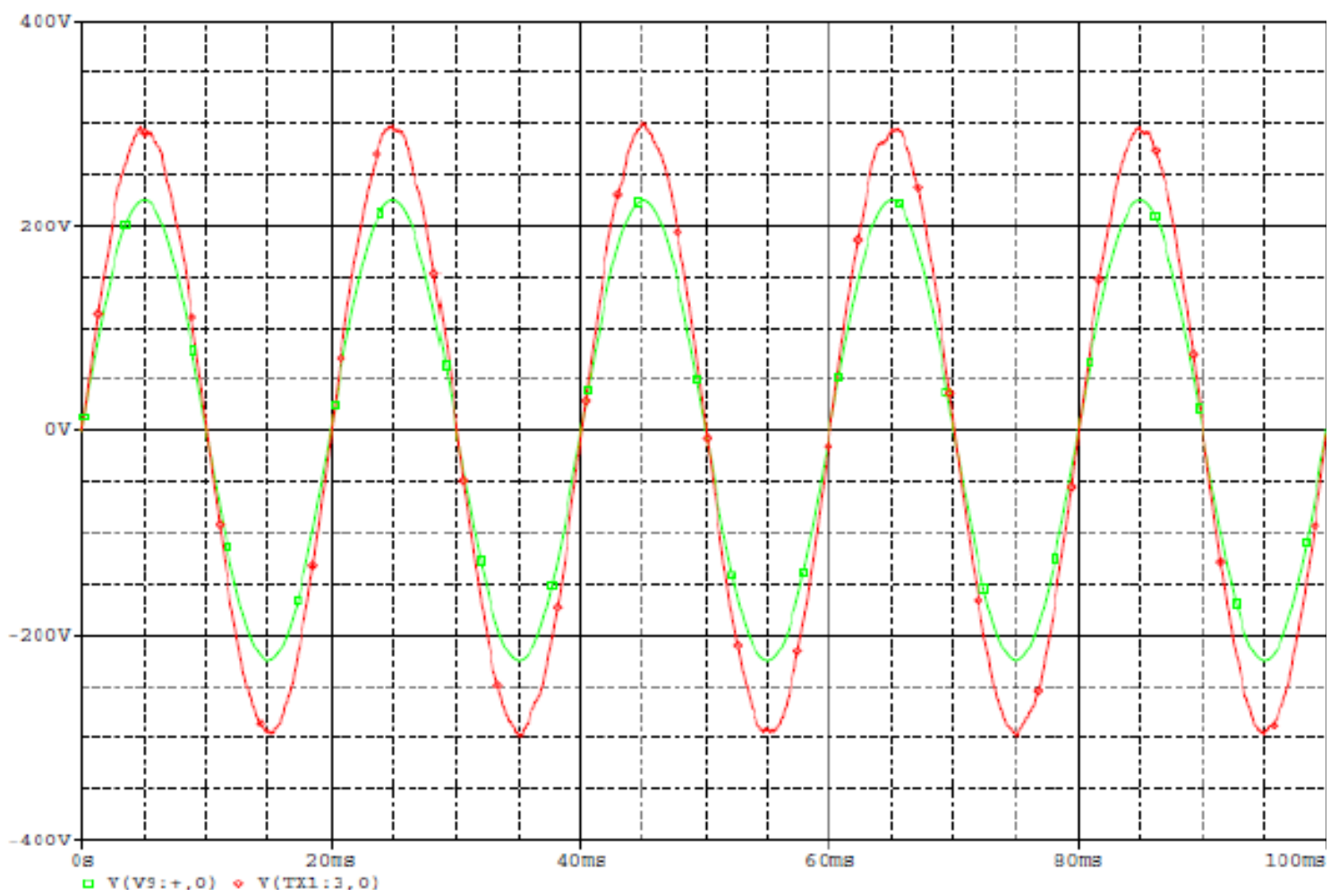

Fig-2.6: Input and output voltage waveforms, when input voltage $225 \mathrm{~V}$, load $50 \mathrm{ohm}$ and $\mathrm{V}_{\mathrm{dc}}=4.0 \mathrm{~V}$ $\mathrm{V}(\mathrm{V} 5:+)-$ Input voltage $=225 \mathrm{~V}$ and $\mathrm{V}(\mathrm{R} 1: 2)-$ Output voltage $=300 \mathrm{~V}$ 


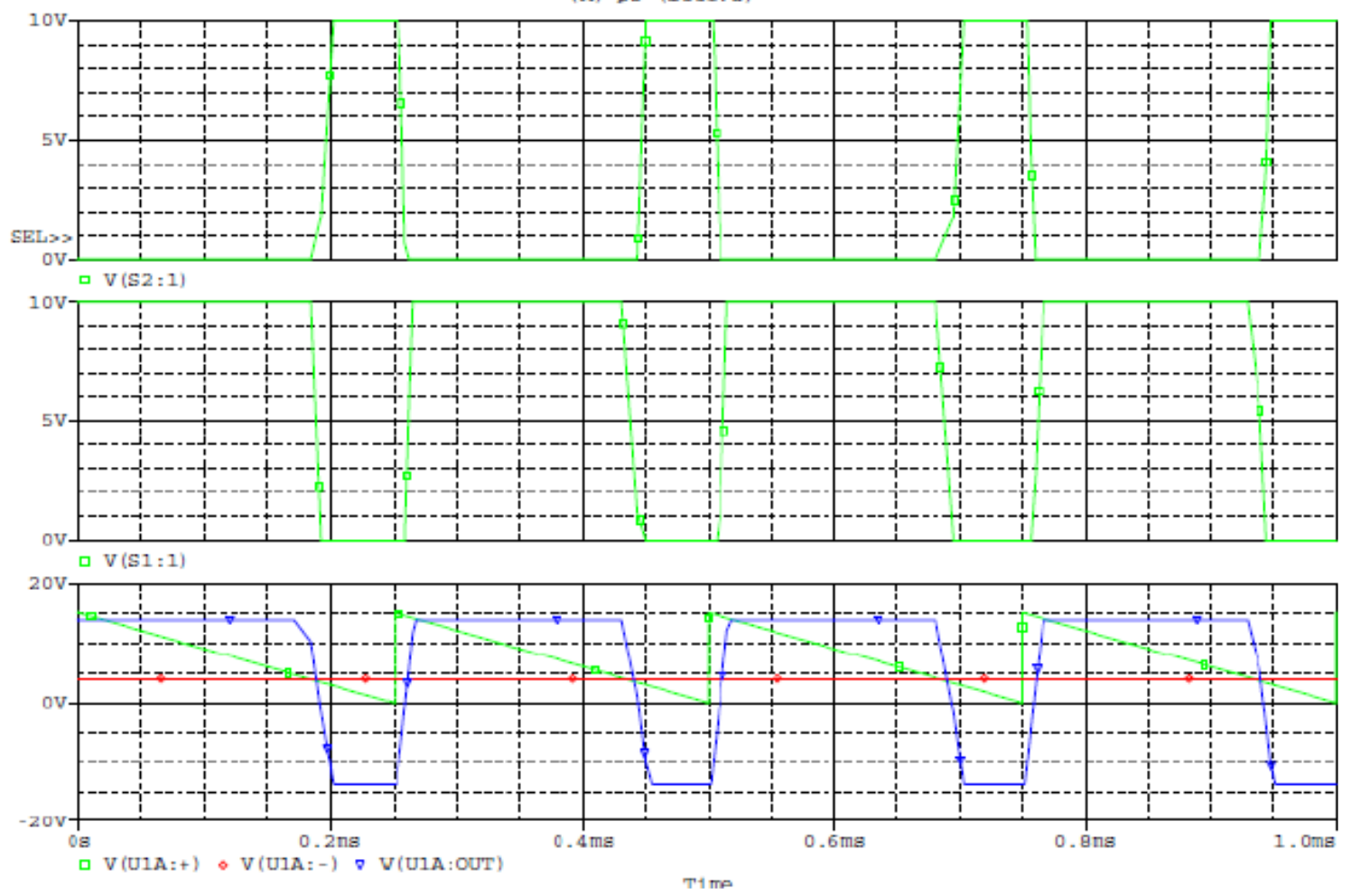

Fig.2.7: Generated PWM signals for switch 1 and 2 when input voltage $=225 \mathrm{~V}$

In this $\mathrm{AC}$ to $\mathrm{AC}$ Buck Converter, when input voltage decreases then the output voltage also decreases. However, when the output voltage is less than the desired value, it can be maintained to the desired value by adding AC input voltage with voltage which is produced in the transformer secondary as shown in fig 2.4 and 2.6. The transformer secondary induced voltage that is added to the input supply voltage can be varied by PWM technique. However, if the input voltage is increased then output will also be increased. It is, therefore, necessary to decrease the output voltage to the desired value by subtracting a suitable voltage from the input voltage, but this Buck arrangement does not allow that to occur. To overcome the above drawback another solution has been suggested [8] by using AC to AC Buck-Boost converter configuration. 


\subsubsection{REVIEW OF AC-AC BUCK-BOOST VOLTAGE REGULATOR (Manually Controlled)}

A transformer - less AC to AC voltage regulator based on Buck-Boost topology has been proposed [8]. The AC to AC Buck-Boost converter topology that uses IGBT and its PWM signals generating circuit is shown in fig 2.8. The input-output waveforms are shown in fig.2.9 for input voltage of 250V. The input voltages of OPAMP'S and its output voltage pulse (which is PWM signals for switch 1 and 2) are shown in fig.2.10. To maintain output $300 \mathrm{~V}$ the input DC voltage of OPAMP'S is required to be $11.8 \mathrm{~V}$. If the input voltage is increased to $300 \mathrm{~V}$ (rated-peak) then output voltage is $300 \mathrm{~V}$ (peak), which is shown in fig.2.11. If the input voltage is increased again from its rated peak value to $350 \mathrm{~V}$ then output voltage is $300 \mathrm{~V}$ (peak), which is shown in fig.2.12. Moreover, if input voltage is further increased to $400 \mathrm{~V}$ then output voltage is $300 \mathrm{~V}$ (peak), which is shown in fig.2.13. So, it has been seen that despite input voltage fluctuation (either decrease or increase) output voltage across the load remains constant (300V-peak) by changing the pulse width (generally called PWM technique) of gate signals of switches S1 and S2 and by changing the input DC voltage of OPAMP. Therefore, pulse width variation controls the duty cycle (D) and output remains constant regardless of the variation in input voltage.

The circuit is simulated by using the following parameters:

$\mathrm{V}_{\mathrm{ac}}=300 \sin (100 \pi \mathrm{t})$, Supply frequency $=50 \mathrm{~Hz}, \mathrm{~L}_{1}=10 \mathrm{mh}, \mathrm{C}_{1}=200 \mathrm{uf}$, Load resistance $=50 \mathrm{Ohm}, \mathrm{f}_{\mathrm{s}}($ switching frequency $)=4 \mathrm{KHz}$. 


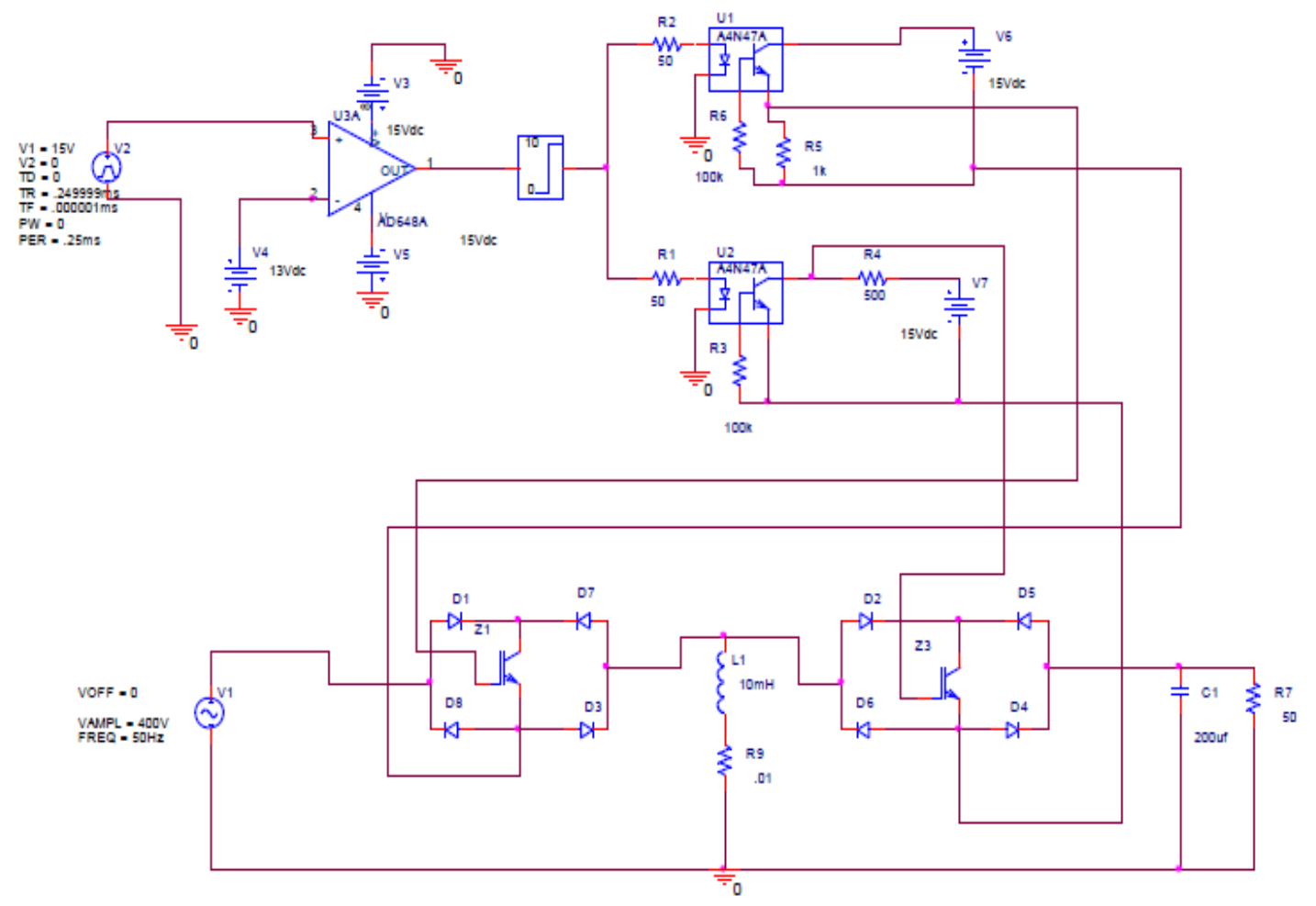

Fig.2.8: AC-AC Buck-Boost Converter Schematic (with IGBT switches)

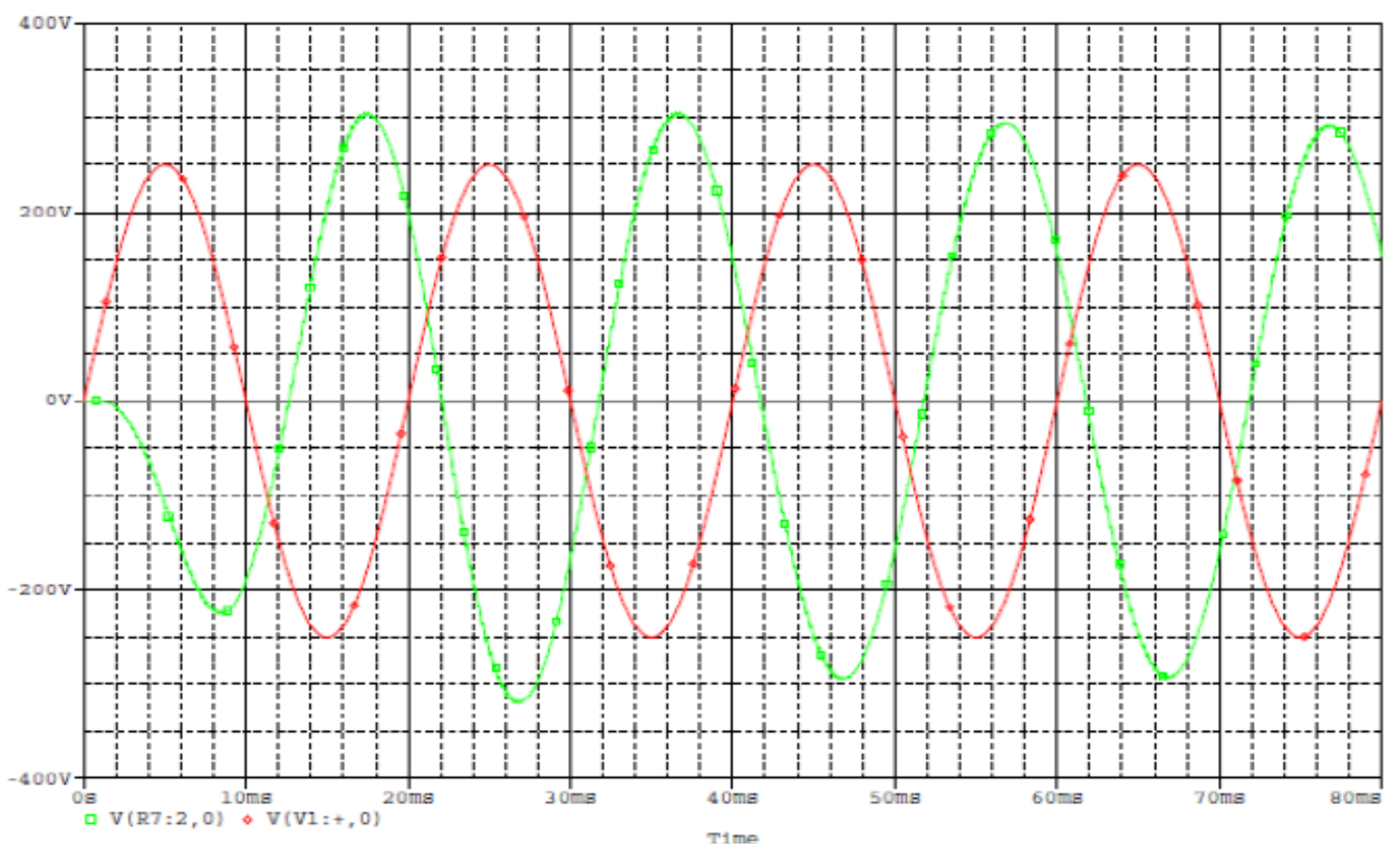

Fig-2.9: Input and output voltage waveforms, when input voltage $250 \mathrm{~V}$, load $50 \mathrm{ohm}$ and $\mathrm{V}_{\mathrm{dc}}=11.8 \mathrm{~V}$

$\mathrm{V}(\mathrm{V} 1:+)-$ Input voltage $=250 \mathrm{~V}$ and $\mathrm{V}(\mathrm{R} 7: 2)-$ Output voltage $=300 \mathrm{~V}$ 

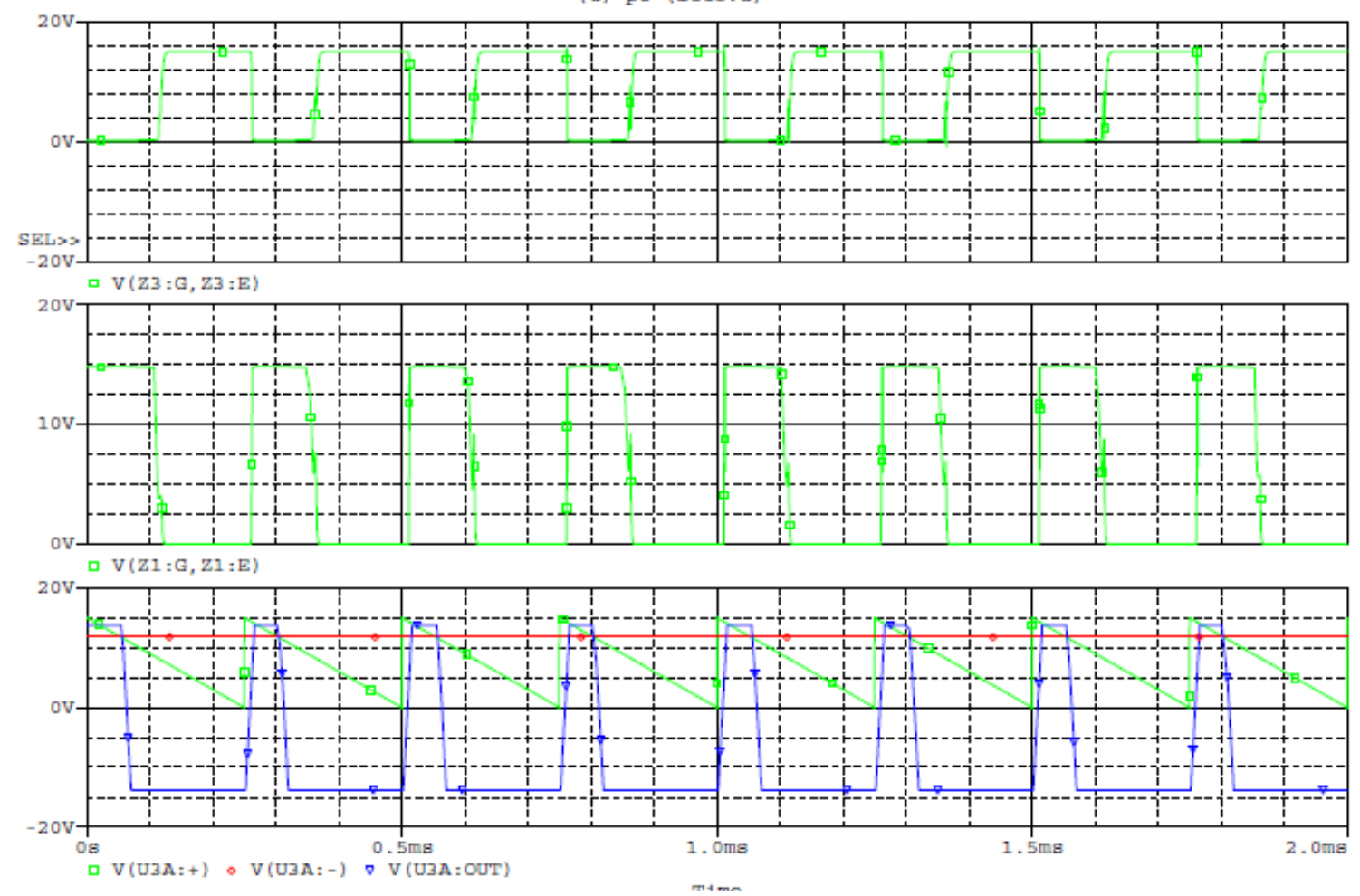

Fig.2.10: Generated PWM signals for switch 1 and 2 when input voltage $=250 \mathrm{~V}$

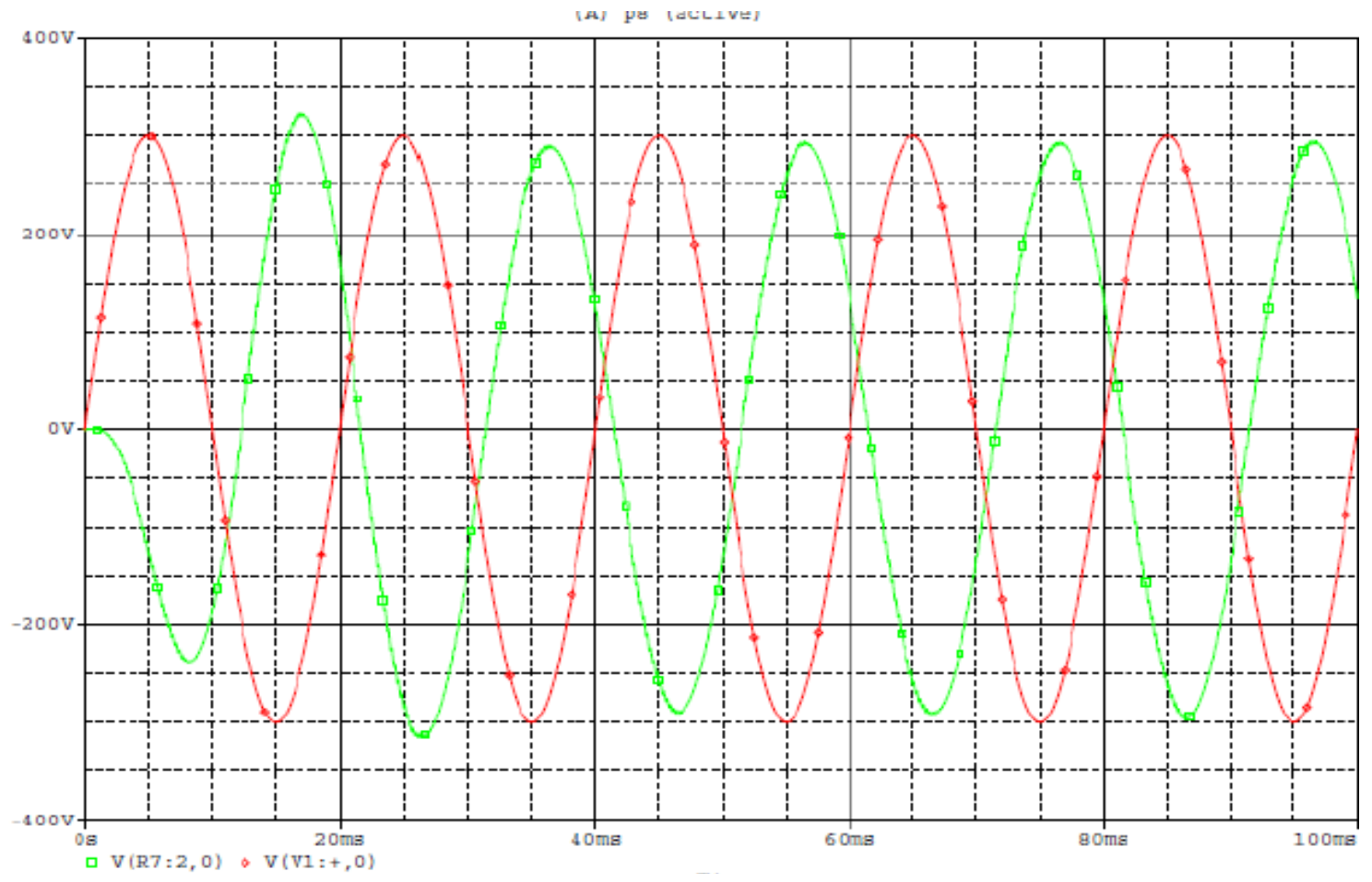

Fig-2.11: Input and output voltage waveforms, when input voltage $300 \mathrm{~V}$, load $50 \mathrm{ohm}$ and $\mathrm{V}_{\mathrm{dc}}=12.30 \mathrm{~V}$

$\mathrm{V}(\mathrm{V} 1:+)-$ Input voltage $=300 \mathrm{~V}$ and $\mathrm{V}(\mathrm{R} 7: 2)-$ Output voltage $=300 \mathrm{~V}$ 


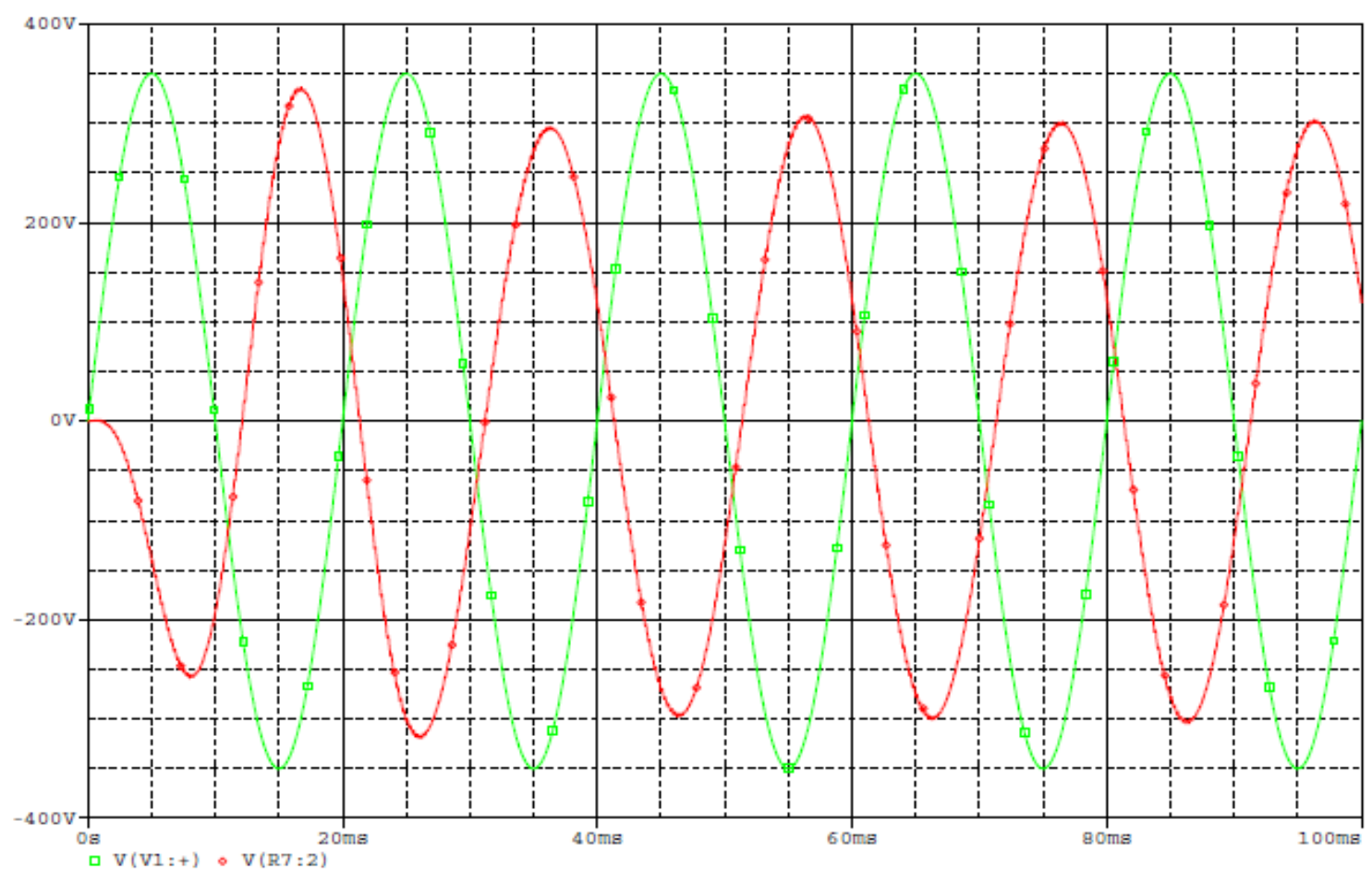

Fig-2.12: Input and output voltage waveforms, when input voltage $300 \mathrm{~V}$, load $50 \mathrm{ohm}$ and $\mathrm{V}_{\mathrm{dc}}=12.70 \mathrm{~V}$

$\mathrm{V}(\mathrm{V} 1:+)-$ Input voltage $=350 \mathrm{~V}$ and $\mathrm{V}(\mathrm{R} 7: 2)-$ Output voltage $=300 \mathrm{~V}$

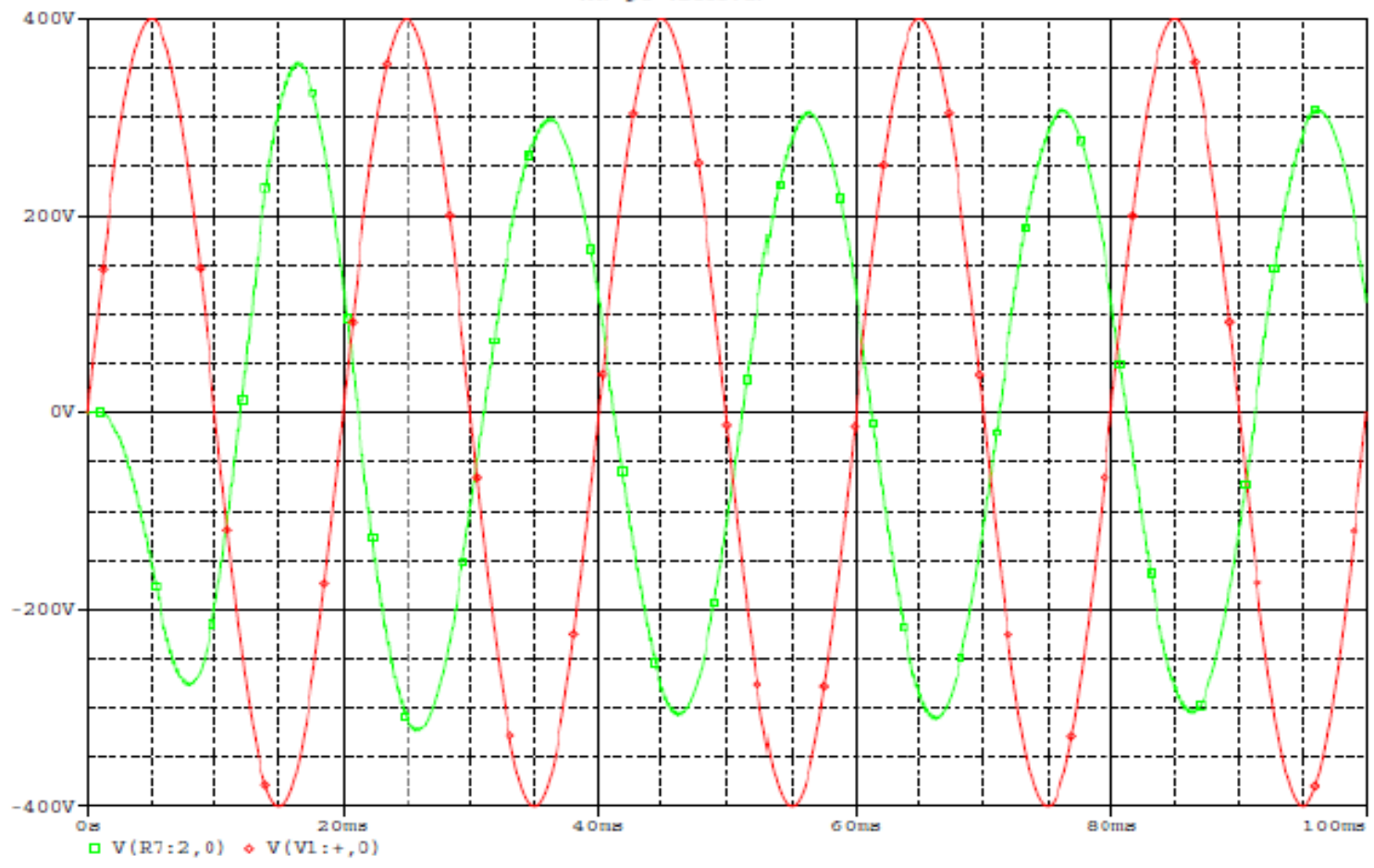

Fig-2.13: Input and output voltage waveforms, when input voltage $400 \mathrm{~V}$, load $50 \mathrm{ohm}$ and $\mathrm{V}_{\mathrm{dc}}=13.0 \mathrm{~V}$

$\mathrm{V}(\mathrm{V} 1:+)-$ Input voltage $=400 \mathrm{~V}$ and $\mathrm{V}(\mathrm{R} 7: 2)-$ Output voltage $=300 \mathrm{~V}$ 


\subsubsection{REVIEW OF AC-AC BUCK-BOOST VOLTAGE REGULATOR (Auto Controlled)}

The use of PWM technique to maintain constant output voltage during fluctuation of input voltage (as discussed in section 2.2.2) has also been established by an automatic feedback control circuit for an AC-AC Buck-Boost voltage regulator [8].
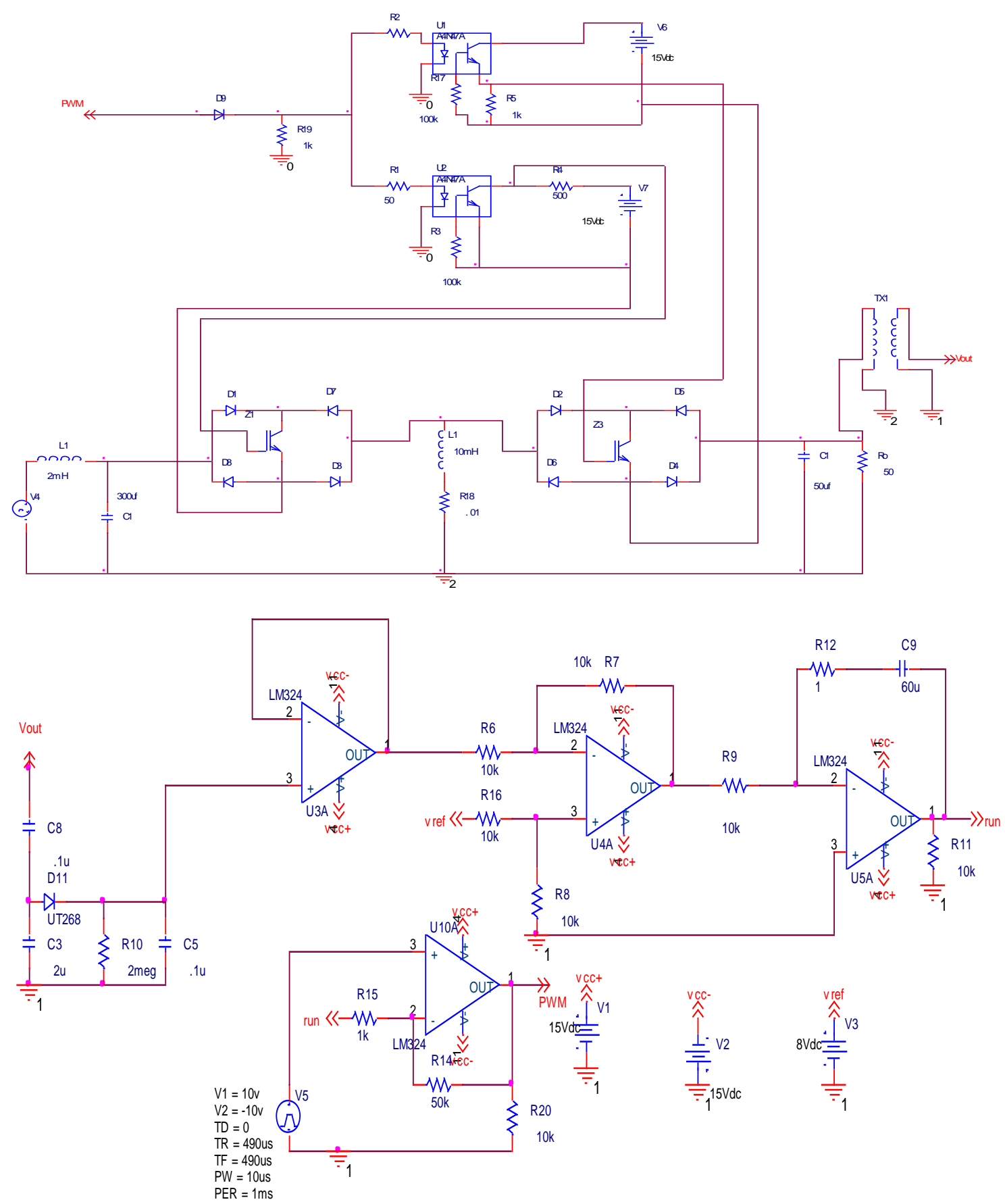

Fig-2.14: AC- AC Buck-Boost converter with automatic feedback control Circuit 
This AC-AC automatic voltage regulator based on Buck-Boost conversion principle is shown in fig 2.14. The simulation results of input-output waveforms of $\mathrm{AC}-\mathrm{AC}$ automatic feedback control Buck-Boost regulator for input voltages $250 \mathrm{~V}, 300 \mathrm{~V}$ and $400 \mathrm{~V}$ are shown in figures $2.15,2.16$ and 2.17 , respectively.

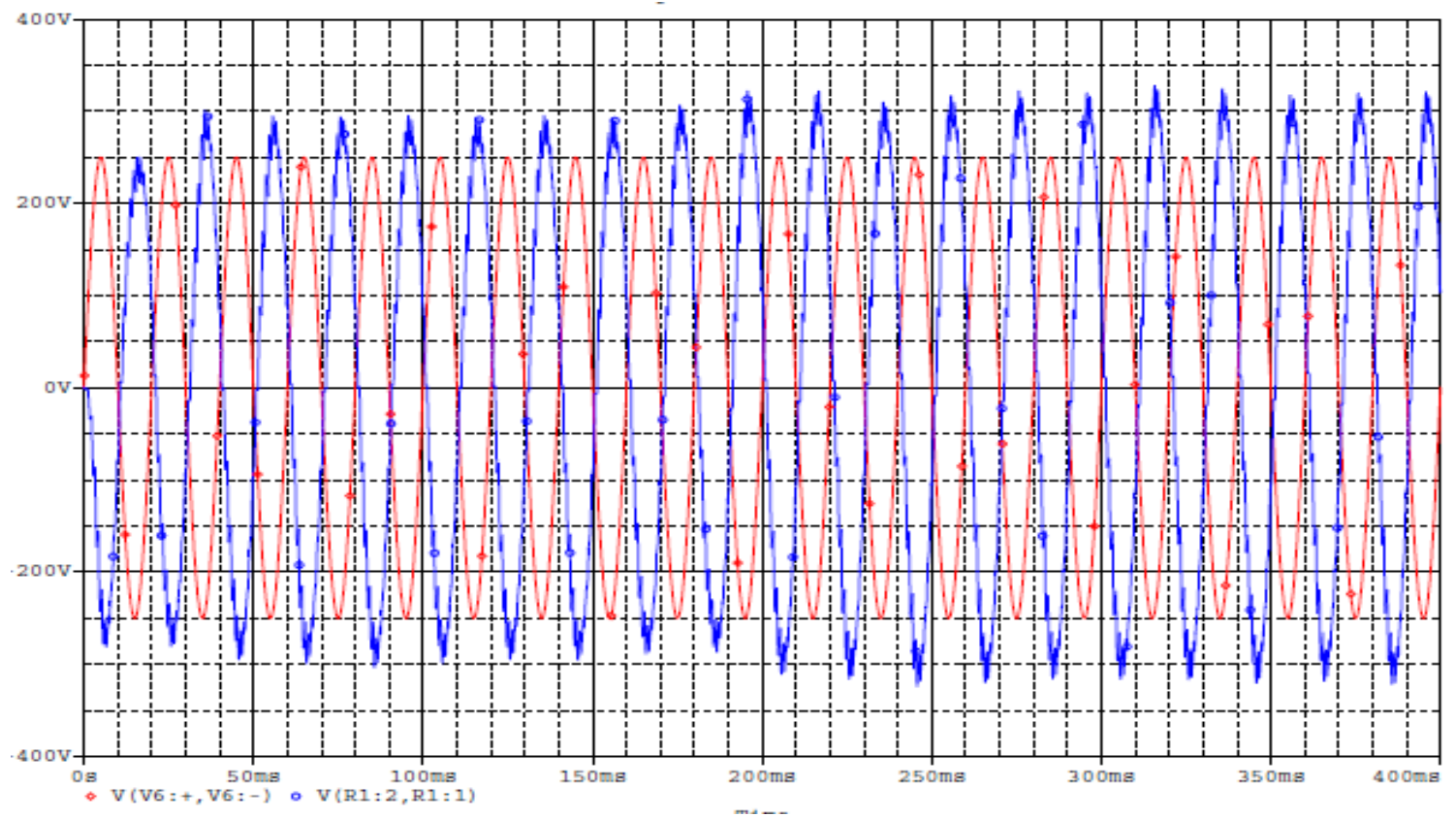

Fig-2.15: Input and output voltage waveforms, when input voltage $250 \mathrm{~V}$ and load $50 \Omega$ $\mathrm{V}(\mathrm{V} 6:+)-$ Input voltage $=250 \mathrm{~V}$ and $\mathrm{V}(\mathrm{R} 1: 2)-$ Output voltage $=300 \mathrm{~V}$

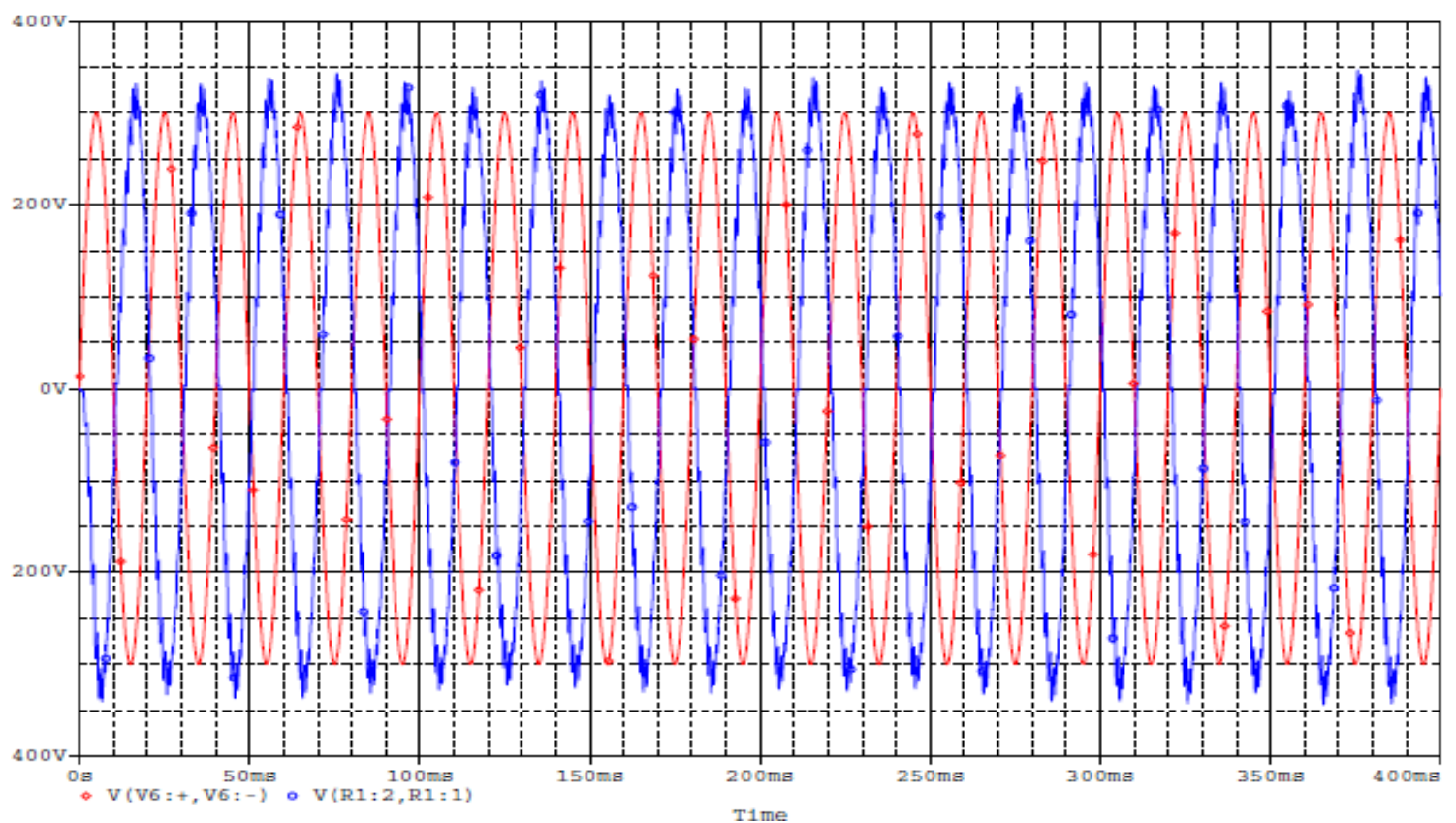

Fig-2.16: Input and output voltage waveforms, when input voltage $300 \mathrm{~V}$ and load $50 \Omega$ $\mathrm{V}(\mathrm{V} 6:+)-$ Input voltage $=300 \mathrm{~V}$ and $\mathrm{V}(\mathrm{R} 1: 2)-$ Output voltage $=300 \mathrm{~V}$ 


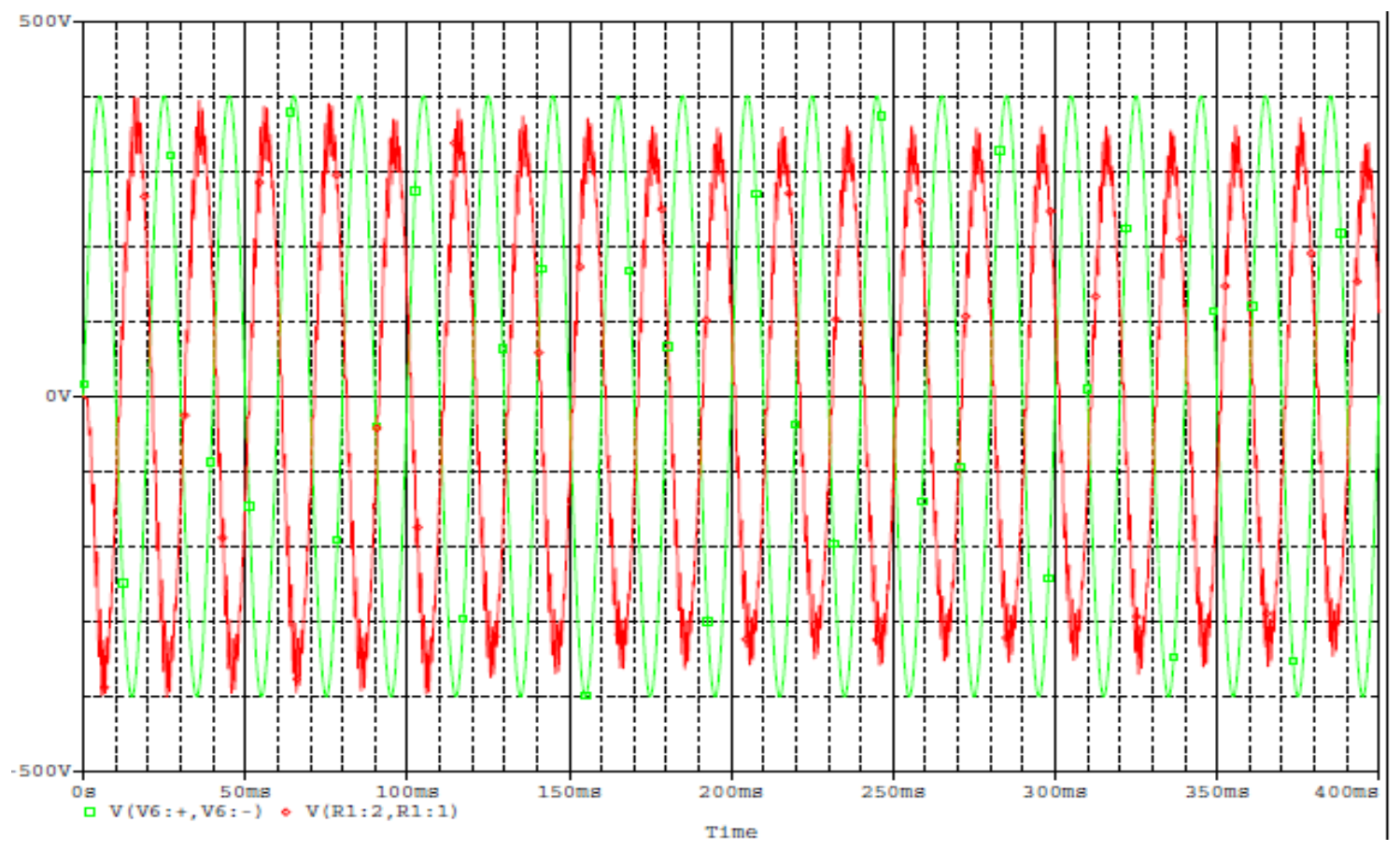

Fig-2.17: Input and output voltage waveforms, when input voltage $400 \mathrm{~V}$ and load $50 \Omega$ $\mathrm{V}(\mathrm{V} 6:+)-$ Input voltage $=400 \mathrm{~V}$ and $\mathrm{V}(\mathrm{R} 1: 2)-$ Output voltage $=300 \mathrm{~V}$

\subsection{OBJECTIVE AND CONTRIBUTION OF THIS RESEARCH}

The reviewed AC-AC Buck-Boost regulator has the ability to regulate the output voltage to the desired value during the input voltage fluctuation by using PWM technique. However, the output voltage contains a significant ripple when automatic feedback control circuit is used. In addition, it has been reported that more harmonics are found in the input current and significant ripple is found in output current in such cases. So, it is important to further investigate how to remove the ripple from output voltage, reduce input and output current ripples and associated harmonics when regulated by automatic feedback control circuit. The objective of this work is to propose an automatic AC to AC Cûk regulator that can maintain constant output voltage in the case of input voltage fluctuation as well as to overcome the previous drawbacks as already reported. 


\section{CHAPTER - 3}

\section{VOLTAGE REGULATOR AND AC VOLTAGE REGULATOR}

\subsection{INTRODUCTION OF POWER CONVERSION PRINCIPLE}

The classical linear power conversion circuit has been shown in fig. $3.1[9,10]$. Here power is controlled by a linear element connected in series; either a resister or a transistor is used in the linear mode. The total load current passes through the series linear element. In such circuit the greater the difference between the input and output voltage, the more power is lost in the controlling device. Linear power conversion is dissipative and, hence, inefficient. The efficiency range is typically 30 to $60 \%$ for linear regulators.

The circuit of fig.-3.2 illustrates the basic principle of a DC-DC switch mode power conversion $[9,10]$. The controlling device is a simple switch. By controlling the ratio of the time intervals spent in the ON and OFF positions (defined as duty ratio), the power flow to the load can be controlled in a very efficient way. Ideally this method is $100 \%$ efficient. In practice, the efficiency is reduced as the switch is imperfect and losses occur in power circuits.

The semiconductor devices can efficiently be used as switches. The DC load to the voltage can be regulated by controlling the duty cycle of the rectangular waveform supplied to the base or gate of the switching device. When the switch is fully ON, it has only a small saturation voltage drop across it. In the OFF position the current through the device is zero.
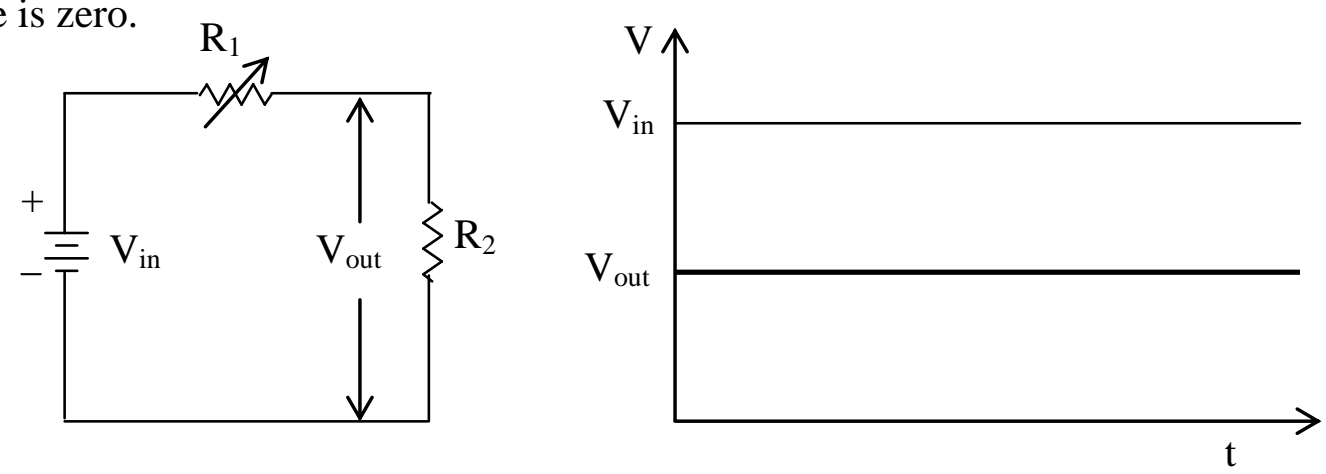

Fig-3.1: Linear (dissipative) power conversion circuit. 

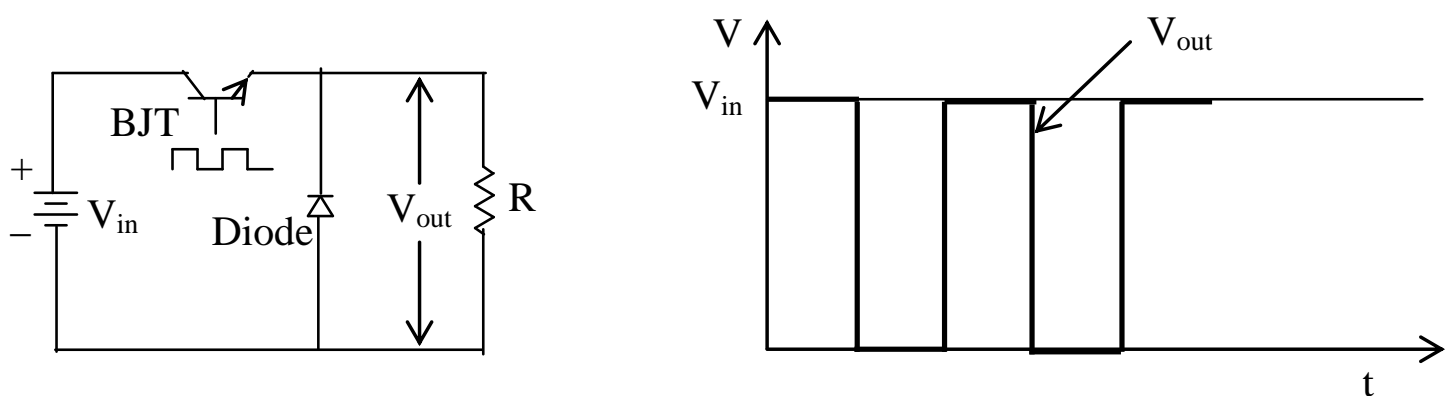

Fig-3.2: Switch mode (non dissipative) power conversion circuit.
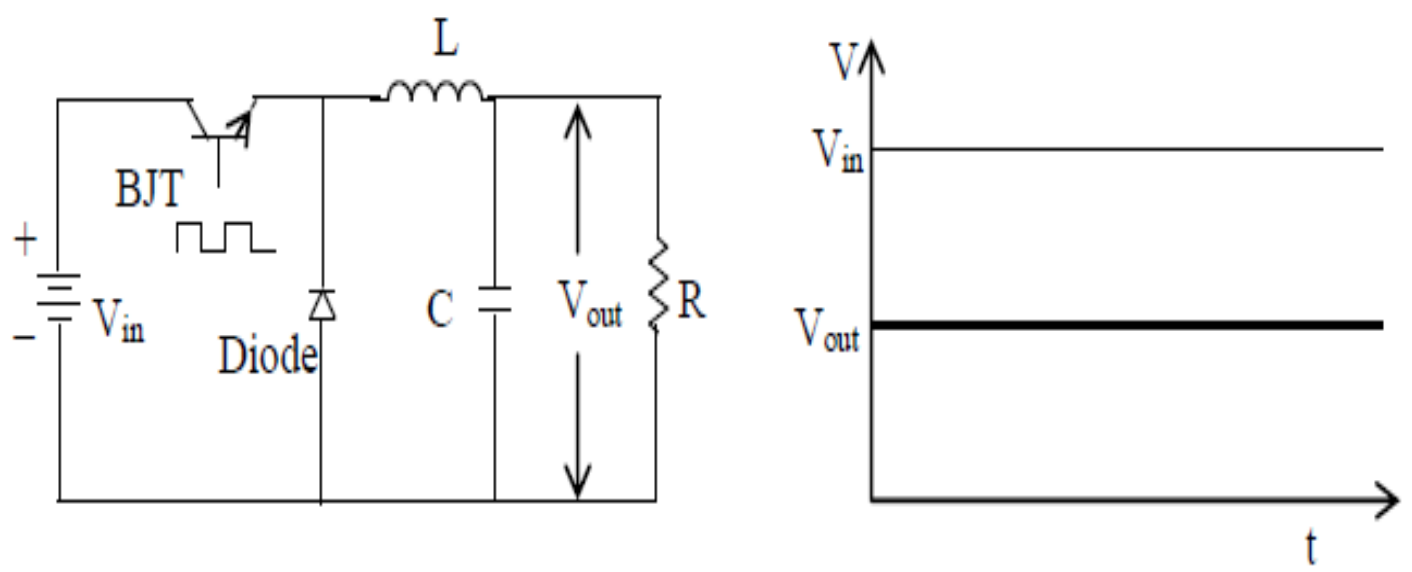

Fig-3.3: Typical switch mode power conversion circuit.

The output of the switch mode power conversion control (fig.-3.2) is not purely DC. This type of output is applicable in cases such as oven heating without proper filtration. If constant DC is required, then output of SMPS has to be smoothed out by the addition of a low-pass LC filter as shown in fig. 3.3 [9, 10]. Switches are required as basic components for efficient electric power conversion and control. Inductors and capacitors are used to smooth the pulsating dc originating from the switching action.

Although the conversion would be $100 \%$ efficient in the ideal case of lossless (there is no loss, i.e: ideal device)) components. In practice, all components loss voltage to some extent and decreasing efficiency. Hence, one of the prime objectives in switch mode power conversion is to realize conversion with the least number of components with better efficiency and reliability. 


\subsection{PRINCIPLE OF DC-DC SWITCH MODE POWER SUPPLY (SMPS)}

A switch mode DC-DC power supply (SMPS) is switched at very high frequency. Conversion of both step down and step up de with insignificant filter size having facility of feed -back regulation by ON/OFF high frequency switching is possible in an SMPS. Usually SMPSs are used in dc-dc conversion for their light weight, high efficiency and isolated multiple outputs with and without voltage regulation. Uses of SMPSs are now universal in space power applications, computers, TV and industrial units. SMPSs have advantages of being low cost, compact, self regulating and self protected. Diverse types of SMPS are investigated to meet user requirements and research is still continuing to find newer ways of switching, increase in switching frequencies, modified topologies and enhanced performance of filters to reduce ripples and EMI.

Figure 3.4 shows the block diagram of a DC-DC SMPS [9, 10]. The main parts of a switch mode power supply are: (a) Power circuit and (b) Control circuit. The power circuit consists mainly the input and output side with the switching device. The switching device is continuously switched at high frequency by the gate signal from the control circuit to transfer power from input to output. The control circuit of a SMPS basically generates high frequency gating pulses for the switching devices to control the output voltage. Switching is performed in multiple pulse width modulation (PWM) fashion according to the feedback error signal from the load to serve the following two purposes:

a) Produce high frequency switching signal

b) Control ON / OFF period of switching signal to maintain constant voltage across load.

High frequency switching reduces filter requirements at the input/output sides of the converter. The simplest PWM control uses multiple pulse modulations generated by comparing a DC with a high frequency carrier triangular wave. 
The PWM control circuit is commonly available in an integrated form. The designer can select the switching frequency by choosing the value of $\mathrm{R}$ and $\mathrm{C}$ of frequency oscillator [10]. As a guideline to maximize the efficiency, the minimum oscillator period should be about 100 times longer than the transistor switching time; for example, if a transistor has a switching time of $0.5 \mu \mathrm{s}$, the oscillator period would be 50 us, which gives the maximum oscillator frequency of $20 \mathrm{KHz}$. The limitation is due to switching loss in the transistor. The transistor switching loss increases with the switching frequency and results in reduced efficiency.

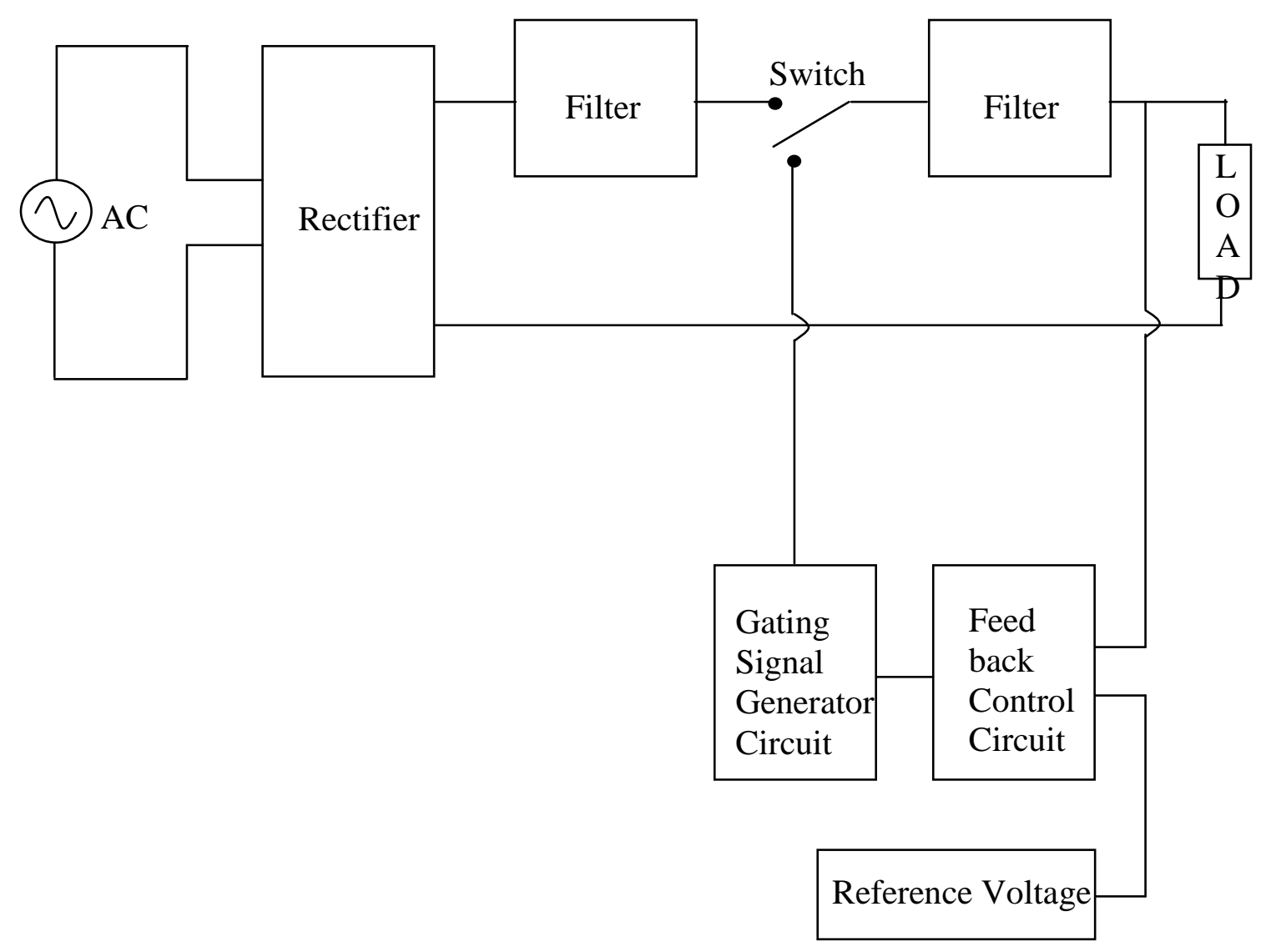

Fig-3.4: Block diagram of DC-DC Switch Mode Power Supply 


\subsection{TYPES OF DC -DC REGULATOR TOPOLOGIES}

There are four basic topologies of switching regulator (Converter) that have been developed in the past, these are $[10,30]$ :
a. Buck (step down) regulator,
b. Boost (step up) regulator,
c. Buck-Boost regulator
d. Cûk regulator

\subsubsection{BUCK REGULATOR}

In Buck regulator, output voltage is controlled to be less than the input voltage, hence the name "Buck". The ideal voltage gain and current gain relationship of this regulator are given by $[9,10,30]$ :

$$
\begin{aligned}
& \frac{V_{\mathrm{o}}}{\mathrm{V}_{\mathrm{in}}}=\mathrm{D} \\
& \frac{\mathrm{I}_{0}}{\mathrm{I}_{\mathrm{in}}}=\frac{1}{\mathrm{D}}
\end{aligned}
$$

From equation (3.1) it is seen that output voltage $V_{0}$ is less than the input voltage $V_{\text {in }}$ since $\mathrm{D}$ is less than 1 . Where $\mathrm{D}$ (sometimes also called $\mathrm{K}$ ) is the duty cycle of the switching waveform of the SMPS.

\subsubsection{BOOST REGULATOR}

In Boost regulator, the output voltage is greater than the input voltage, hence the name "Boost". The voltage gain and current gain of the boost configuration are given by [9, 10, 30]:

$$
\frac{\mathrm{V}_{0}}{\mathrm{~V}_{\text {in }}}=\frac{1}{1-\mathrm{D}}
$$




$$
\frac{\mathrm{I}_{0}}{\mathrm{I}_{\mathrm{in}}}=1-\mathrm{D}
$$

From equation (3.3) it is seen that output $V_{0}$ is greater than the input $V_{\text {in }}$ since $D$ is less than 1.

\subsubsection{BUCK- BOOST REGULATOR}

Buck regulators can step-down while Boost regulators can step-up voltages individually. The Buck-Boost regulator can be obtained by cascade connection of these two basic regulators. The output voltage polarity is opposite to input voltage; as a result the converter is also known as an inverting regulator.

The voltage gain and current gain of the Buck - Boost regulator are given by $[9,10,30]$ :

$$
\begin{aligned}
& \frac{V_{0}}{V_{\text {in }}}=-\frac{D}{(1-D)} \\
& \frac{I_{0}}{I_{\text {in }}}=-\frac{(1-D)}{D}
\end{aligned}
$$

From equation (3.5) it is seen that output $V_{0}$ is greater than input $V_{i n}$, when $D$ is greater than 0.5 and output $\mathrm{V}_{0}$ is less than input $\mathrm{V}_{\mathrm{in}}$, when $\mathrm{D}$ is less than 0.5. So, step-up and step-down conversion can be achieved with same regulator.

\subsubsection{CûK REGULATOR}

It is the modified form of Buck-Boost regulator that has the capability of regulating input voltage in both a buck and boost manner. The Cûk regulator is based on capacitive energy transfer. The voltage gain and current gain of Cûk regulator are same as shown by equations (3.5) and (3.6).

The efficiency of these regulators are ideally $100 \%$ if the switch and other components are considered impermeable. In the real world the voltage gain, current gain and 
efficiency of all regulators deviates from ideal one due to components subject to loss, switching and conduction losses of a switch and voltage drop across the switch. The voltage gain and current gain relationship may also be different for discontinuous conduction mode of the inductor current and switching and conduction losses of the switch as well as stray resistances of magnetic circuits and capacitors used in the circuit.

\subsection{SWITCH MODE AC VOLTAGE REGULATOR}

In switch mode $\mathrm{AC}$ voltage regulator, in order to transfer the electric energy from input to output the switching devices are continuously switching ON and OFF at high frequency. Typical frequency range of SMPS is from several $\mathrm{KHz}$ to several MHz. As SMPS is operated with very high frequency, so the size of power transformer, inductors and filter capacitors size are small because the sizes are inversely proportional to the frequency. These power supplies have high efficiency because the regulating devices in them work as switches to ensure low device loss. Some drawbacks, however, are that the SMPS are more complicated and more expensive, their switching current can cause noise problems, and simple designs can have a poor power factor. The design of the regulator depends on power requirement, degree of stability and efficiency. Solid state AC regulators using phase control technique have been widely used in many application, such as heating and lighting control. These regulators are not suited for critical loads because the output waveforms are truncated sine waves, which contain a large percentage

of distortion. The input power factor is low. These drawbacks are largely overcome, and the voltage can be efficiently controlled by means of a solid-state AC regulator using PWM technique.

Finally, there are four common types of switch mode regulators are used in DC-DC conversion. Our objective is to apply same DC regulator's theory to an AC voltage regulator. Some researchers have already suggested modification of DC regulators to control AC voltages using PWM technique as already reported in the literature review. 


\section{CHAPTER - 4}

\section{DEVELOPMENT AND ANALYSIS OF PROPOSED SWITCH MODE AC -AC CÛK VOLTAGE REGULATOR}

\section{0 INTRODUCTION}

Voltage sag is an important power quality problem that may affect domestic, industrial and commercial consumers. Voltage sag is the momentary decrease or increase in the magnitude of system voltage. Equipment used in modern industrial plants, domestic appliances, etc are becoming more sensitive to voltage fluctuations as the complexity of the equipment increase. In order to maintain the load voltage constant in case of any fluctuation of input supply voltage some type of regulating device is necessary.

In this chapter, high frequency switching AC Cûk voltage regulator is proposed to maintain constant voltage across the load in case of input voltage fluctuations. The principles of operation of high frequency switching AC Cûk voltage regulator, gate signals generating circuit, harmonics analysis will be described. The performance of the Cûk voltage regulator is analyzed using simulation software OrCAD version 16.1. Simulation results will be compared to the AC Buck-Boost regulator.

\subsection{OPERATION PRINCIPLE OF PROPOSED SWITCH MODE AC CûK VOLTAGE REGULATOR}

Cûk converter is the modified form of Buck-Boost converter. Cûk converter provides an output voltage that is less than or greater than the input voltage whereas output voltage polarity is opposite to that of the input voltage. The Cûk converter is based on capacitive energy transfer as the capacitor $\mathrm{C}_{1}$ is the medium for transferring energy from the source to the load. The proposed AC Cûk voltage regulator is shown in figure-4.1 (without controlled circuit). 


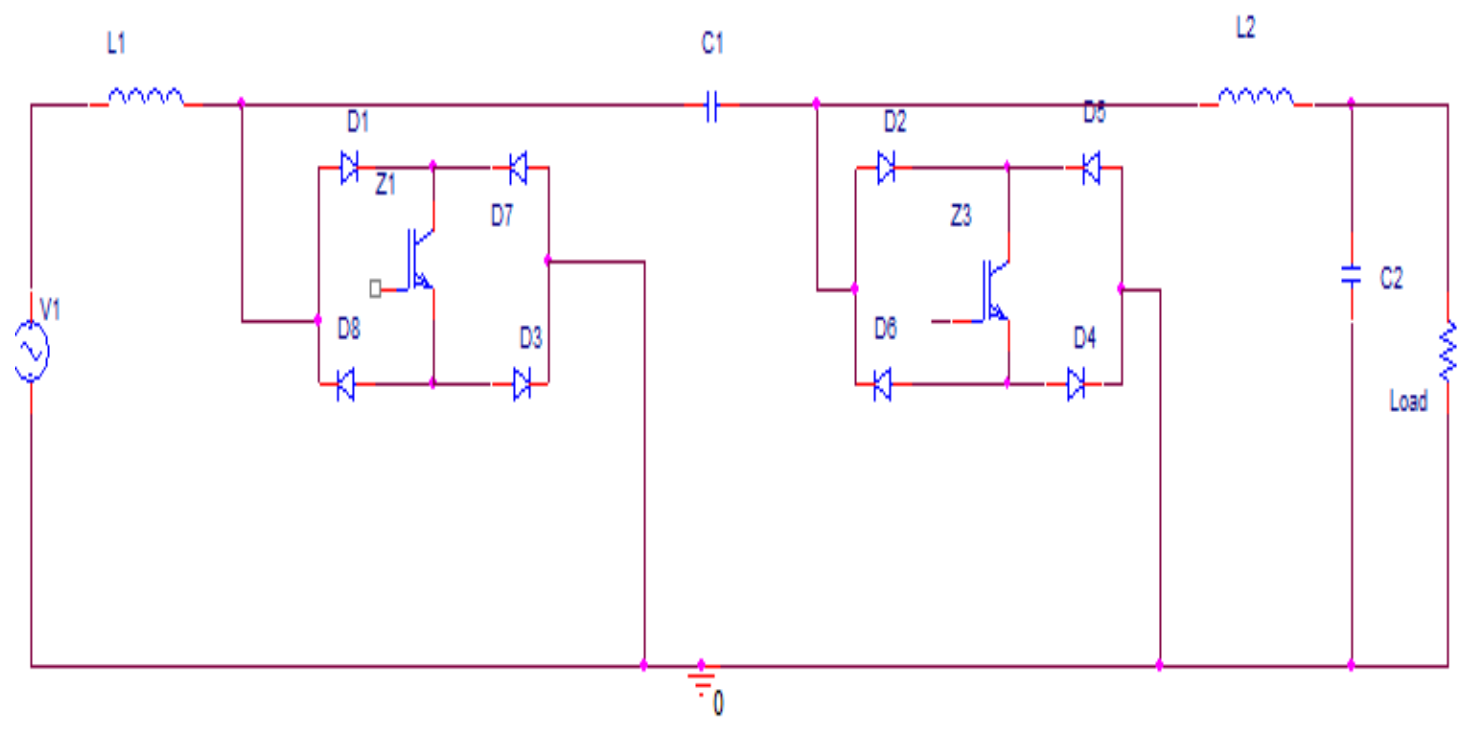

Fig 4.1: AC Cûk regulator configuration by using IGBT switches with manual control circuit

The circuit operation can be explained in positive and negative half- cycle of input voltage. The circuit operation during the positive half - cycle of AC input voltage can be explained with the help of figure 4.2 (a) and (b). During the positive half - cycle of input voltage when IGBT- $1\left(\mathrm{Z}_{1}\right)$ is ON (by gate signal) and IGBT-2 $\left(\mathrm{Z}_{2}\right)$ is OFF, the current passes through inductor $\mathrm{L}_{1}$ (rises-energy stored), diode $\mathrm{D}_{1}, \operatorname{IGBT}-1\left(\mathrm{Z}_{1}\right)$ and diode $\mathrm{D}_{3}$, and at the same time previously charged capacitor $\mathrm{C}_{1}$ discharges (transfers) its energy to the circuit formed by $\mathrm{C}_{1}$, diode D1, IGBT-1(Z1), diode D3, the load and L2 (energy stored). This operation is shown in figure 4.2 (a).

Moreover, when IGBT- $1\left(\mathrm{Z}_{1}\right)$ is OFF and IGBT-2 $\left(\mathrm{Z}_{2}\right)$ is ON (by gate signal), the stored energy of the inductor $L_{1}$ is transferred to the capacitor $C_{1}$ (charging) by forming circuit L1, capacitor C1, diode D2, IGBT-2(Z3) and diode D4. Meanwhile, previously stored energy of $L_{2}$ is transferred to the load by formed circuit $\mathrm{L}_{2}$, diode D2, IGBT-2, diode D4, and the load. This operation is shown in figure 4.2 (b). 


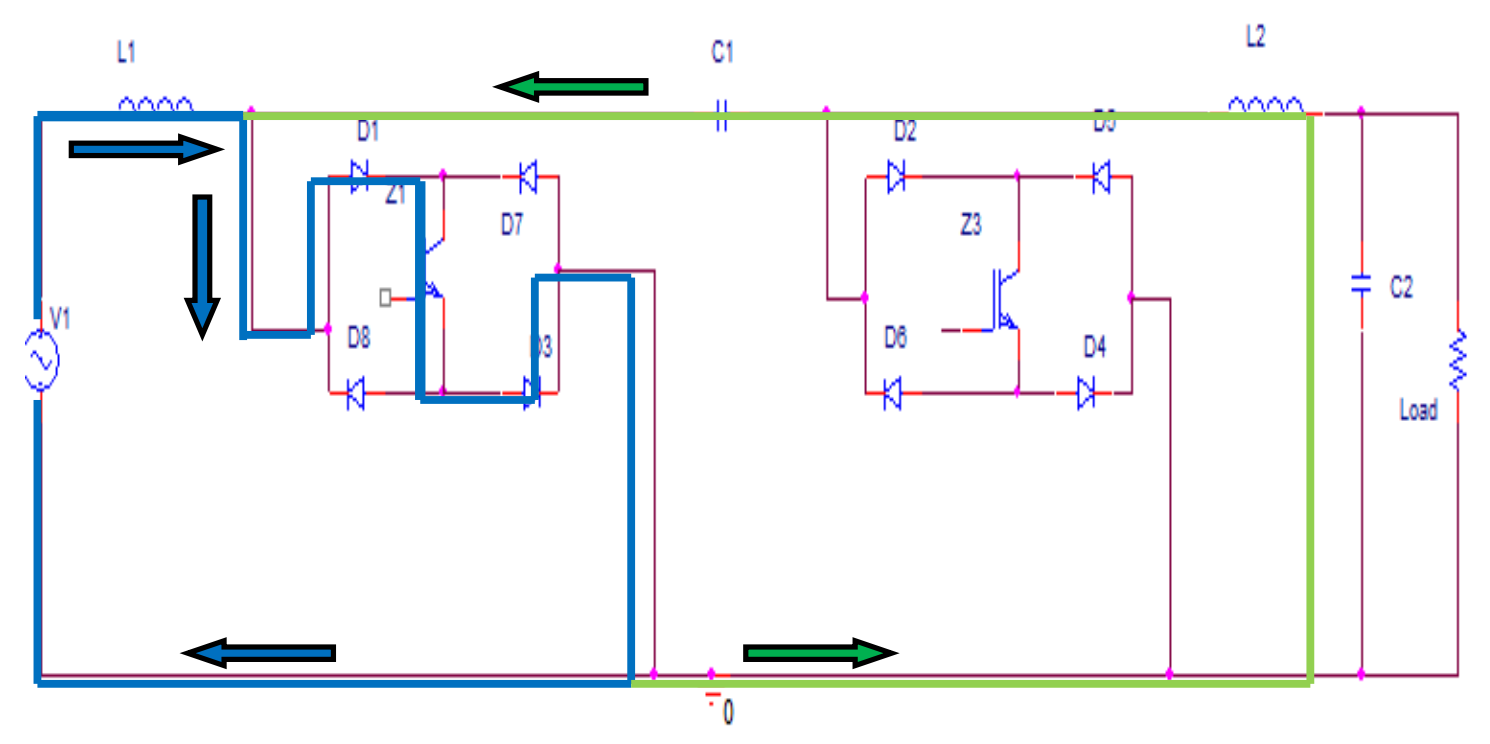

Fig 4.2: (a) Circuit operation during positive half- cycle of AC input supply, when IGBT-1 is ON (by gate signal) and IGBT-2 is OFF.

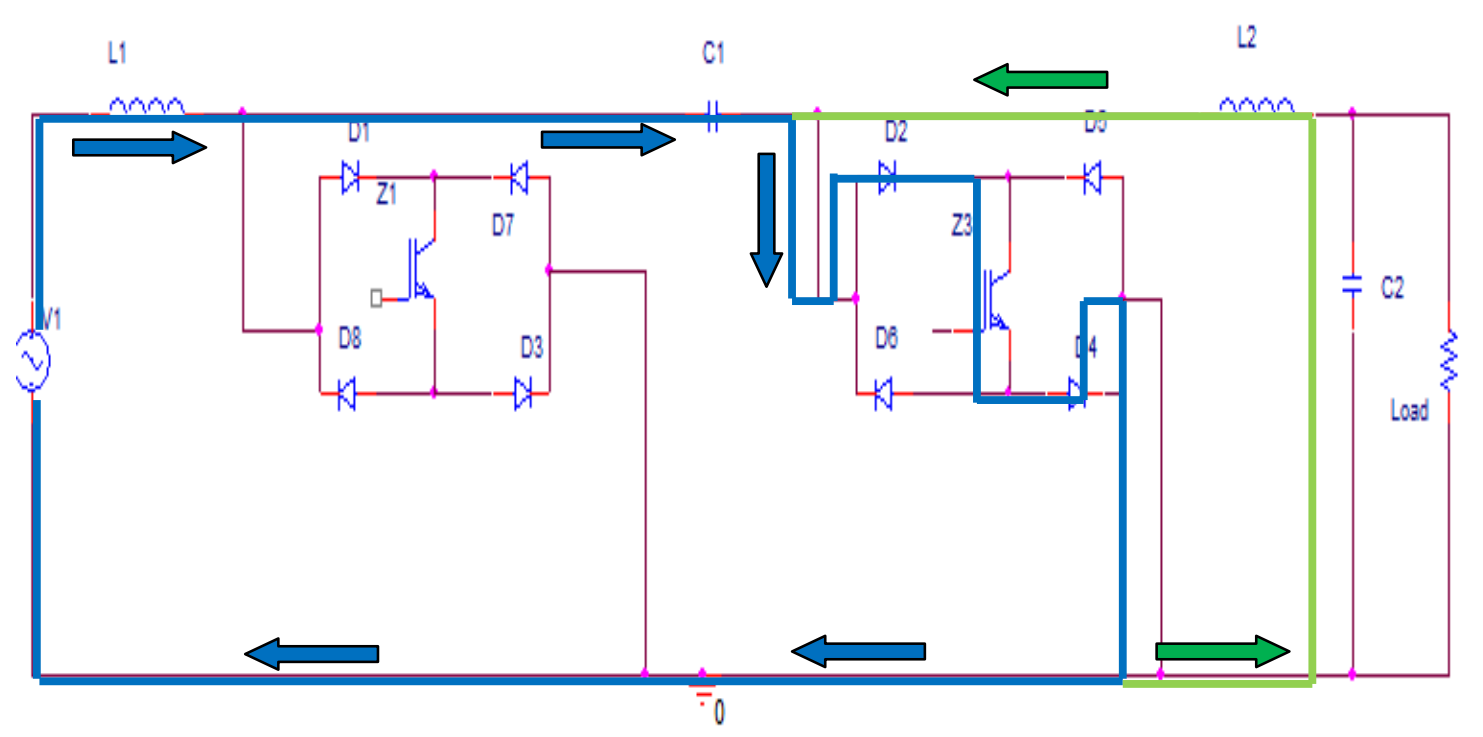

Fig 4.2: (b) Circuit operation during positive half - cycle of AC input supply, when IGBT-1 is OFF and IGBT-2 is ON (by gate signal).

The circuit operation during the negative half - cycle of AC input voltage can be explained with the help of figure 4.3 (a) and (b). The operation of the negative half -cycle for $\mathrm{AC}$ input voltage is the same as the positive half - cycle, but direction is opposite. During the negative half - cycle of input voltage when IGBT-1( $\left.Z_{1}\right)$ is ON (by gate signal) 
and IGBT-2 $\left(\mathrm{Z}_{2}\right)$ is OFF, the current passes through diode $\mathrm{D}_{7}$, IGBT- $1\left(\mathrm{Z}_{1}\right)$, diode $\mathrm{D}_{8}$ and inductor $\mathrm{L}_{1}$ (rises-energy stored). At the same time the previously charged capacitor $\mathrm{C}_{1}$ discharges (transfers) its energy to the circuit formed by L2 (energy stored), load, diode D7, IGBT-1, diode D8 and $\mathrm{C}_{1}$. This operation is shown in figure 4.3 (a).

Moreover, when IGBT- $1\left(\mathrm{Z}_{1}\right)$ is OFF and IGBT-2 $\left(\mathrm{Z}_{2}\right)$ is ON (by gate signal), the stored energy of the inductor $L_{1}$ is transferred to the capacitor $C_{1}$ (charging) by forming circuit D5, IGBT-2, D6, C1 and L1. ; at the same time previously stored energy of $\mathrm{L}_{2}$ is transferred to the load by formed circuit $\mathrm{L}_{2}$, load, D5, IGBT-2, D6.

So in both cycles we get the output voltage across the load. This operation is shown in figure $4.3(\mathrm{~b})$.

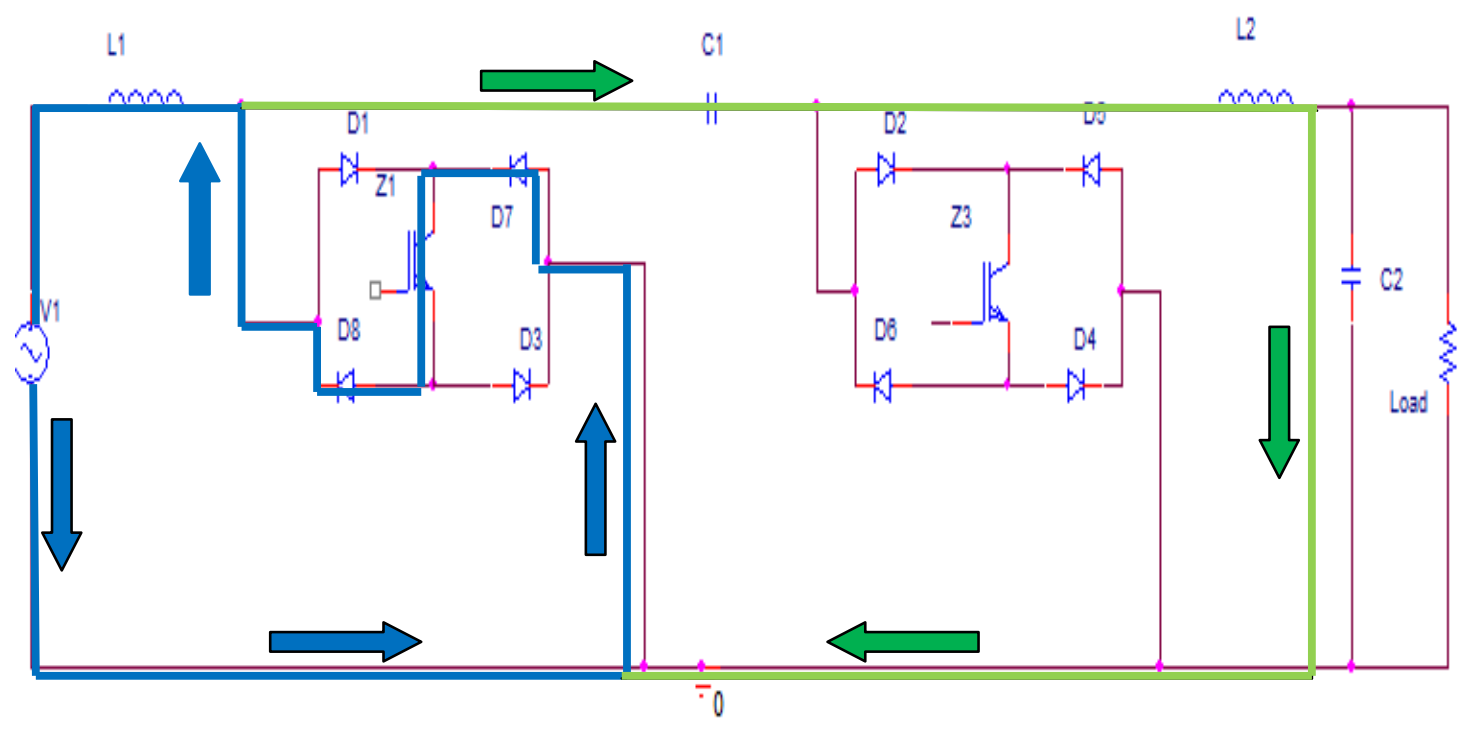

Fig 4.3: (a) Circuit operation during negative half - cycle of AC input supply, when IGBT-1 is ON (by gate signal) and IGBT-2 is OFF. 


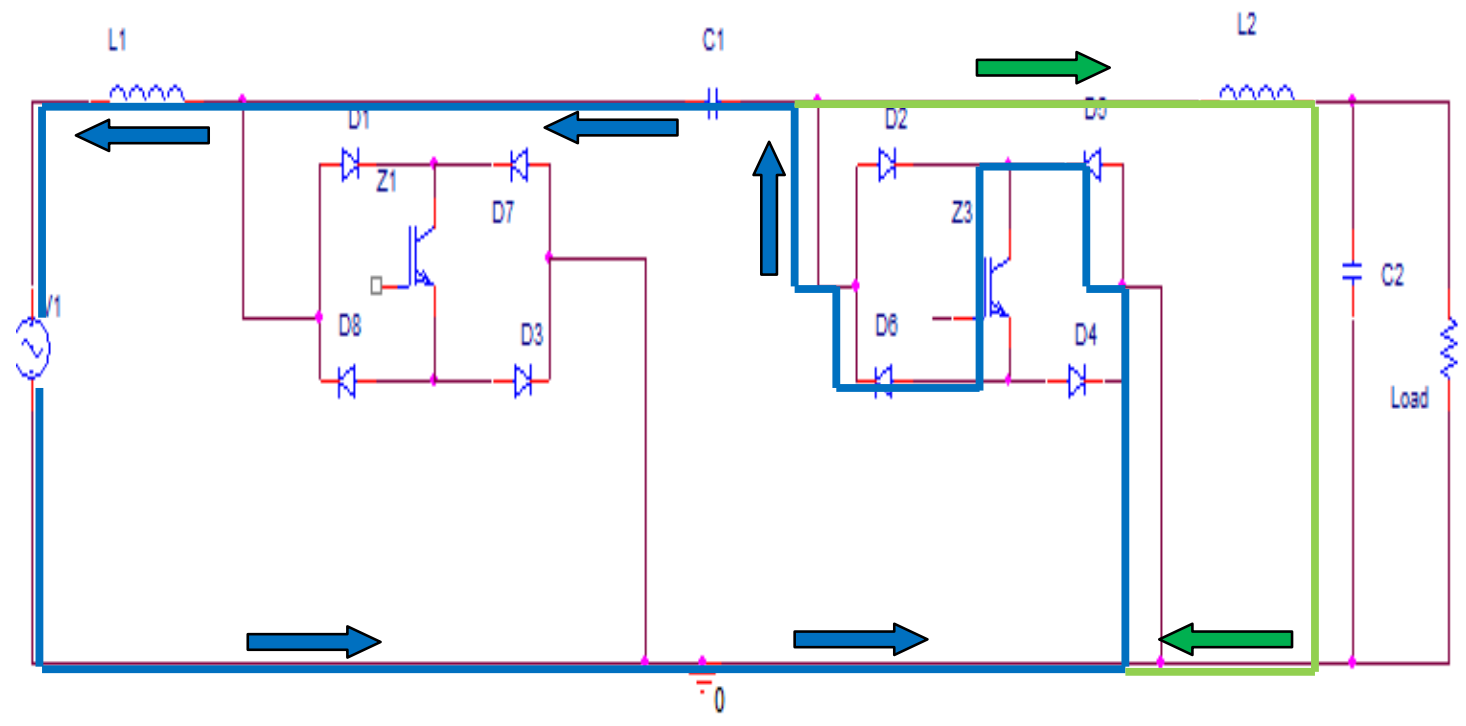

Fig 4.3: (b) Circuit operation during negative half- cycle of AC input supply, when IGBT-1 is OFF and IGBT-2 is ON (by gate signal)

\subsection{MANUALly CONTROLled PROPOSED AC Cûk VOLTAGE REGULATOR}

When the stability is not very stringent, manual control is generally preferred due to economic considerations. The power circuit of a manually controlled AC Cûk voltage regulator is shown in figure-4.4. In this regulator, output voltage across the load may be kept constant irrespective of increase or decrease in the input voltage by controlling the duty cycle of gate pulses manually. The constant output is achieved by using PWM technique, which is manually controlled at the outset. Output pulse width of OPAMP is varied by changing DC control voltage to the OPAMP. Two opto-couplers are used to generate signaling voltage with ground isolation. By changing ON/OFF time of IGBT-1 (switch $Z_{1}$ ) and IGBT-2 (switch $Z_{2}$ ), output voltage across the load can be kept constant for any change of input voltage. In this work our objective is to always keep output voltage at $300 \mathrm{~V}$ (peak) in case of input voltage fluctuations (either increase or decrease). 


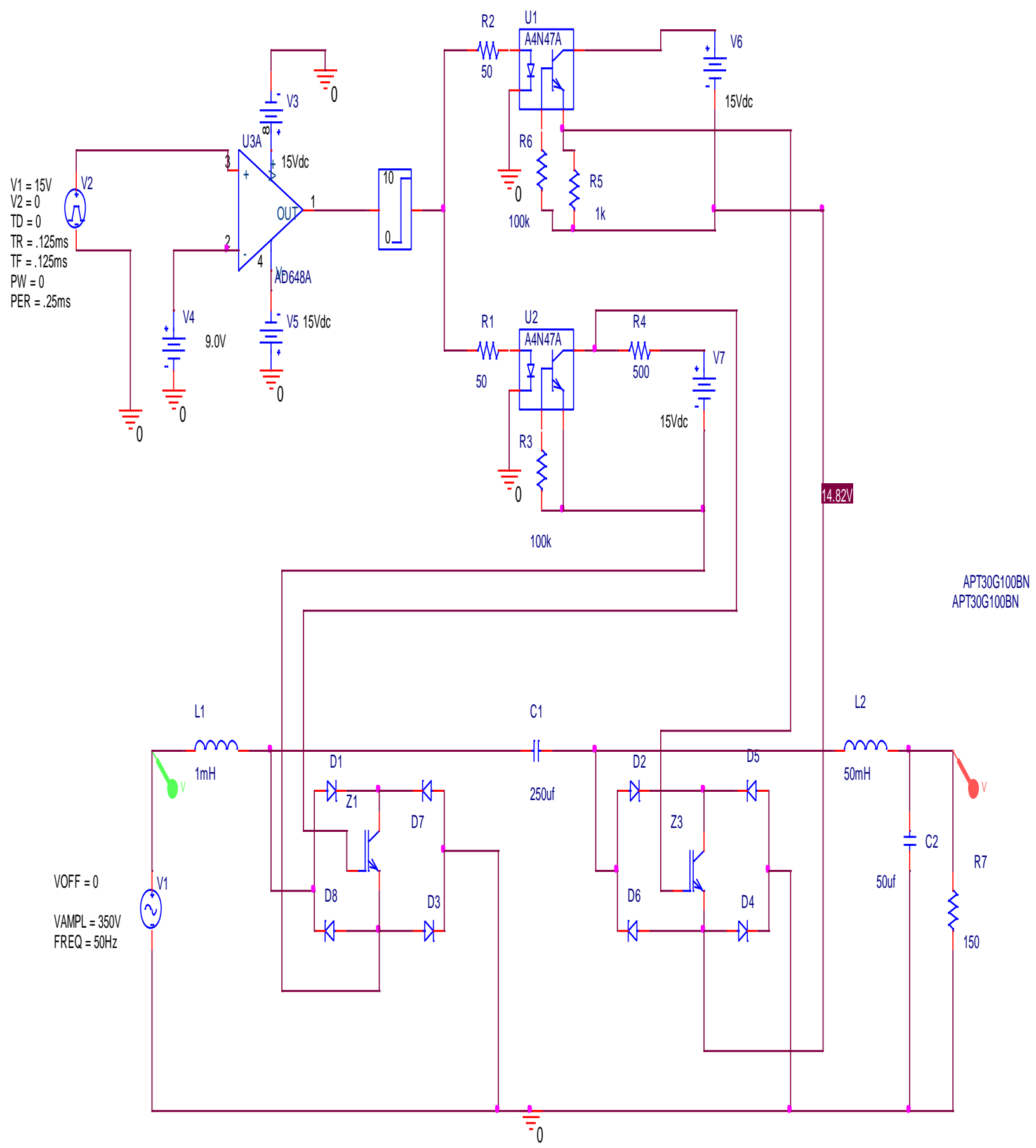

Fig 4.4: AC Cûk regulator configuration with manual control circuit 


\subsection{GATE SIGNAL GENERATING CIRCUIT FOR MANUALLY CONTROLLED PROPOSED AC Cûk REGULATOR}

The gate signal generating circuit for the manually controlled AC Cûk voltage regulator can be explained with the help of figure-4.4. The control circuit shows an OPAMP that has positive input as a triangular signal voltage and negative input as a variable DC voltage. In this circuit the OPAMP acts as a comparator, and the output of the OPAMP depends on the difference between the two inputs, viz. $\left(\mathrm{V}_{+}-\mathrm{V}_{-}\right)$. In this circuit positive input (triangular wave) remains fixed, but negative input (DC voltage) is varied. Thus output pulse width (i.e. Duty cycle =D) depends upon the DC input voltage of OPAMP, i.e. when DC input is higher the output of comparator will be wider (for IGBT-1) and when DC input is lower the output of comparator will be narrower (for IGBT-1). The outputs of OPAMP are used to activate the on/off the switches of the regulator's power circuit to control the output voltage. The output of OPAMP is passed directly through the limiter. The limiter is limit the comparator's output from 0 to $10 \mathrm{~V}$. Then limiter's output is passed through two opto-couplers (U1 and U2). Two opto-coupler are used to generate signaling voltage with ground isolation. Output of opto-couplers is used for the gate signal of IGBT switch-1 and IGBT switch-2 accordingly. When IGBT switch-1 of the power circuit is ON then IGBT switch-2 should be OFF. Therefore, the gate signal generating circuit is arranged in such a way that when gate signal of IGBT switch-1 is ON then gate signal for IGBT switch-2 is OFF and vice versa. Hence, by varying the Duty cycle (D), output voltage of proposed AC Cûk regulator can be maintained at a constant level regardless of input voltage fluctuation.

\subsection{RESUlts OF MANUALly CONTROLlED PROPOSED AC Cûk REGULATOR}

First, input voltage was kept constant at $300 \mathrm{~V}$ (Peak-rated) with a load of $150 \mathrm{ohm}$ for the proposed AC Cûk regulator to investigate the variation of output voltage with the variation of duty cycle. The corresponding input-output waveforms of proposed AC Cûk 
regulator with the variation of DC input voltage of the manually control circuit are shown in figures-4.5 to 4.11 , respectively (for $\mathrm{DC} 4.5,6 \mathrm{~V}, 7.5 \mathrm{~V}, 9 \mathrm{~V}, 10.5 \mathrm{~V}, 11.2 \mathrm{~V}$ and $13.5 \mathrm{~V})$. The result of variation of output voltage with variation of duty cycle at constant input voltage (300V-peak) is shown in fig 4.12. From this figure it is concluded that the variation of output voltage with duty cycle (D) is nearly linear.

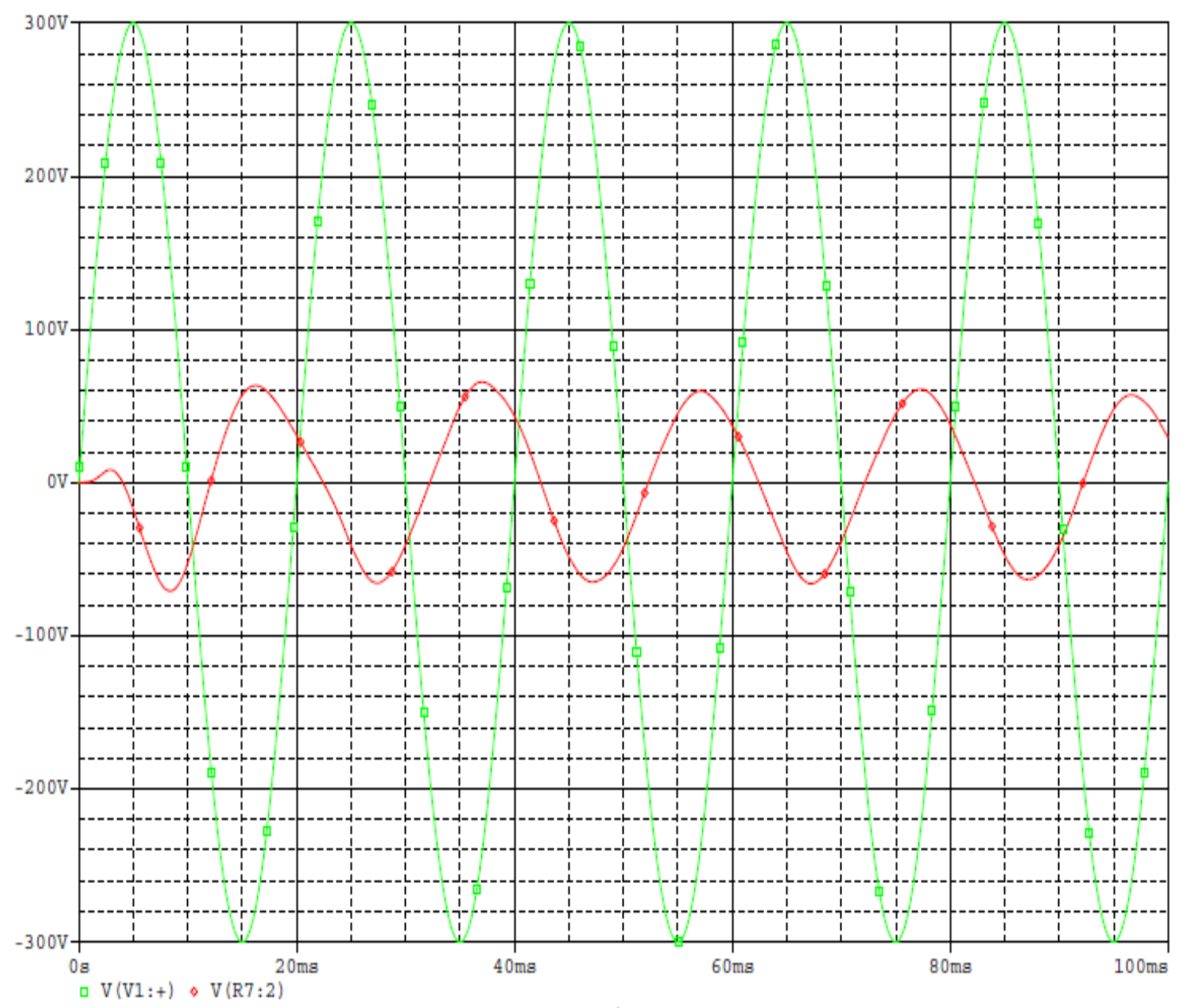

Fig-4.5: Input and output voltage waveforms, when input voltage $300 \mathrm{~V}$, load $150 \mathrm{ohm}$ and duty cycle $\mathrm{D}=0.3$.

$\mathrm{V}(\mathrm{V} 1:+)-$ Input voltage $=300 \mathrm{~V}$

$\mathrm{V}(\mathrm{R} 7: 2)-$ Output voltage $=60 \mathrm{~V}$ 


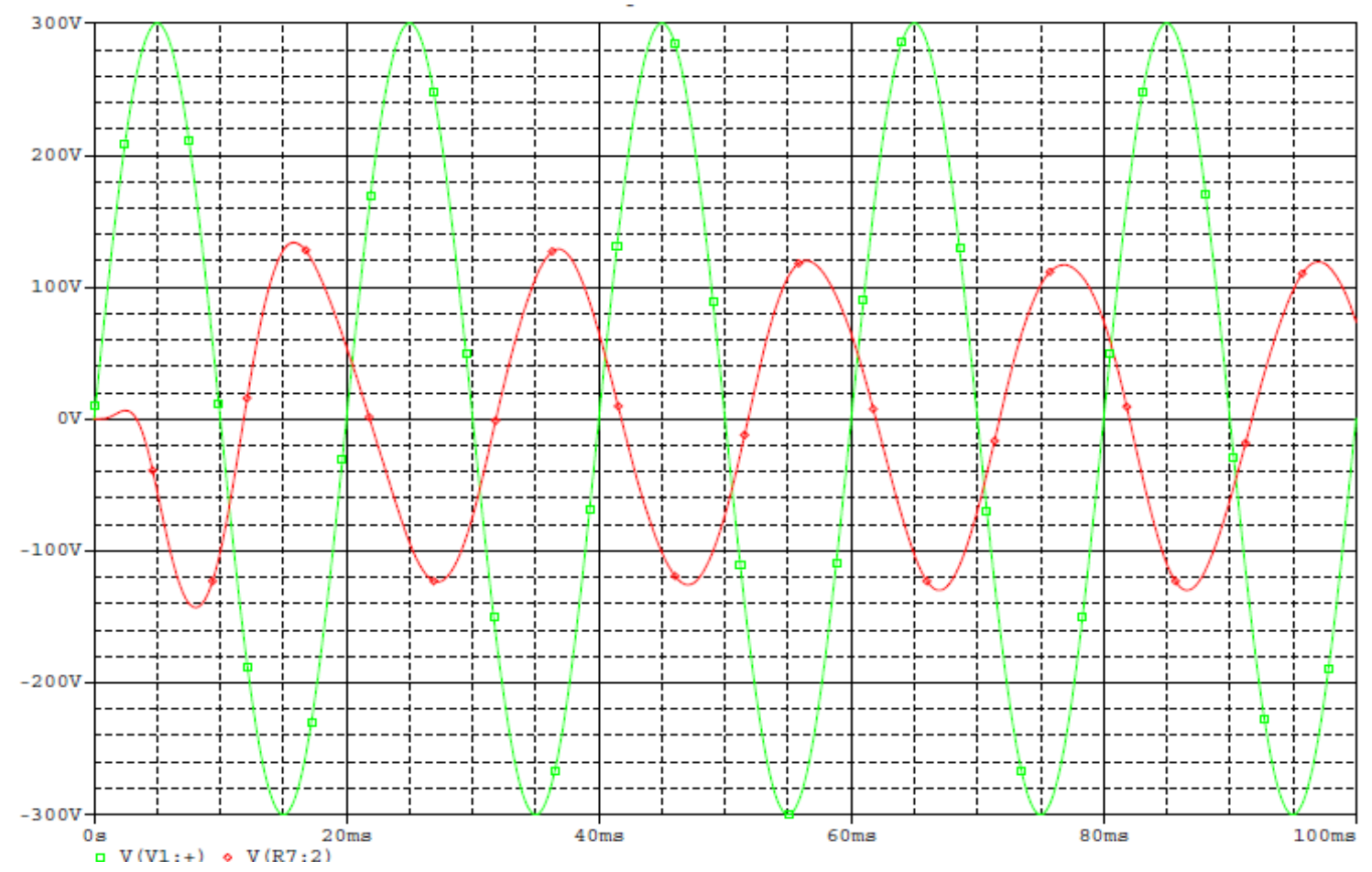

Fig-4.6: Input and output voltage waveforms, when input voltage $300 \mathrm{~V}$, load $150 \mathrm{ohm}$ and duty cycle $\mathrm{D}=0.4$ $\mathrm{V}(\mathrm{V} 1:+)-$ Input voltage $=300 \mathrm{~V}$ and $\mathrm{V}(\mathrm{R} 7: 2)-$ Output voltage $=120 \mathrm{~V}$

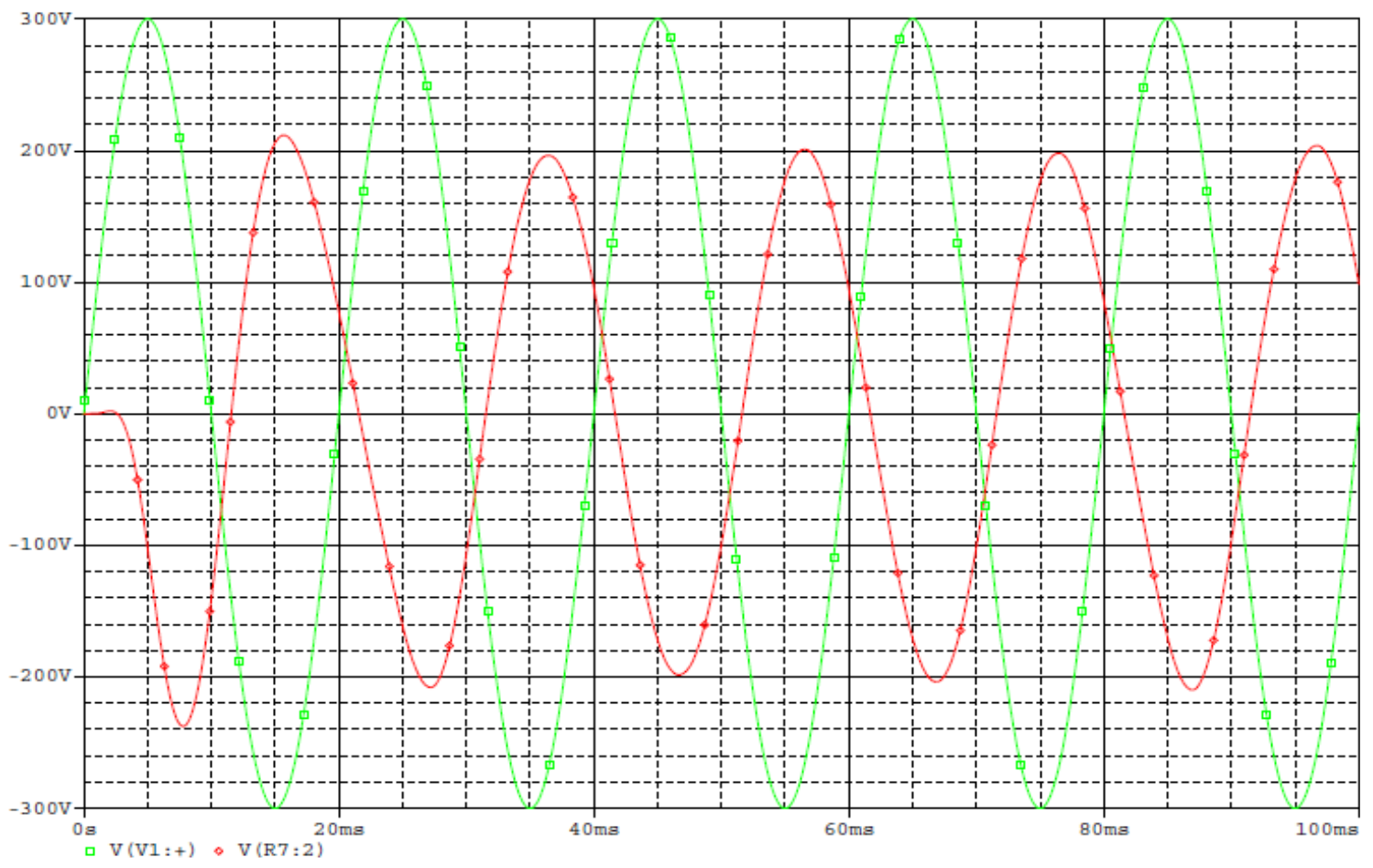

Fig-4.7: Input and output voltage waveforms, when input voltage $300 \mathrm{~V}$, load $150 \mathrm{ohm}$ and duty cycle $\mathrm{D}=0.5$

$\mathrm{V}(\mathrm{V} 1:+)-$ Input voltage $=300 \mathrm{~V}$ and $\mathrm{V}(\mathrm{R} 7: 2)-$ Output voltage $=200 \mathrm{~V}$ 


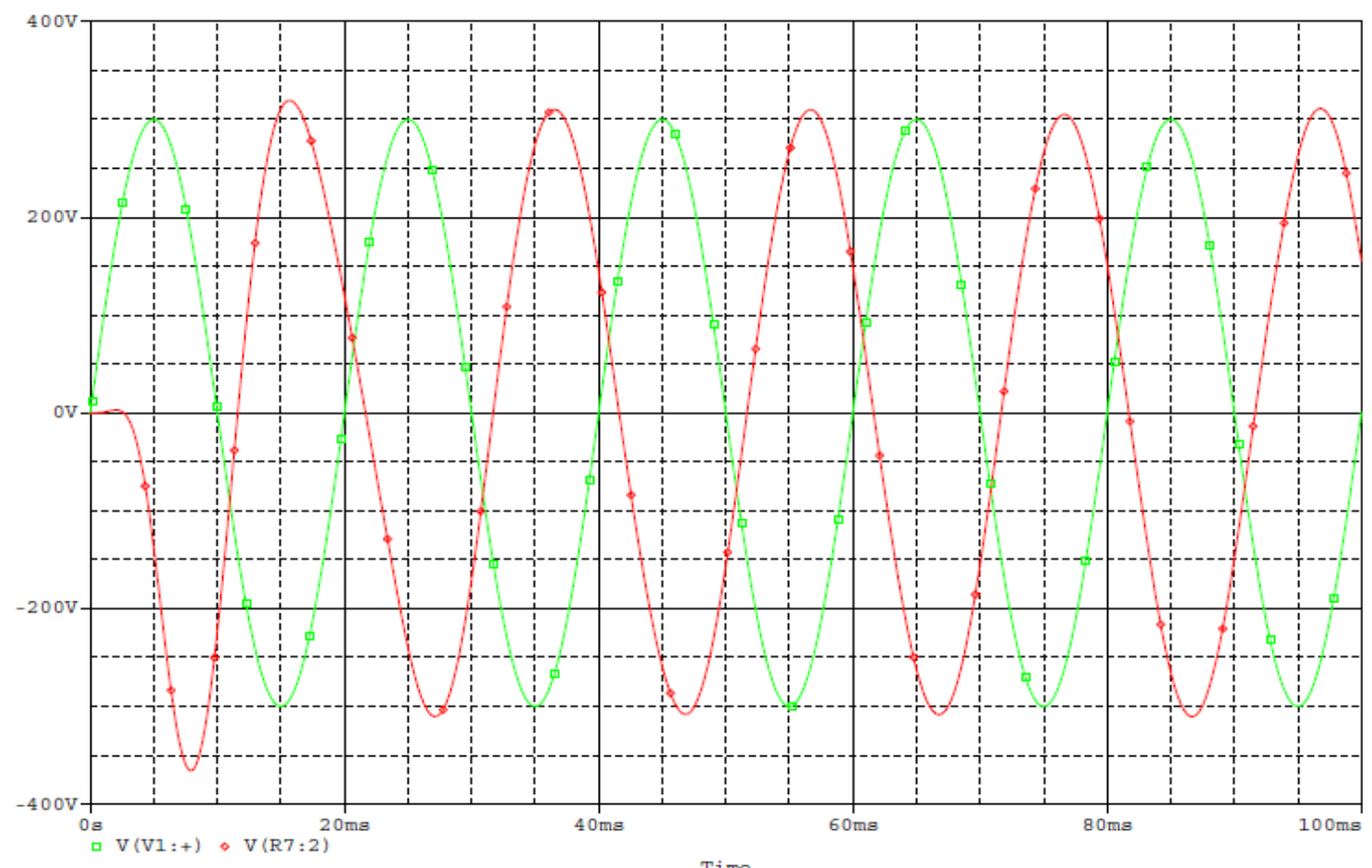

Fig-4.8: Input and output voltage waveforms, when input voltage $300 \mathrm{~V}$, load $150 \mathrm{ohm}$ and duty cycle $\mathrm{D}=0.6$

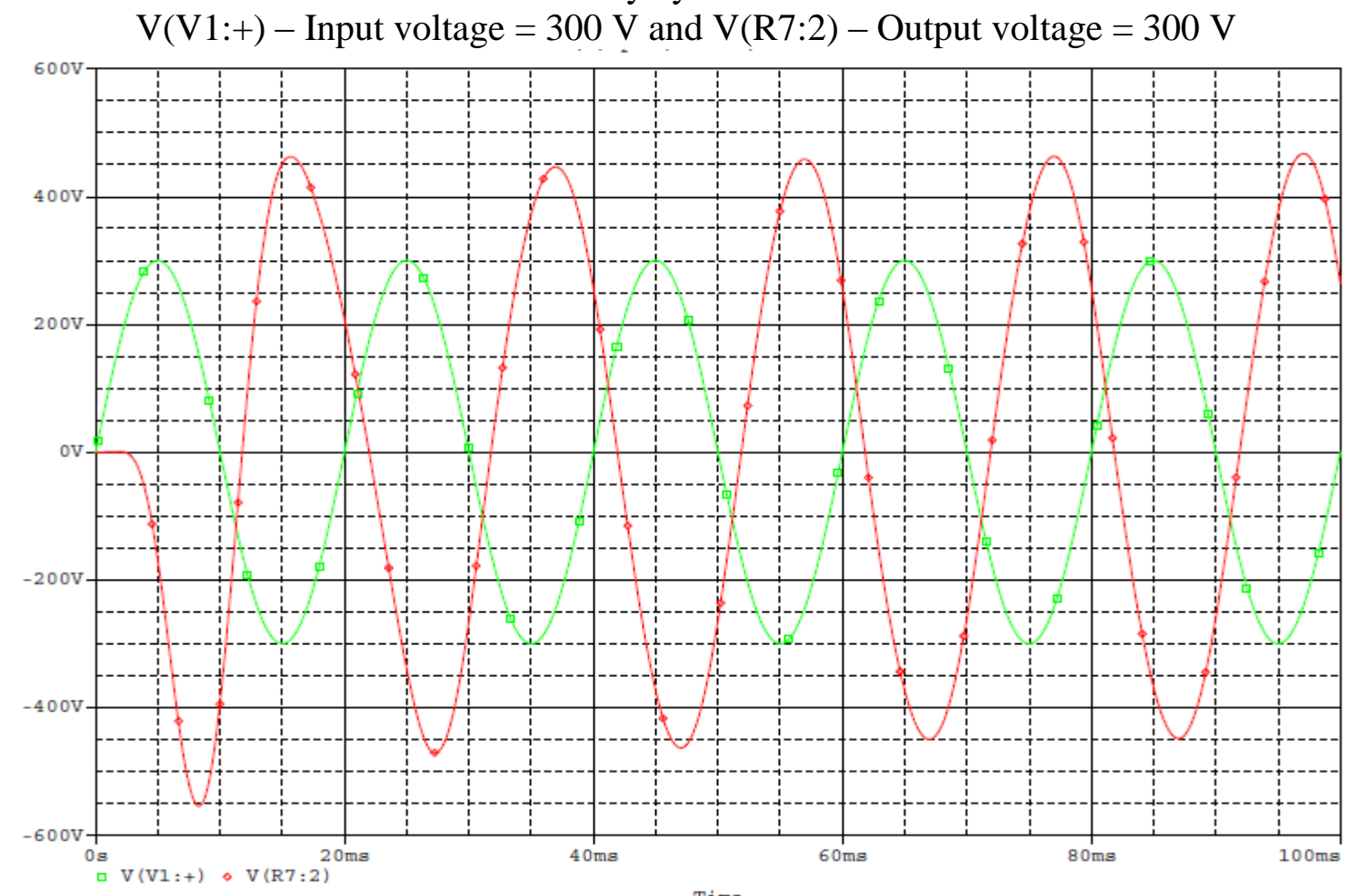

Fig-4.9: Input and output voltage waveforms, when input voltage $300 \mathrm{~V}$, load $150 \mathrm{ohm}$ and duty cycle $\mathrm{D}=0.7$

$\mathrm{V}(\mathrm{V} 1:+)-$ Input voltage $=300 \mathrm{~V}$ and $\mathrm{V}(\mathrm{R} 7: 2)-$ Output voltage $=450 \mathrm{~V}$ 


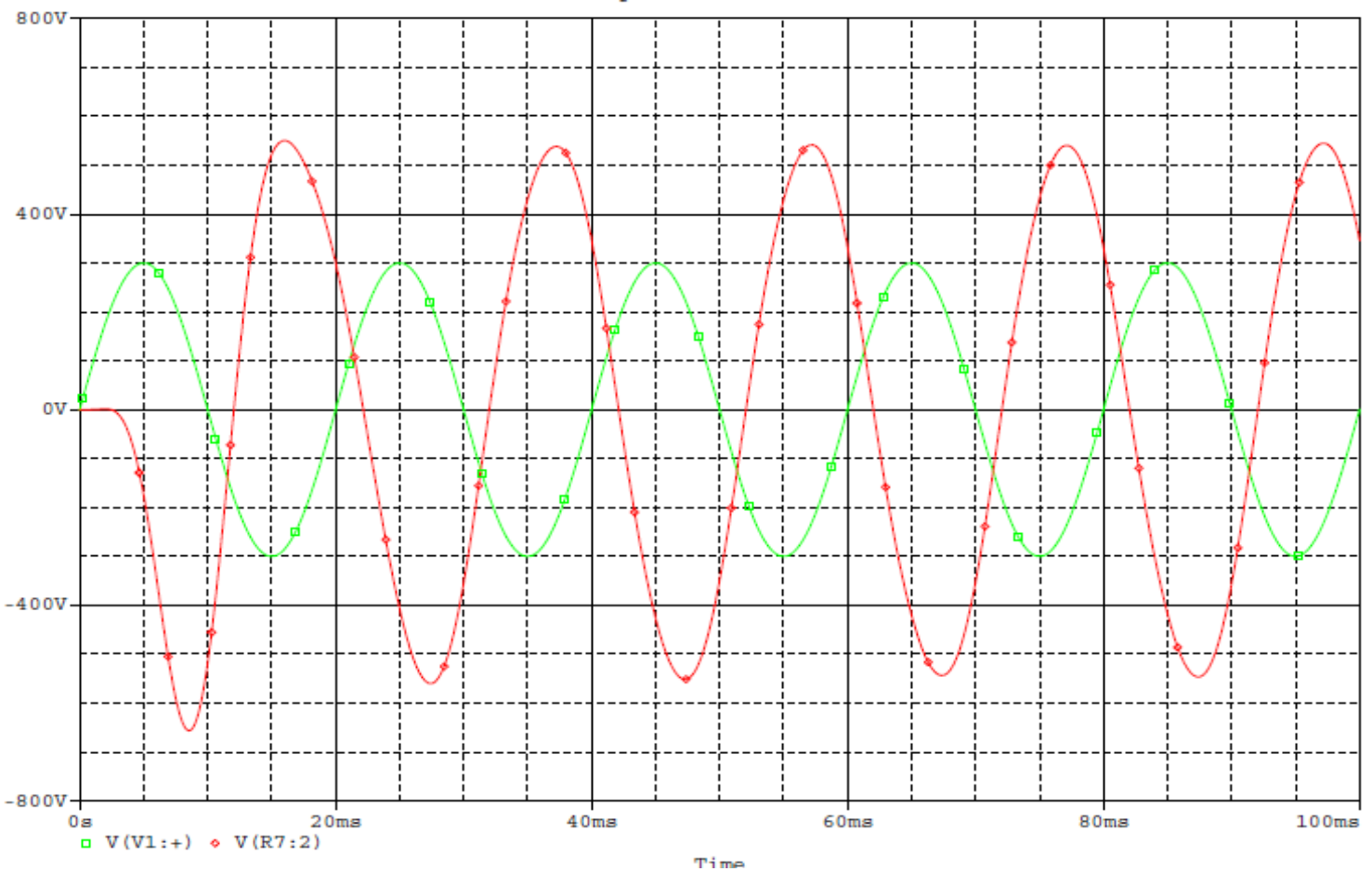

Fig-4.10: Input and output voltage waveforms, when input voltage $300 \mathrm{~V}$, load $150 \mathrm{ohm}$ and duty cycle $\mathrm{D}=0.8$

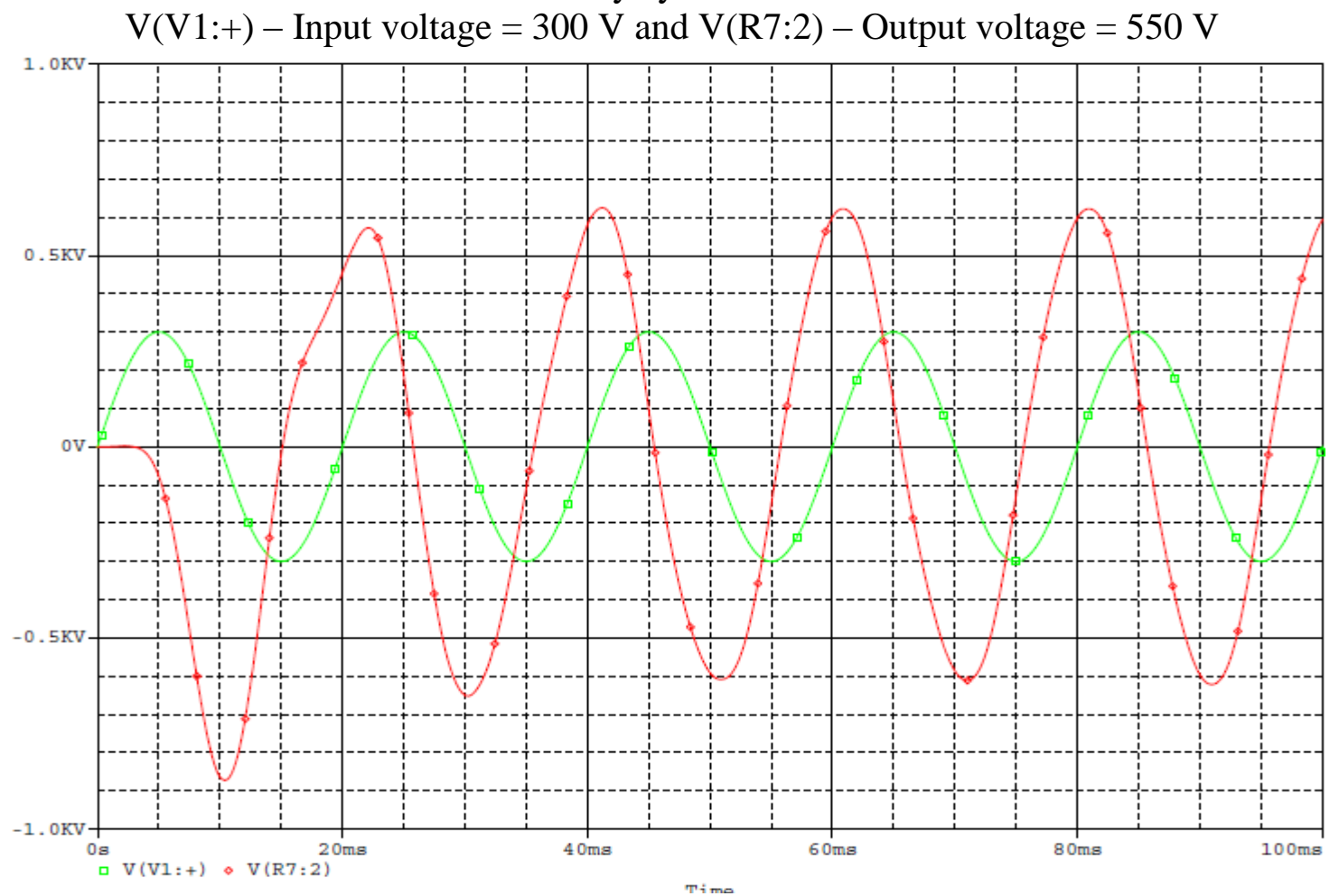

Fig-4.11: Input and output voltage waveforms, when input voltage $300 \mathrm{~V}$, load $150 \mathrm{ohm}$ and duty cycle $\mathrm{D}=0.9$

$\mathrm{V}(\mathrm{V} 1:+)-$ Input voltage $=300 \mathrm{~V}$ and $\mathrm{V}(\mathrm{R} 7: 2)-$ Output voltage $=625 \mathrm{~V}$ 


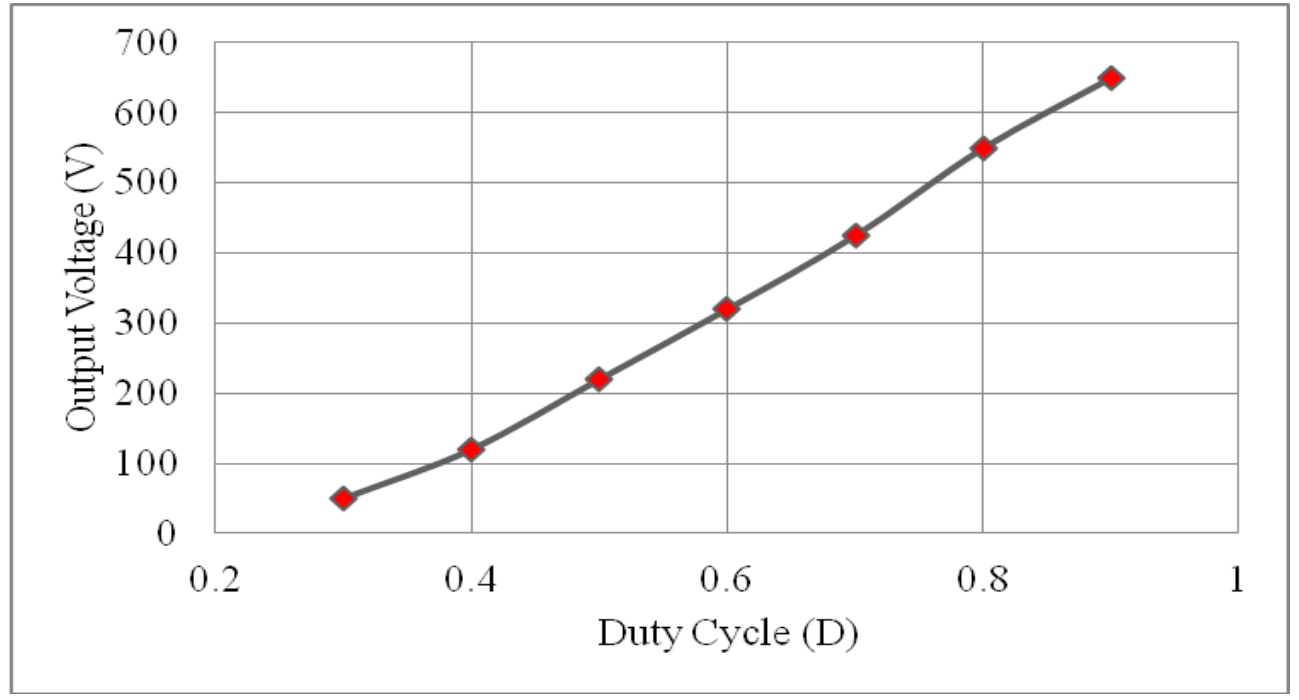

Fig- 4.12: Variation of output voltage with Duty Cycle (When input voltage=300V)

Moreover, it is necessary to observe the variation of duty cycle with the variation of input voltage to maintain a constant output voltage across the load (300V - peak voltage and load is $150 \mathrm{ohm}$ ) of the proposed manually controlled AC Cûk regulator. Now, input voltage is diverse from below the rated voltage to above the rated voltage (i.e. $200 \mathrm{~V}$ to $400 \mathrm{~V}$ ) but output voltage is regulated and kept constant across the load at $300 \mathrm{~V}$ (peakdesired). The input-output waveforms for input voltage $200 \mathrm{~V}, 250 \mathrm{~V}, 300 \mathrm{~V}, 350 \mathrm{~V}$ and $400 \mathrm{~V}$ are shown in figure 4.13 to 4.17 , respectively. The corresponding switching signals (PWM) for input voltage $250 \mathrm{~V}, 300 \mathrm{~V}$ and $400 \mathrm{~V}$ are also shown in figures 4.18 to 4.20 , respectively. These results indicate that by changing the pulse width of gate signals (changing Duty cycle) of switches S1 and S2, output voltage across the load can be maintained at a constant level. The variation of duty cycle along with the range of input voltage from $200 \mathrm{~V}$ to $400 \mathrm{~V}$ in order to maintain the output voltage constant at $300 \mathrm{~V}$ (peak) is shown in figure 4.21. The relationship between the variation of duty cycle and the variation of input voltage is concluded to be inversely proportional.

The circuit is simulated by using the following parameters:

$\mathrm{V}_{\mathrm{ac}}=300 \sin (100 \pi \mathrm{t})$, Supply frequency $=50 \mathrm{~Hz}, \mathrm{~L}_{1}=1 \mathrm{mh}, \mathrm{L}_{2}=50 \mathrm{mh}, \mathrm{C}_{1}=250 \mathrm{uf}, \mathrm{C}_{2}$ $=50 \mathrm{uf}$, Load resistance $=150 \mathrm{Ohm}, \mathrm{f}_{\mathrm{s}}($ switching frequency $)=4 \mathrm{KHz}$. 


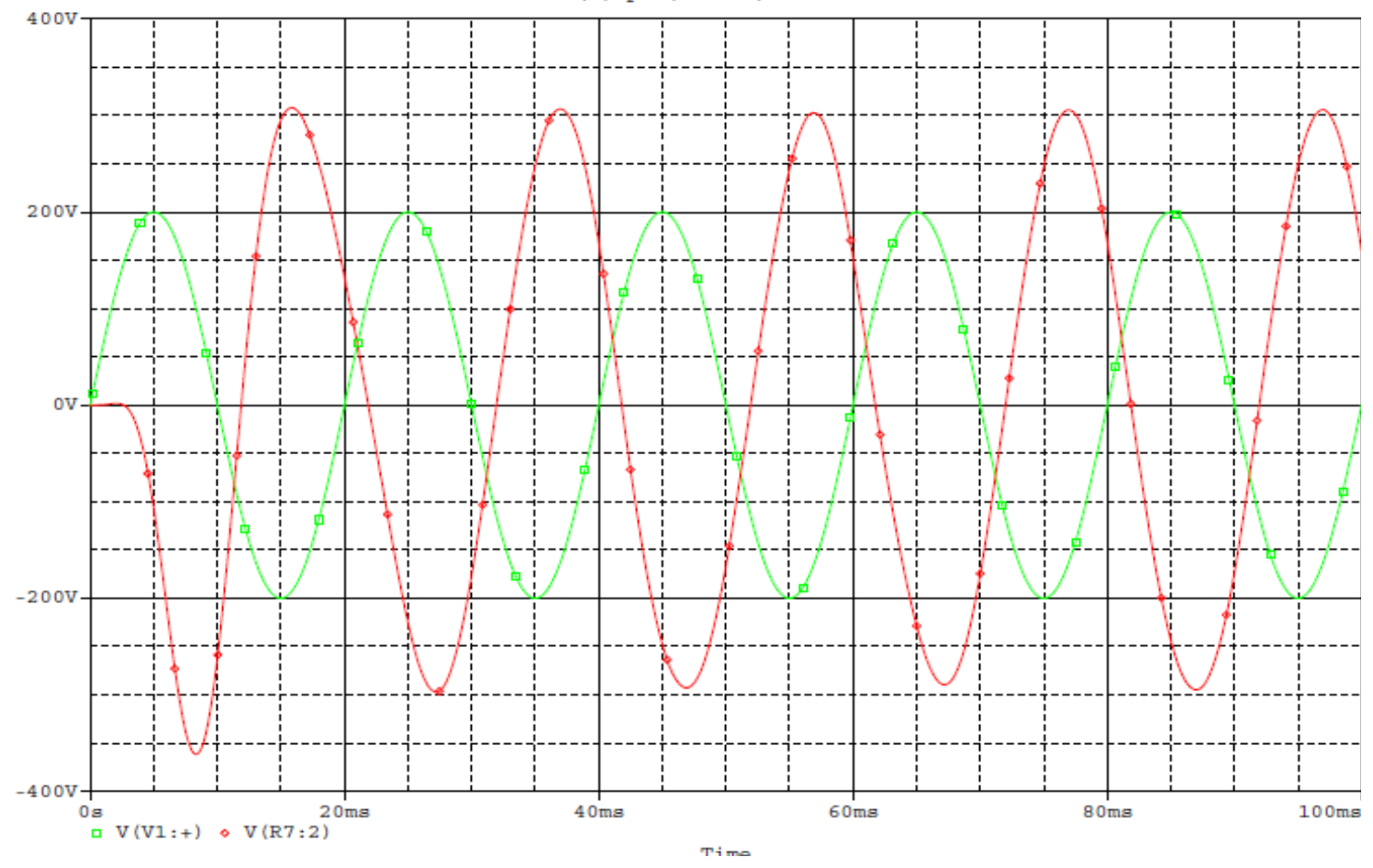

Fig-4.13: Input and output voltage waveforms, when input voltage $200 \mathrm{~V}$, load $150 \mathrm{ohm}$ $\mathrm{V}(\mathrm{V} 1:+):$ Input voltage $=200 \mathrm{~V}$ and $\mathrm{V}(\mathrm{R} 7: 2):$ Output voltage $=300 \mathrm{~V}$

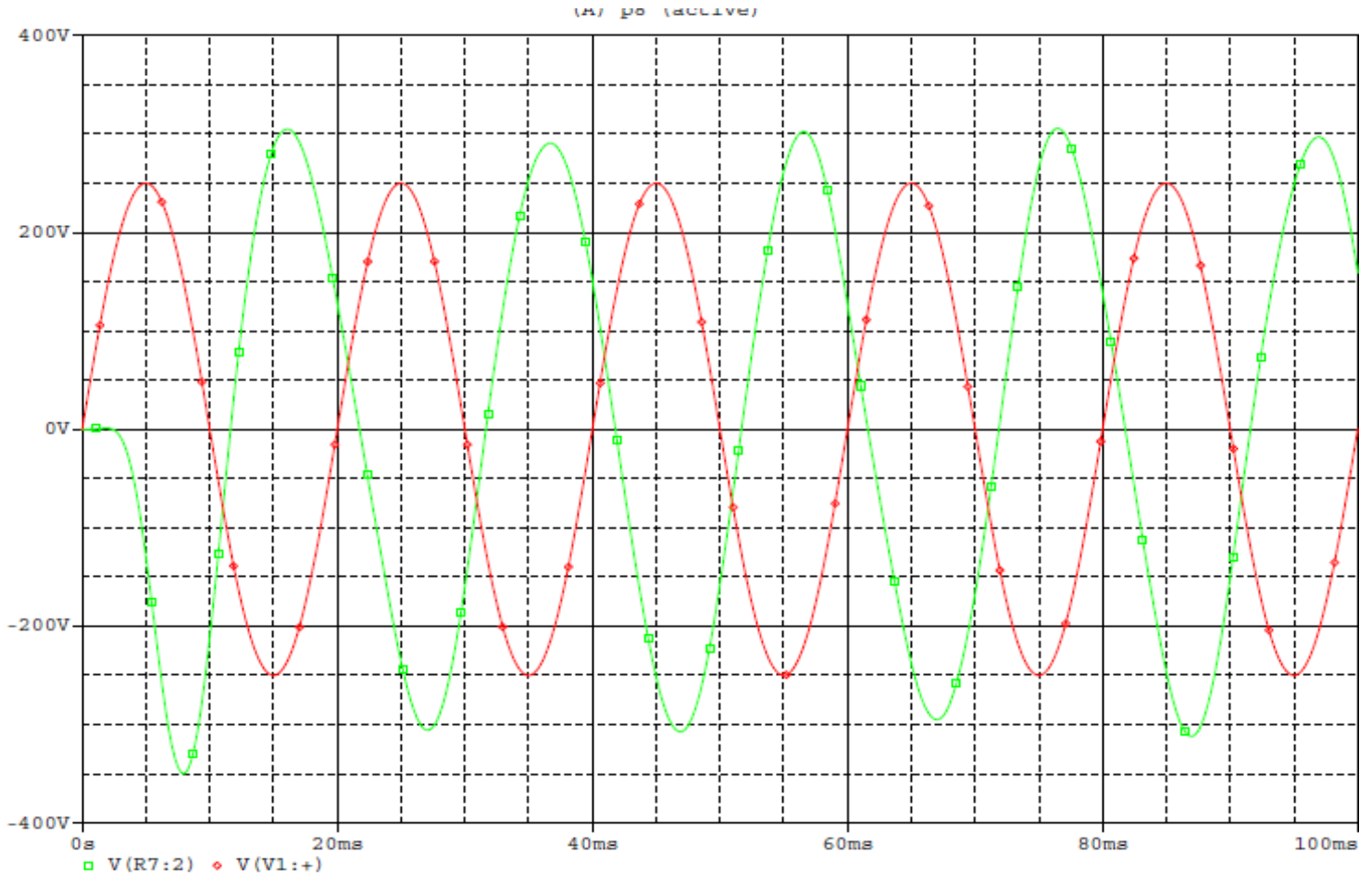

Fig-4.14: Input and output voltage waveforms, when input voltage $250 \mathrm{~V}$, load $150 \mathrm{ohm}$ $\mathrm{V}(\mathrm{V} 1:+):$ Input voltage $=250 \mathrm{~V}$ and $\mathrm{V}(\mathrm{R} 7: 2):$ Output voltage $=300 \mathrm{~V}$ 


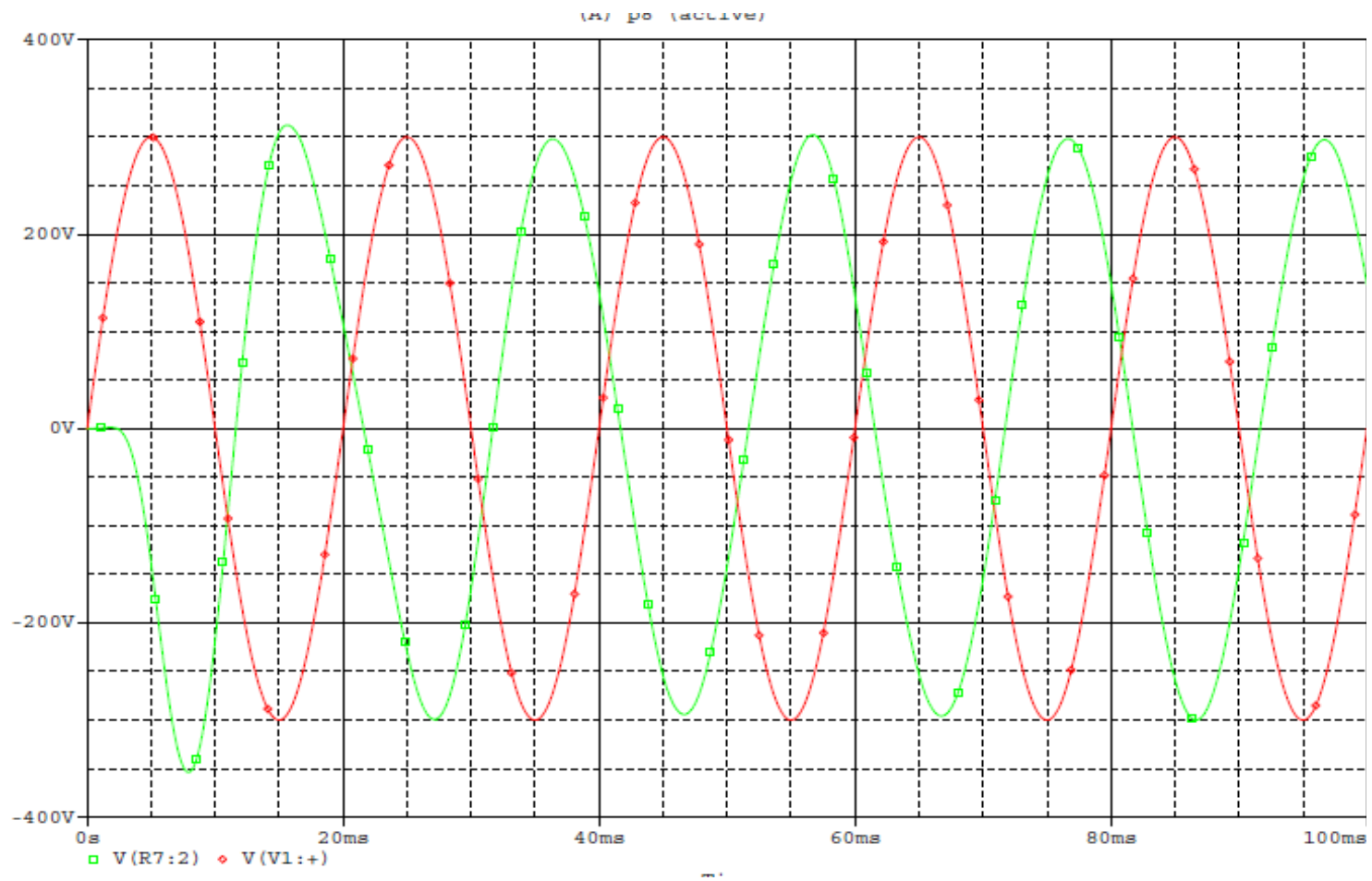

Fig-4.15: Input and output voltage waveforms, when input voltage $300 \mathrm{~V}$, load $150 \mathrm{ohm}$ $\mathrm{V}(\mathrm{V} 1:+):$ Input voltage $=300 \mathrm{~V}$ and $\mathrm{V}(\mathrm{R} 7: 2):$ Output voltage $=300 \mathrm{~V}$

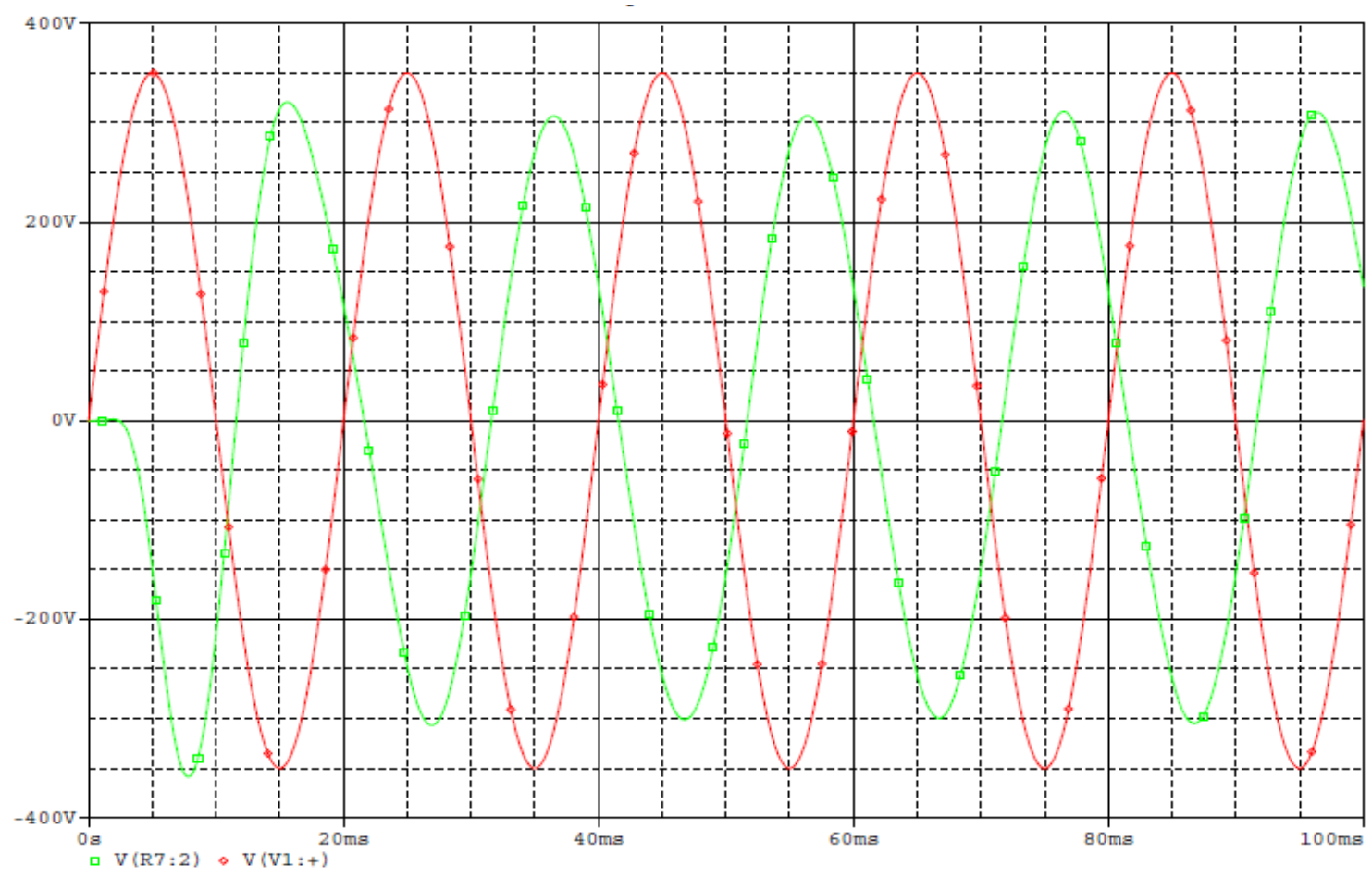

Fig-4.16: Input and output voltage waveforms, when input voltage $350 \mathrm{~V}$, load $150 \mathrm{ohm}$ $\mathrm{V}(\mathrm{V} 1:+):$ Input voltage $=350 \mathrm{~V}$ and $\mathrm{V}(\mathrm{R} 7: 2):$ Output voltage $=300 \mathrm{~V}$ 


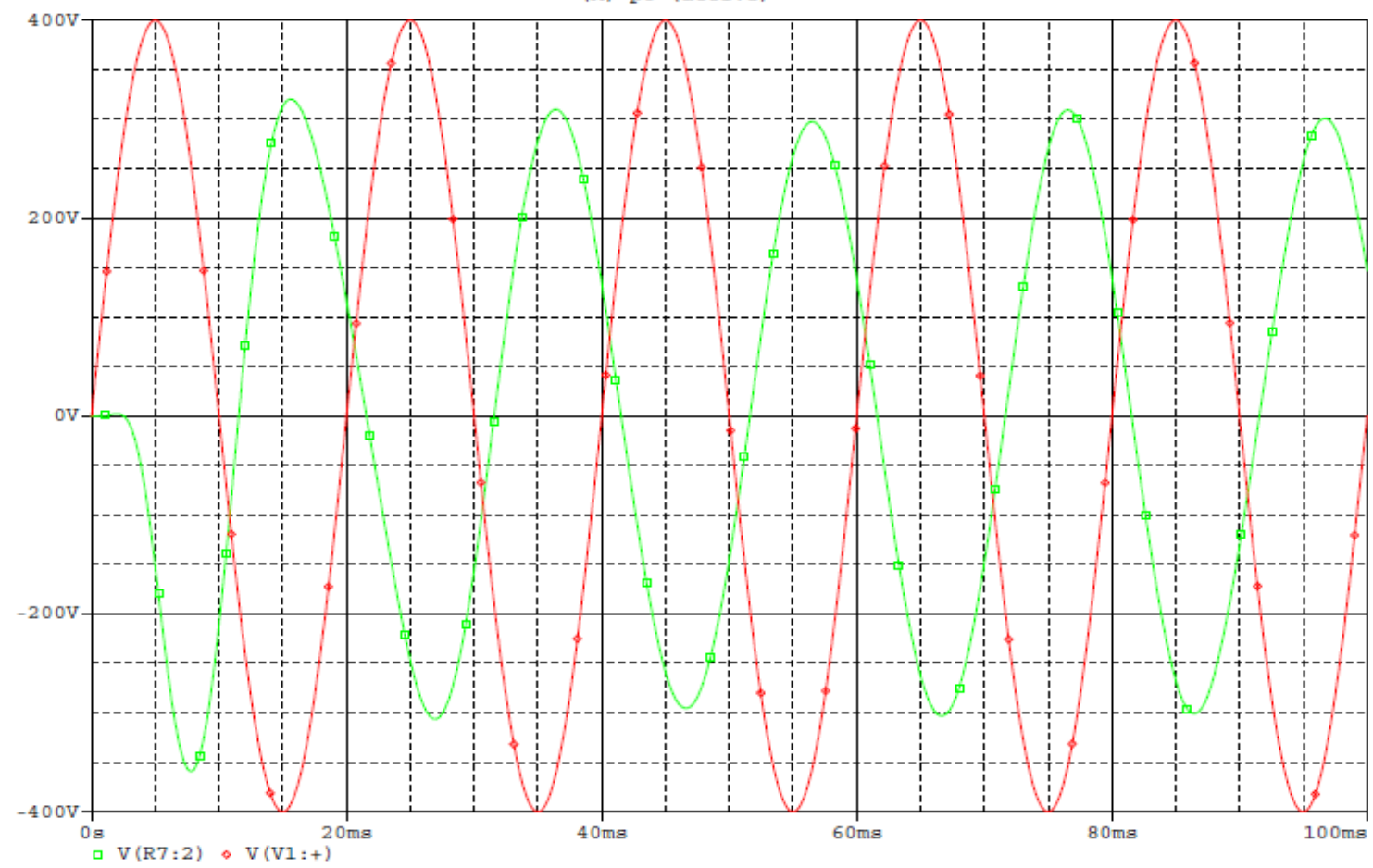

Fig-4.17: Input and output voltage waveforms, when input voltage $400 \mathrm{~V}$, load $150 \mathrm{ohm}$ $\mathrm{V}(\mathrm{V} 1:+):$ Input voltage $=400 \mathrm{~V}$ and $\mathrm{V}(\mathrm{R} 7: 2):$ Output voltage $=300 \mathrm{~V}$

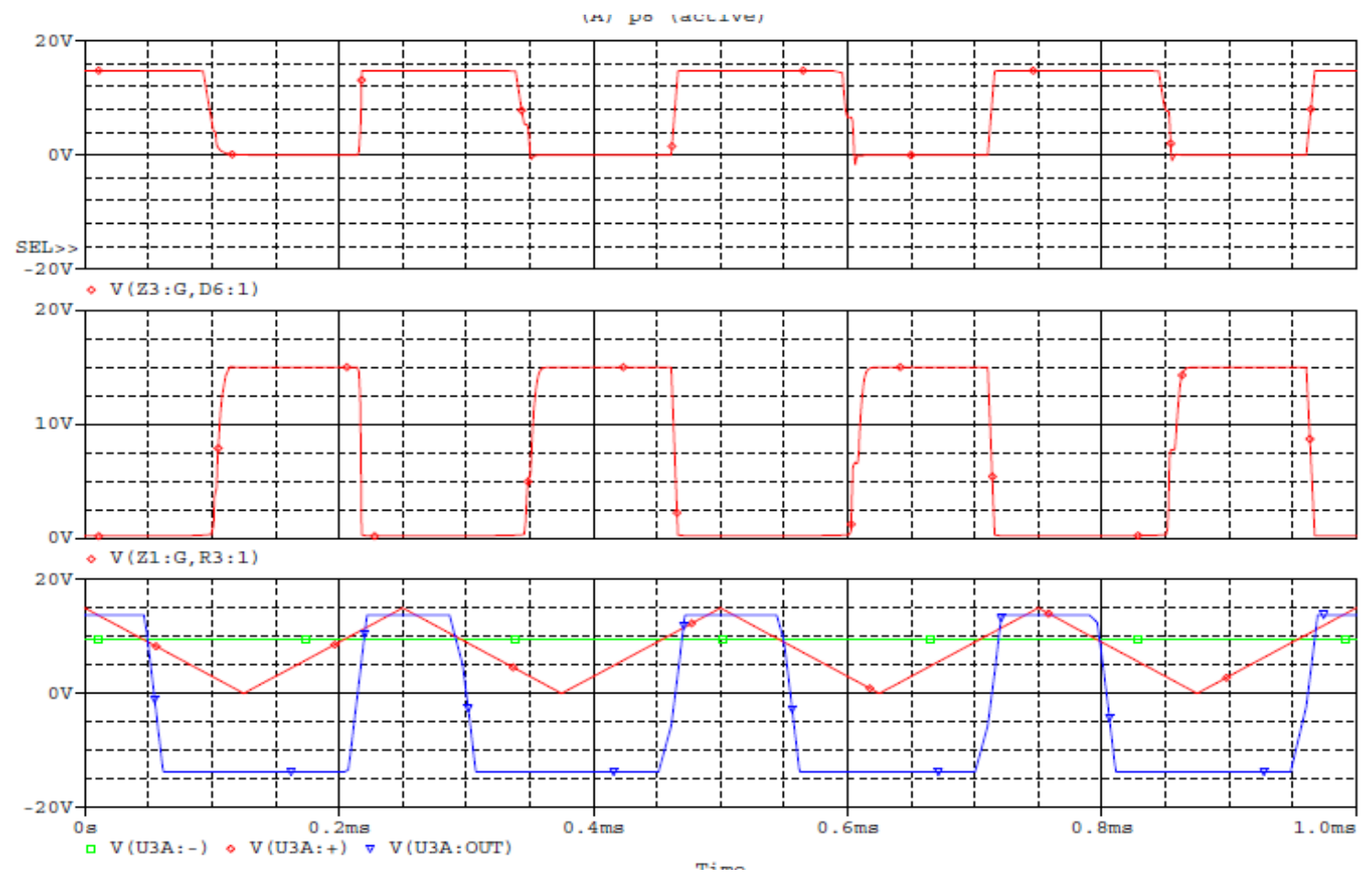

Fig-4.18: Switching pulses, when input voltage $250 \mathrm{~V}$, load $150 \mathrm{ohm}$ $\mathrm{V}(\mathrm{Z1})$ - Switching voltage of switch-1 and V(Z3) - Switching voltage of switch-2 

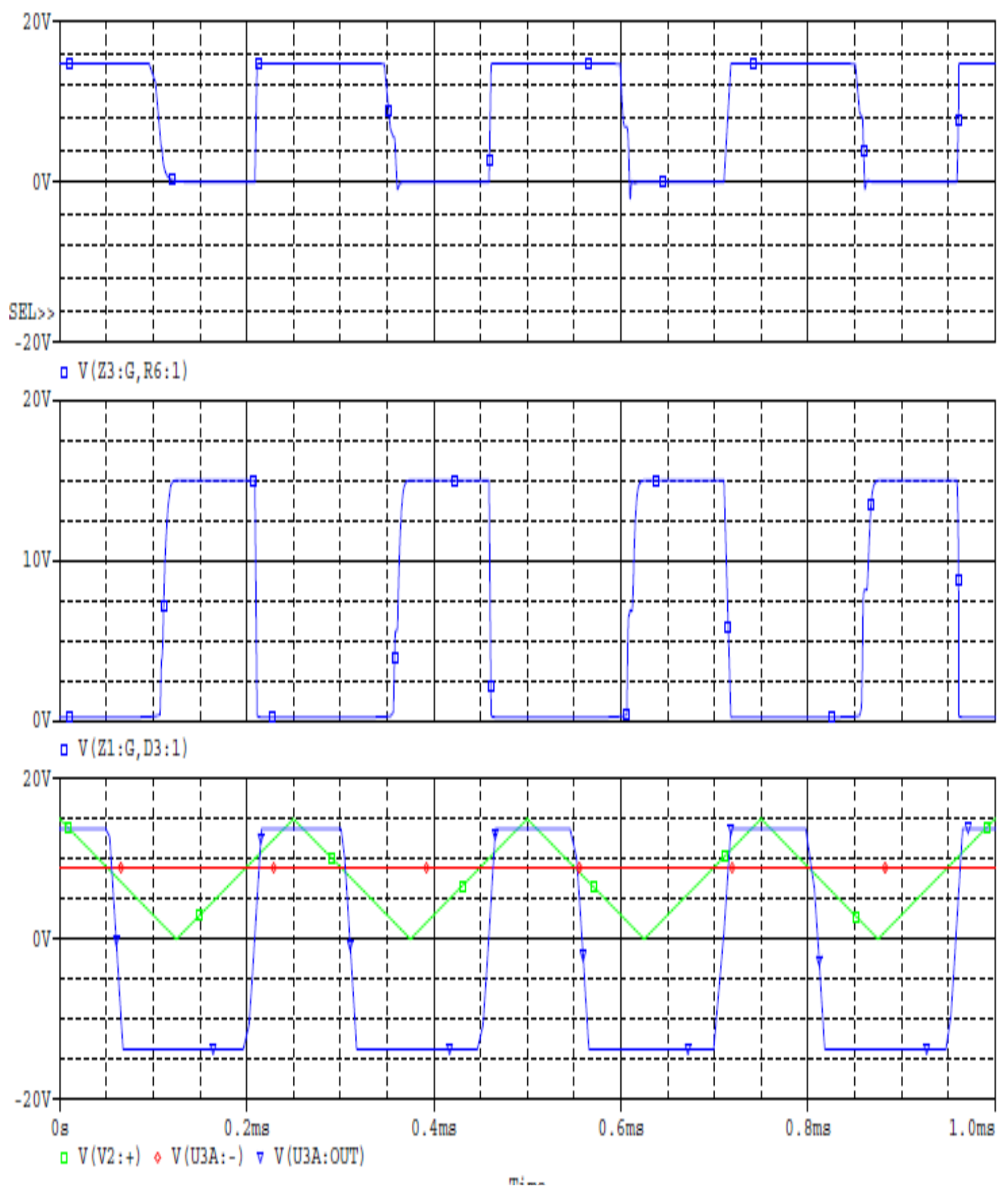

Fig-4.19: Switching pulses, when input voltage $300 \mathrm{~V}$, load $150 \mathrm{ohm}$

$\mathrm{V}(\mathrm{Z1})$ - Switching voltage of switch-1

$\mathrm{V}(\mathrm{Z3})$ - Switching voltage of switch-2 

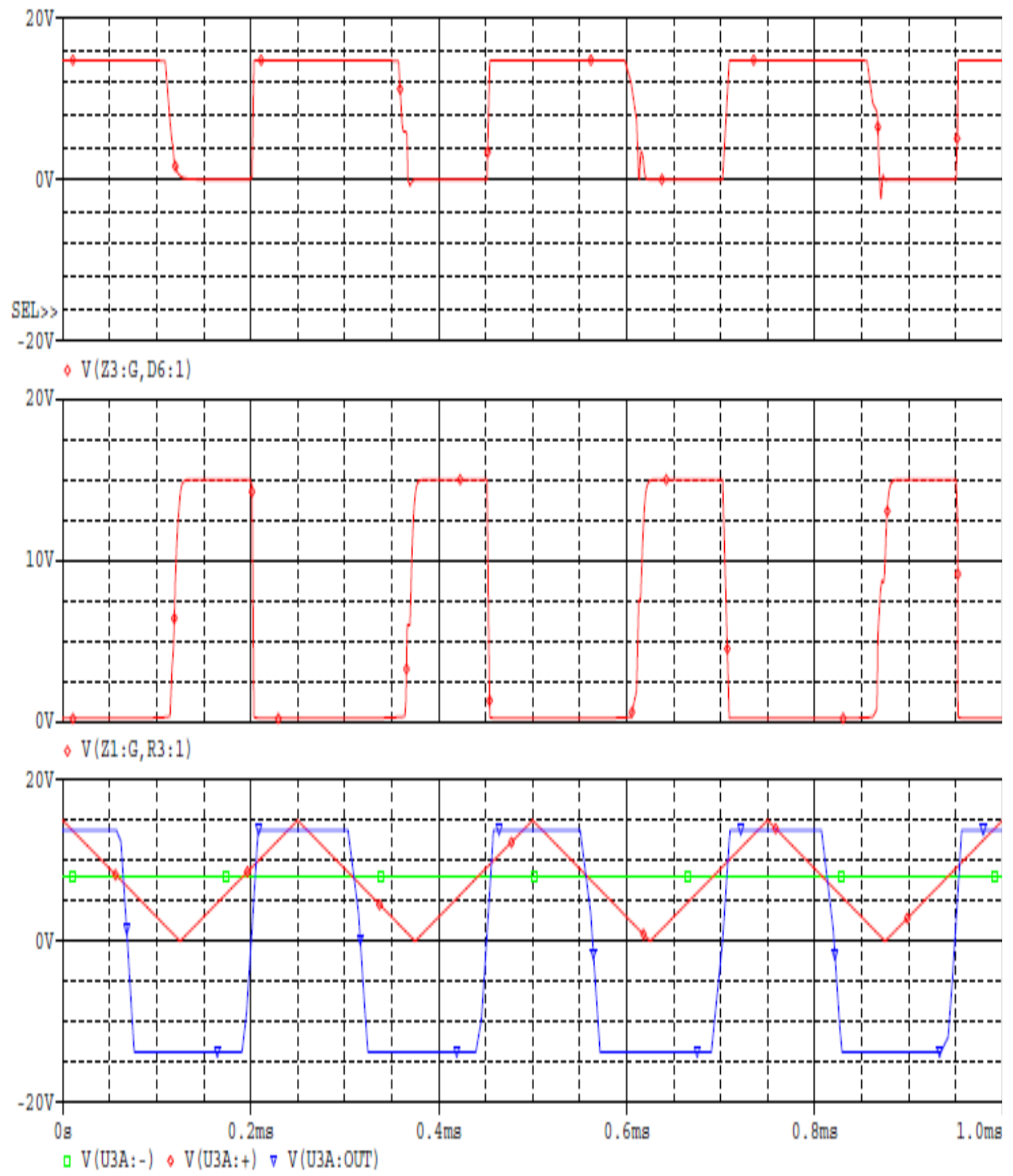

Fig-4.20: Switching pulses, when input voltage 400V, load $150 \mathrm{ohm}$

$\mathrm{V}(\mathrm{Z1})$ - Switching voltage of switch-1

$\mathrm{V}(\mathrm{Z3})$ - Switching voltage of switch-2 


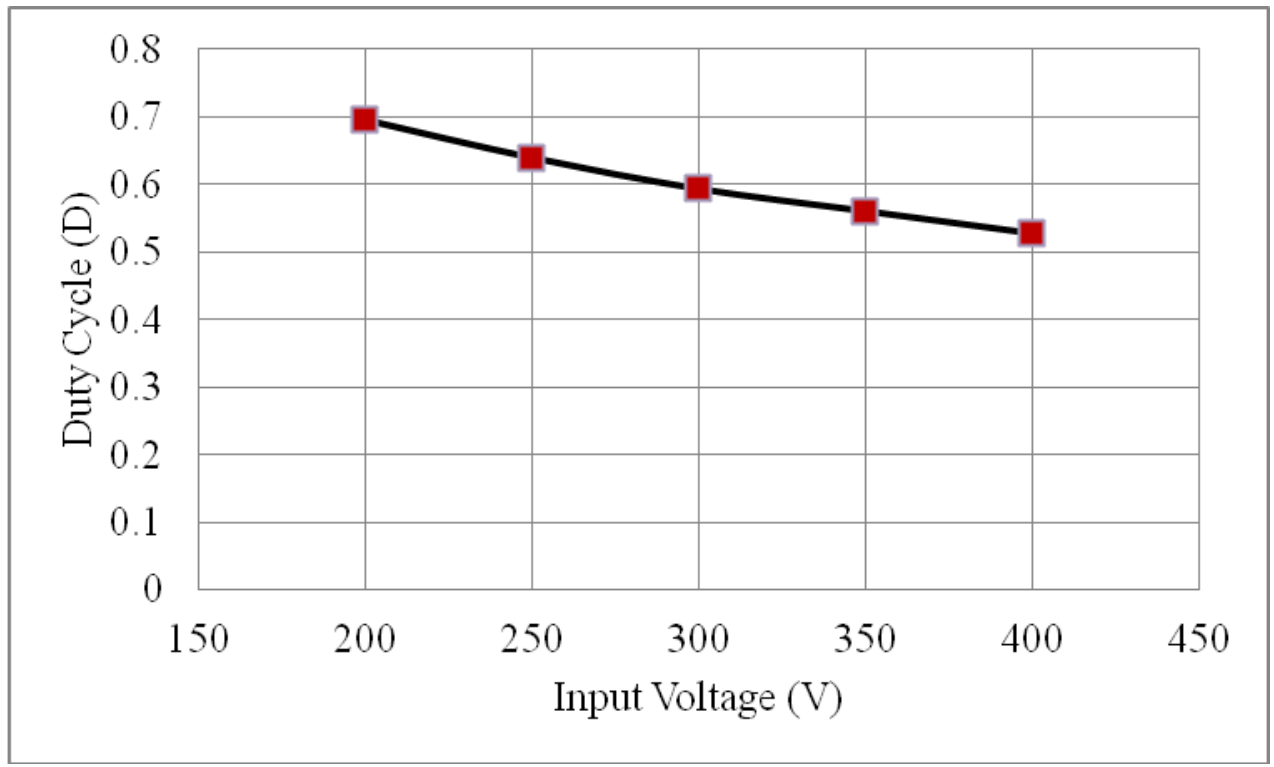

Fig-4.21: Variation of duty cycle with input voltage to maintain output constant at 300V

\subsection{AUTOMATICALLY CONTROLLED PROPOSED AC CÔK VOLTAGE REGULATOR}

In manual control, the output voltage is sensed through a voltmeter connected at the output; the decision and correcting, however, operation is made by a human judgment. Manual control may not always be feasible due to various factors. In automatic voltage regulators, on the other hand, all functions are performed by instruction, and give much better performance, as far as stability, speed of correction, consistency, fatigue, etc. are concerned.

The proposed automatic control AC Cûk regulator and gate signal generating circuit are shown in figure 4.22. In the proposed automatic control AC Cûk regulator, circuit parameters of the manually controlled AC Cûk regulator are modified and rearranged. As well, a control circuit is added to generate a PWM signal as per requirement. The previously used manual control circuit is replaced by an automatic control circuit. 
For the operation of the automatic control circuit, a fraction of the output voltage (output of power circuit), after capacitor voltage dividing and rectifying, is passed through an OPAMP buffer (U3A :+). Buffer (U3A) is used to remove the loading effect. Output of the buffer is identical to its input. The output of buffer (U3A) is compared to a fixed reference voltage by using difference circuit (U4A); and the error thus generated is amplified, integrated or differentiated whenever necessary by U5A. Next, the processed error voltage is fed to the main controlling unit (U10A) to have required corrective action. Output of (U10A) consists of the generated PWM signals for IGBT-1 and IGBT-2. The control circuit directs not only the duty cycle but also PWM. In turn, PWM controls the ON and OFF time of IGBT-1 and IGBT-2 as per requirement. As a result, it maintains constant output voltage at $300 \mathrm{~V}$ (peak value) across the load for any change of input voltage within the limit.

All regulators take a finite time to effect a change in the supply voltage or load. This time is referred to as the time constant of the regulator, but in most case it is termed "response time". In some cases, the response time is dependent on the magnitude of the change in output voltage, but the rate of change remains constant. The maximum allowable response time depends upon the type of application. It is always desirable to make the response time as small possible so that the transients in output voltage are reduced. 

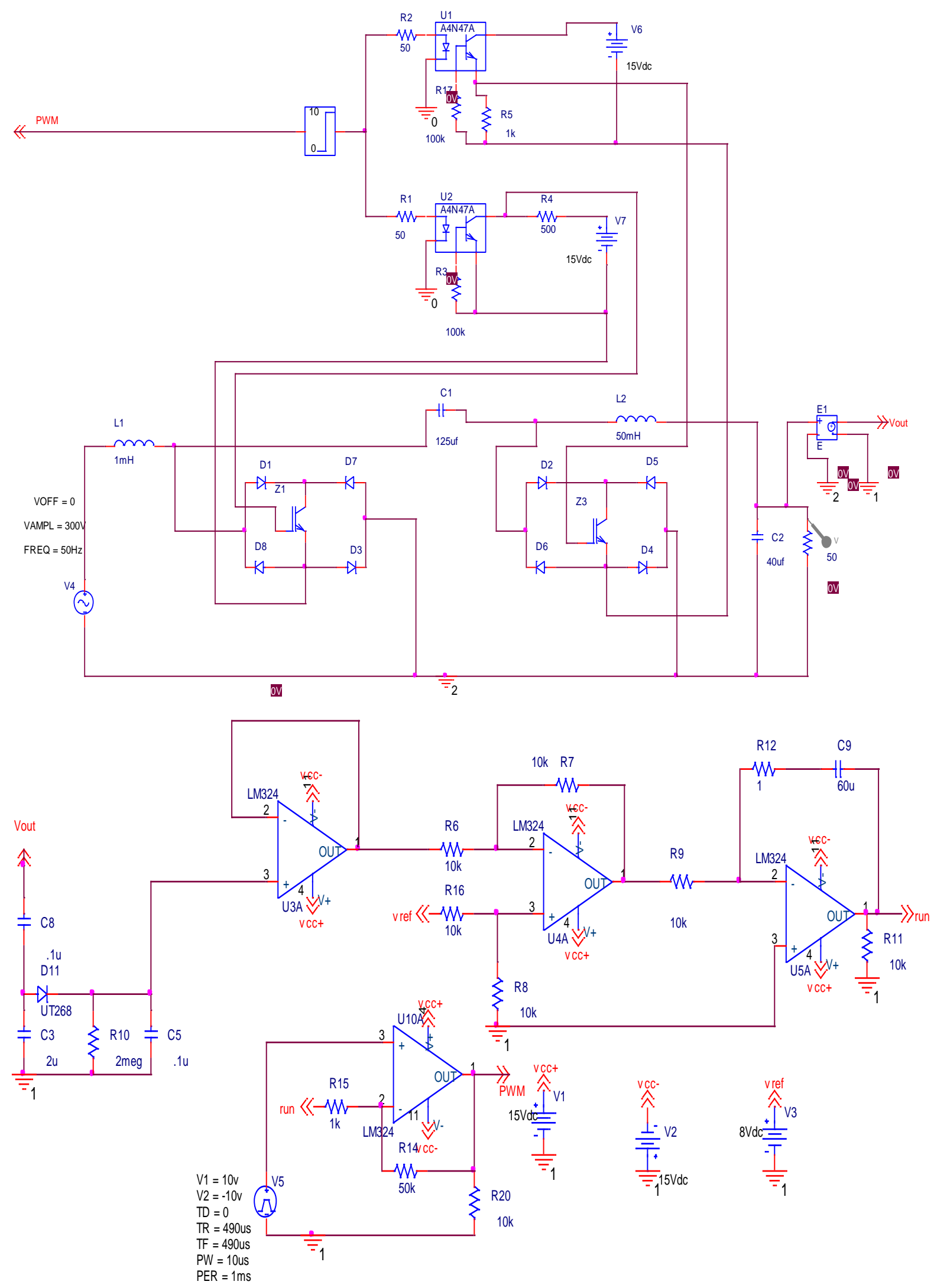

Fig 4.22: Proposed Automatically controlled AC Cûk regulator configuration with IGBT switches 


\subsection{RESULTS OF PROPOSED AUTOMATIC CONTROLLED AC CÛK REGULATOR}

The input-output voltage waveforms of the proposed automatic controlled AC Cûk regulator as shown in figure 4.23 when input voltage is $250 \mathrm{~V}$. Figures 4.24 to 4.26 show the input-output voltage waveforms when input voltage is $300 \mathrm{~V}, 325 \mathrm{~V}$ and $350 \mathrm{~V}$, respectively. From these results it can be concluded that the proposed automatic controlled AC Cûk regulator can maintain constant output voltage (300V-peak) in case of input voltage variation within the given limit (250V to $350 \mathrm{~V}$ ).

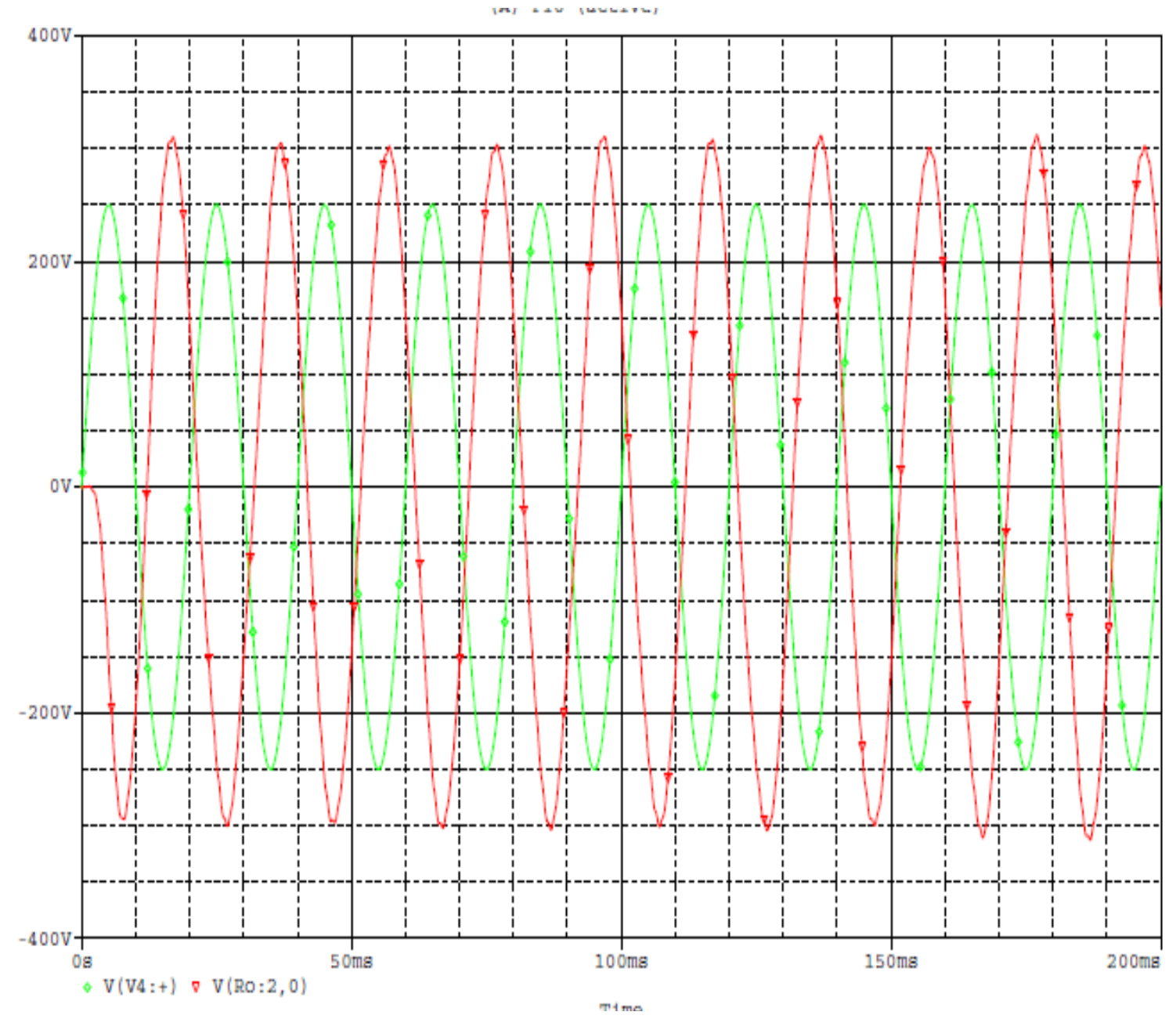

Fig-4.23: Input and output voltage waveforms, when input voltage $250 \mathrm{~V}$ $\mathrm{V}(\mathrm{V} 4:+):$ Input voltage $=250 \mathrm{~V}$ and $\mathrm{V}(\mathrm{R} 0: 2):$ Output voltage $=300 \mathrm{~V}$ 


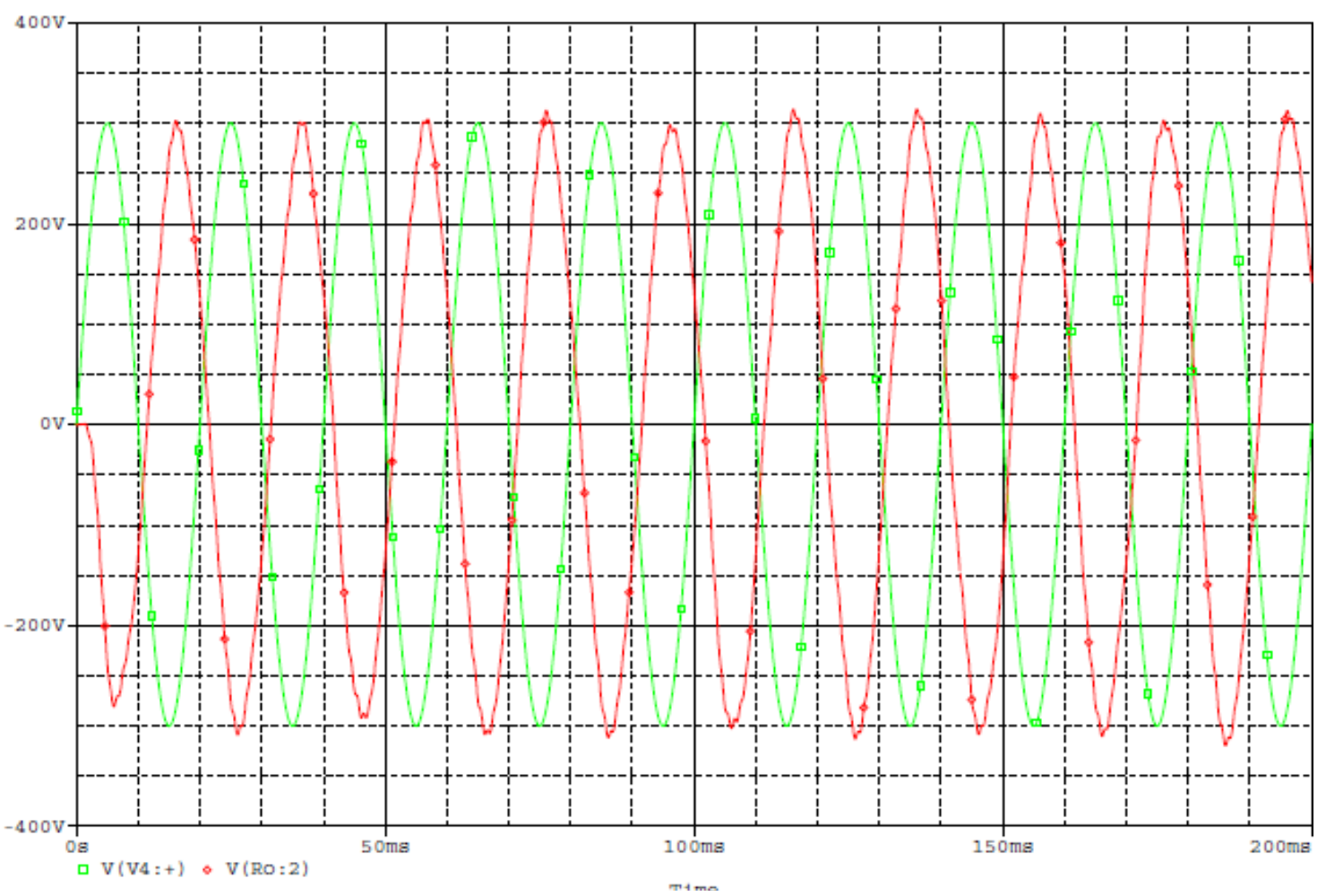

Fig-4.24: Input and output voltage waveforms, when input voltage $300 \mathrm{~V}$ $\mathrm{V}(\mathrm{V} 4:+)$ : Input voltage $=300 \mathrm{~V}$ and $\mathrm{V}(\mathrm{R} 0: 2):$ Output voltage $=300 \mathrm{~V}$

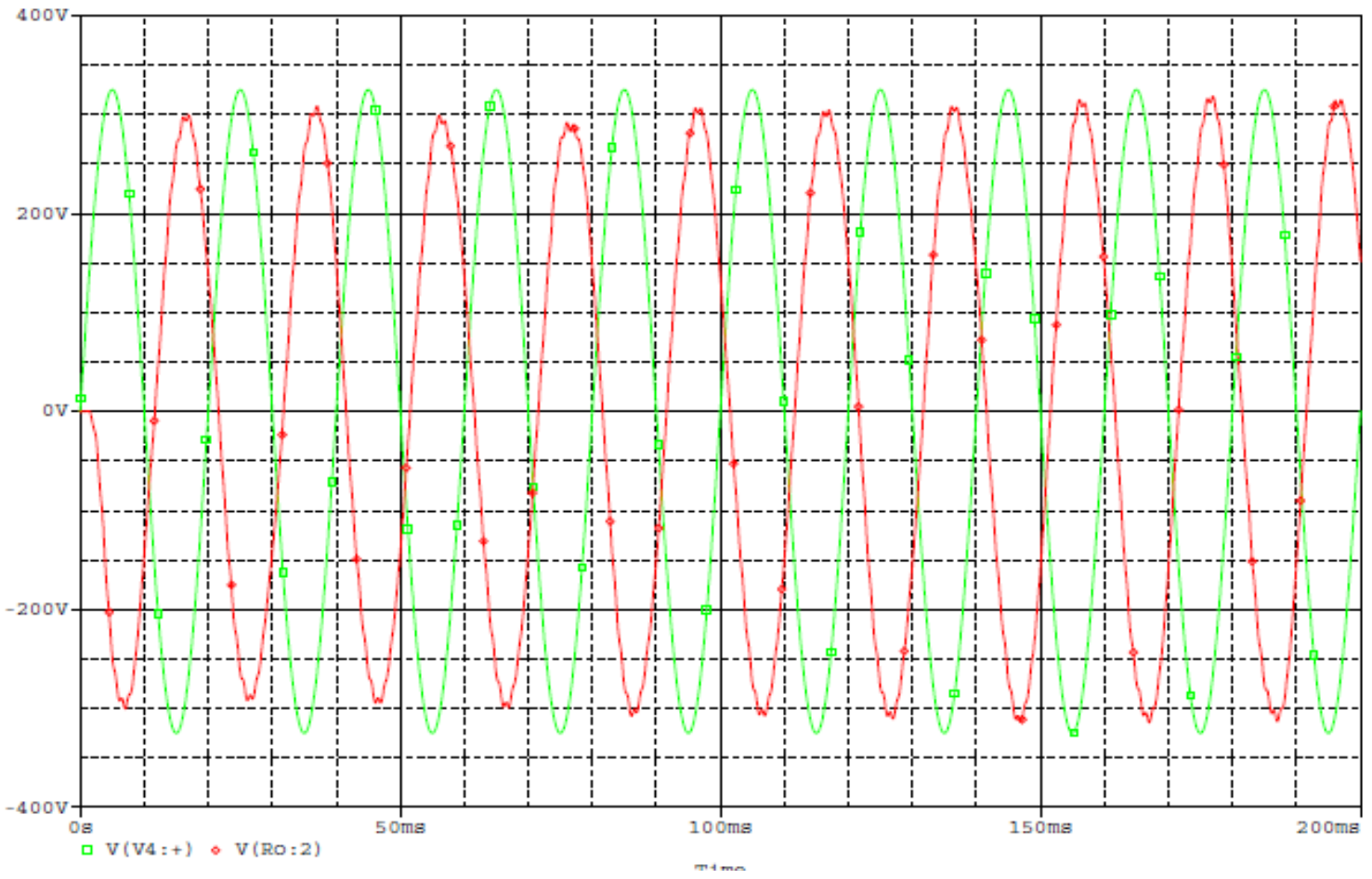

Fig-4.25: Input and output voltage waveforms, when input voltage $325 \mathrm{~V}$ $\mathrm{V}(\mathrm{V} 4:+)$ : Input voltage $=325 \mathrm{~V}$ and $\mathrm{V}(\mathrm{R} 0: 2):$ Output voltage $=300 \mathrm{~V}$ 


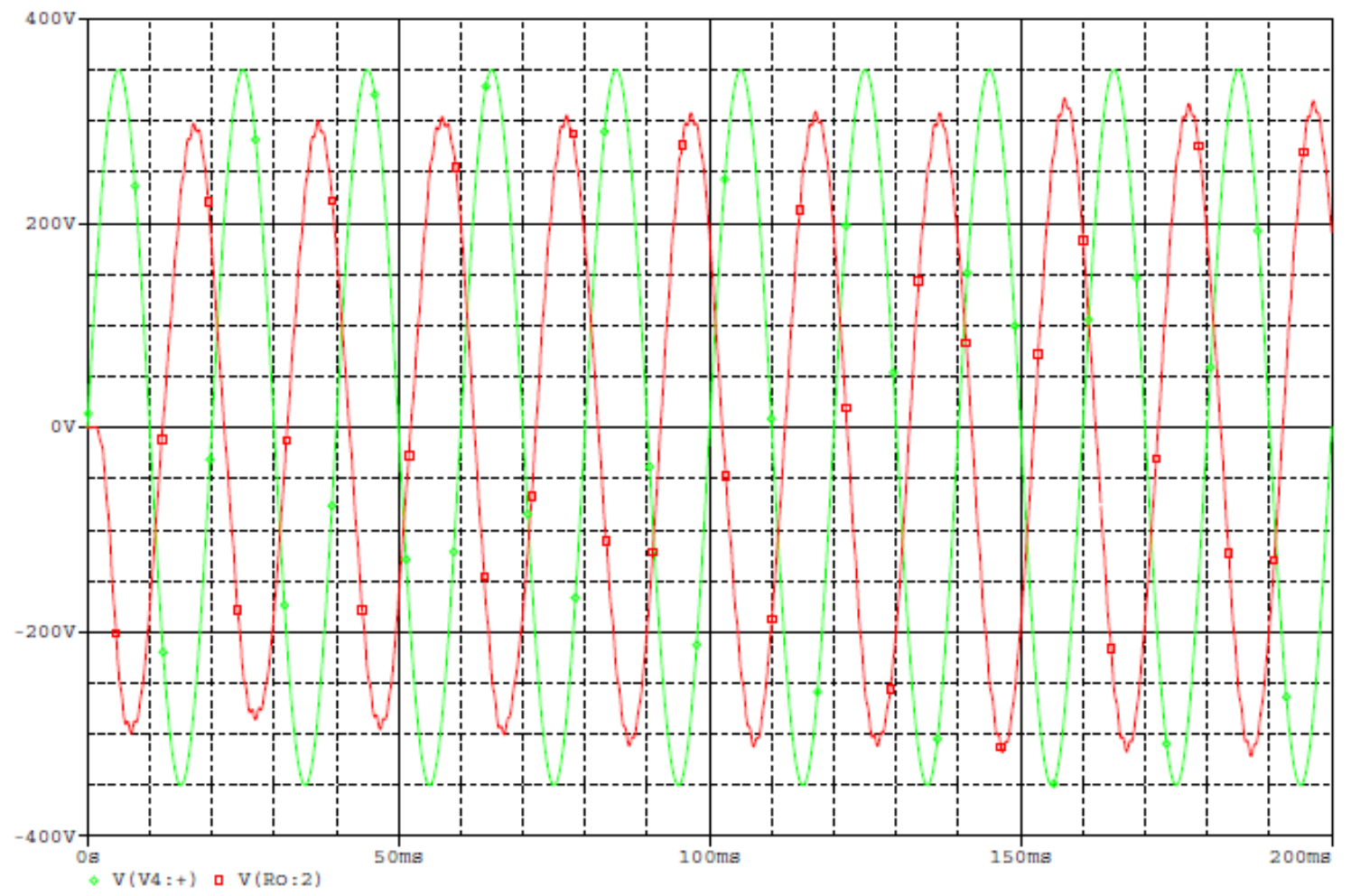

Fig 4.26: Input and output voltage waveforms, when input voltage $350 \mathrm{~V}$ $\mathrm{V}(\mathrm{V} 4:+)$ : Input voltage $=350 \mathrm{~V}$ and $\mathrm{V}(\mathrm{R} 0: 2):$ Output voltage $=300 \mathrm{~V}$

\subsection{HARMONICS ANALYSIS OF PROPOSED AUTOMATIC CONTROLLED AC CÛK REGULATOR}

Harmonics analysis is essential to understand the performance of a regulator. Total harmonics distortion (THD) is one of the components to evaluate the regulator's performance. The following formula [27] is used to analyze the THD values of the proposed automatic controlled AC Cûk regulator.

$T H D \%=\frac{\sqrt{\sum_{h=2}^{h=\infty}\left(M_{h}\right)^{2}}}{M_{1}} \times 100$

Where $M_{h}$ is the magnitude of either voltage or current harmonic component and $M_{1}$ is the magnitude of the fundamental component (either voltage or current). The simulated waveforms of input current, output current and output voltage of the proposed AC Cûk regulator for input voltage $250 \mathrm{~V}$ and for spectrums of corresponding waveform are shown in figures 4.27 and 4.28, respectively. 
The simulated waveforms of input current, output current and output voltage for input voltage $325 \mathrm{~V}$ and for spectrums of corresponding waveform are shown in figures 4.29 and 4.30 , respectively.

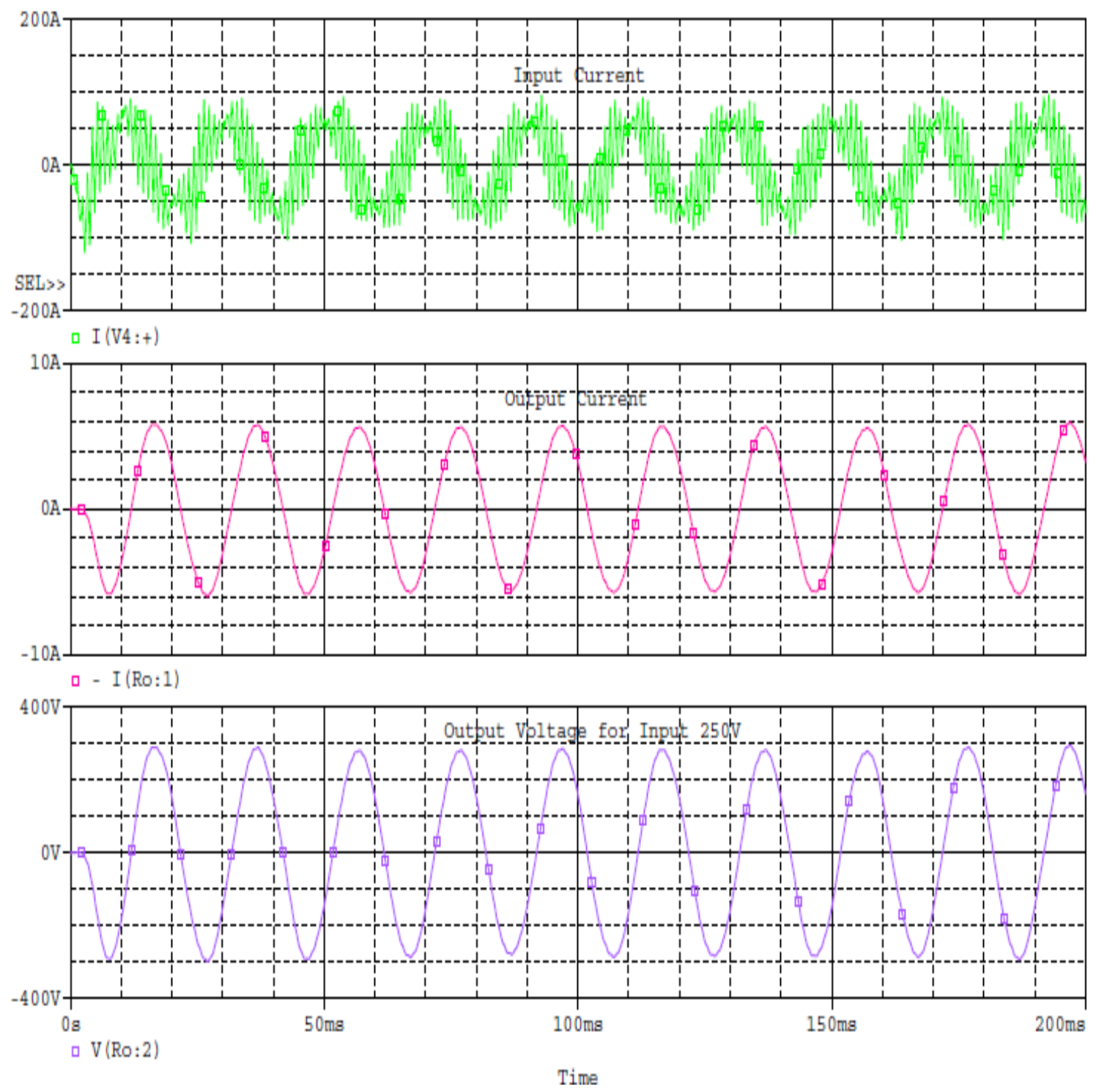

Fig-4.27: Input current, output current and output voltage waveforms when input voltage $250 \mathrm{~V}$ 

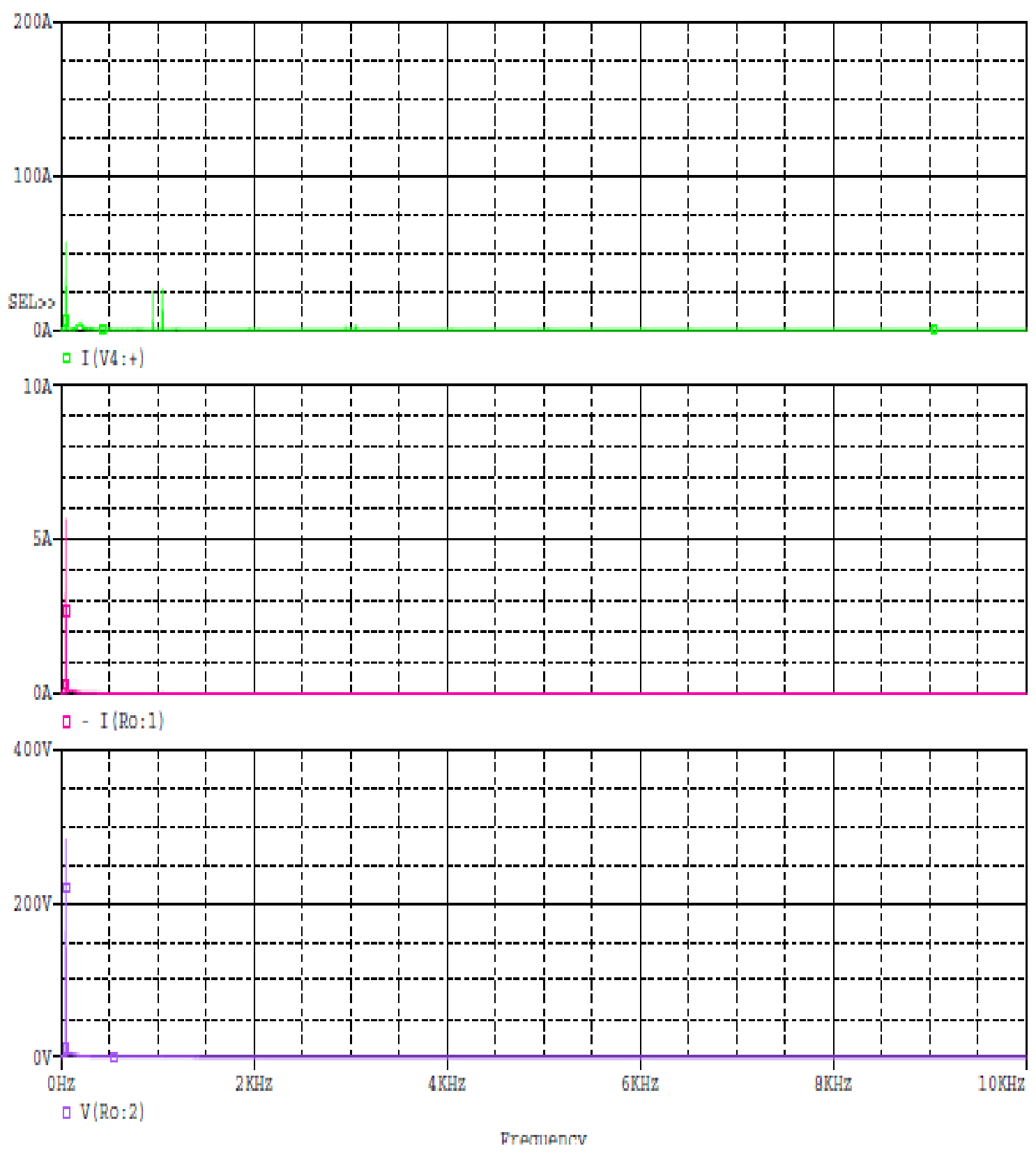

Fig-4.28: Spectrums of input current, output current and output voltage according to figure 4.27 

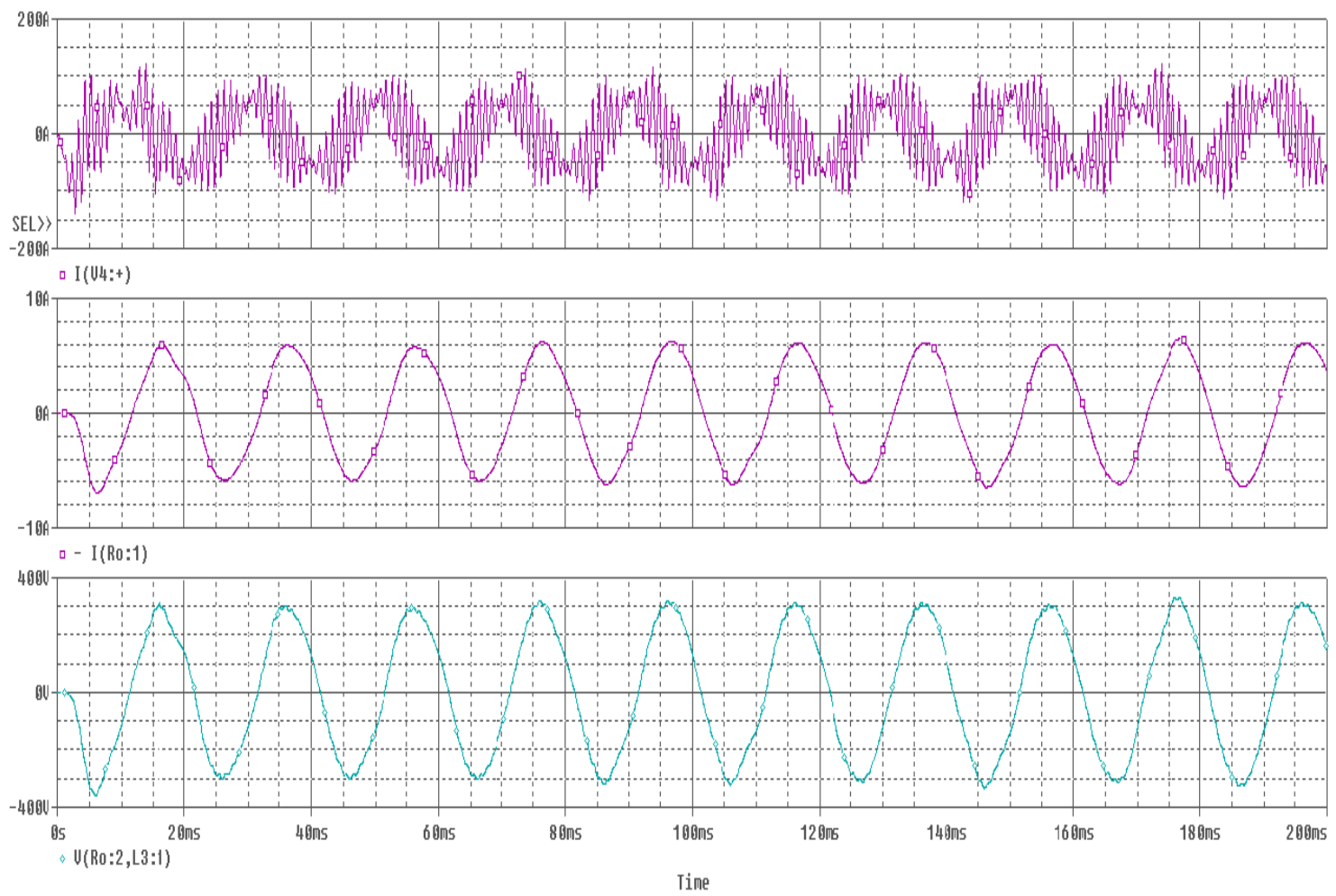

Fig-4.29: Input current, output current and output voltage waveforms when input voltage $325 \mathrm{~V}$

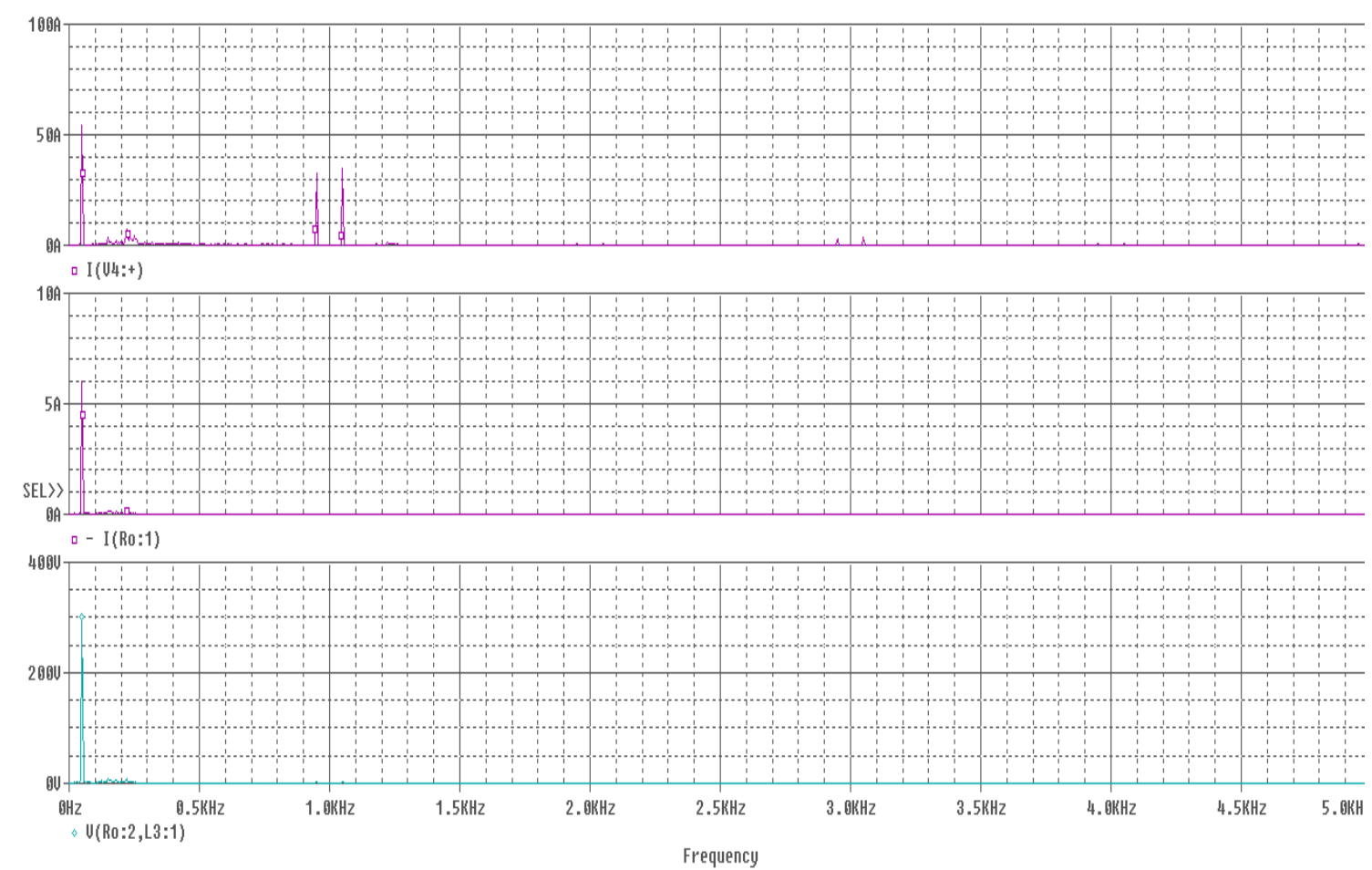

Fig-4.30: Spectrums of input current, output current and output voltage according to figure 


\subsection{HARMONICS ANALYSIS OF AUTOMATICALLY CONTROLLED AC BUCK-BOOST REGULATOR}

Since the objective was to compare a proposed regulator with existing ones, a harmonics analysis of the automatically controlled AC Buck-Boost regulator is essential. The simulated waveforms of input current, output current and output voltage as well as the spectrums of corresponding waveforms of AC Buck-Boost regulator for input voltage $250 \mathrm{~V}$ are shown in figures 4.31 and 4.32 , respectively. The simulated waveforms of input current, output current and output voltage as well as the spectrums of corresponding waveforms for input voltage $325 \mathrm{~V}$ are shown in figures 4.33 and 4.34 , respectively. 
(B) py (active)
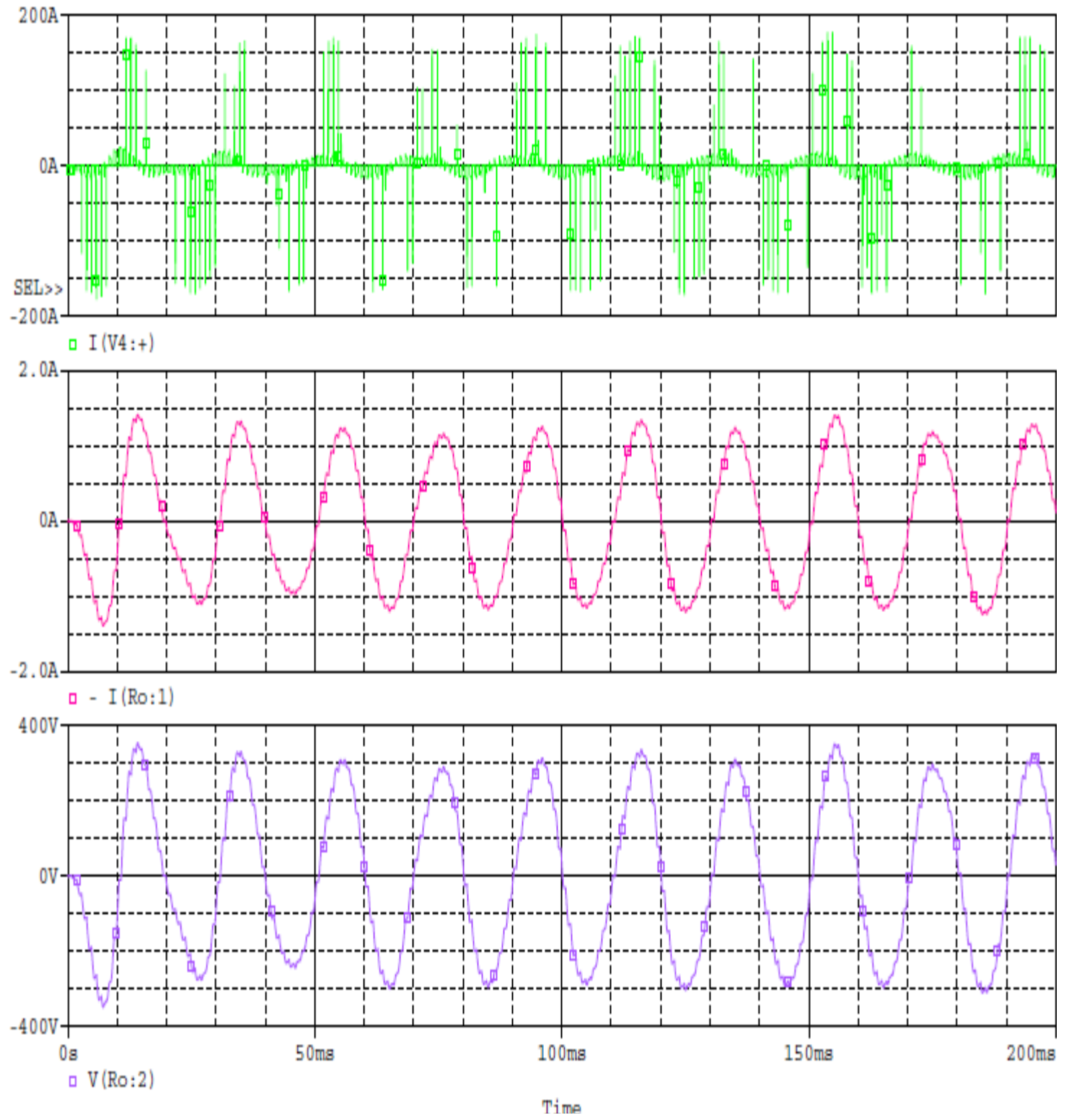

Fig-4.31: Input current, output current and output voltage waveforms when input voltage $250 \mathrm{~V}$ 

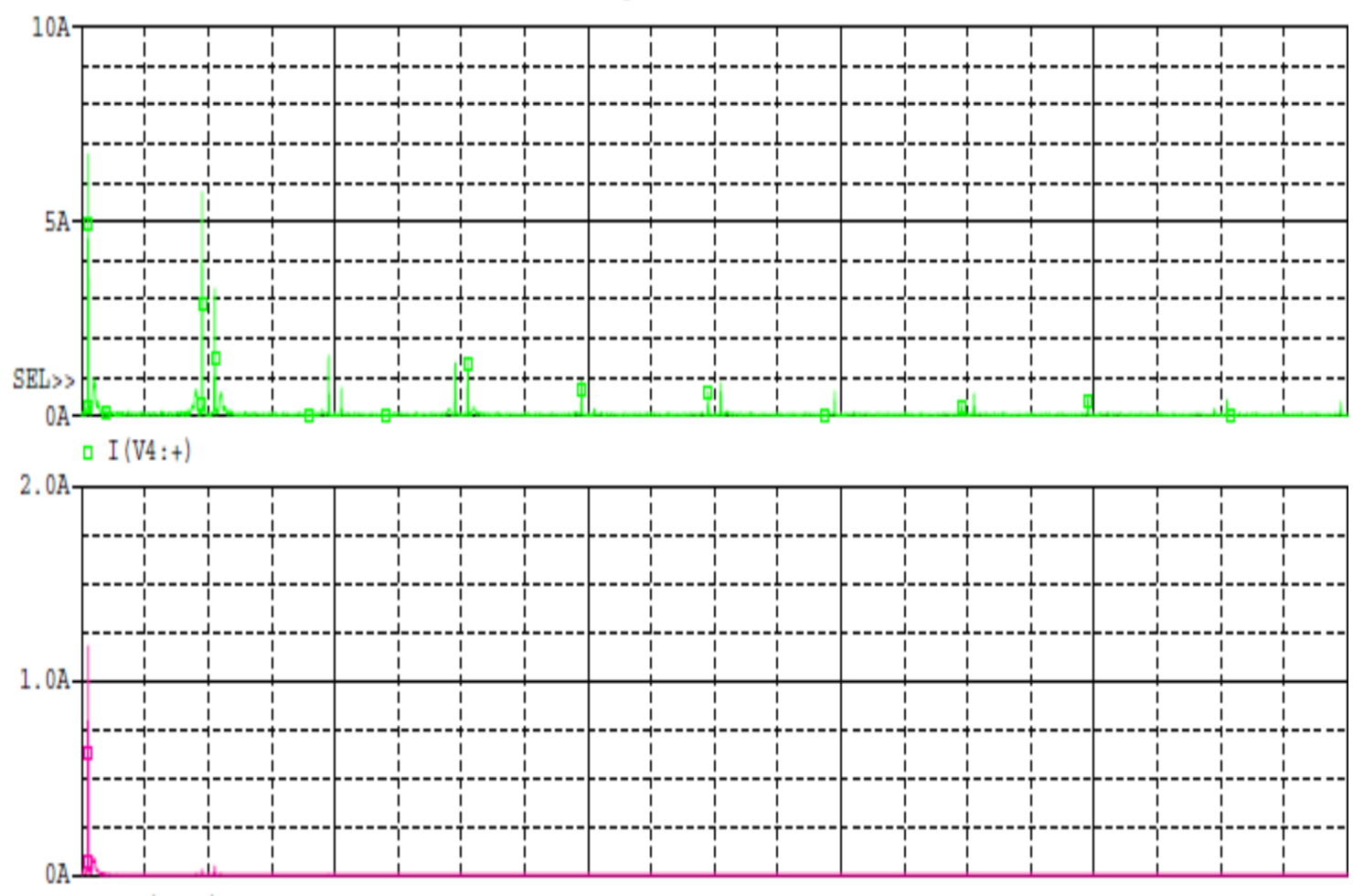

$$
\text { 口 - I (Ro:1) }
$$

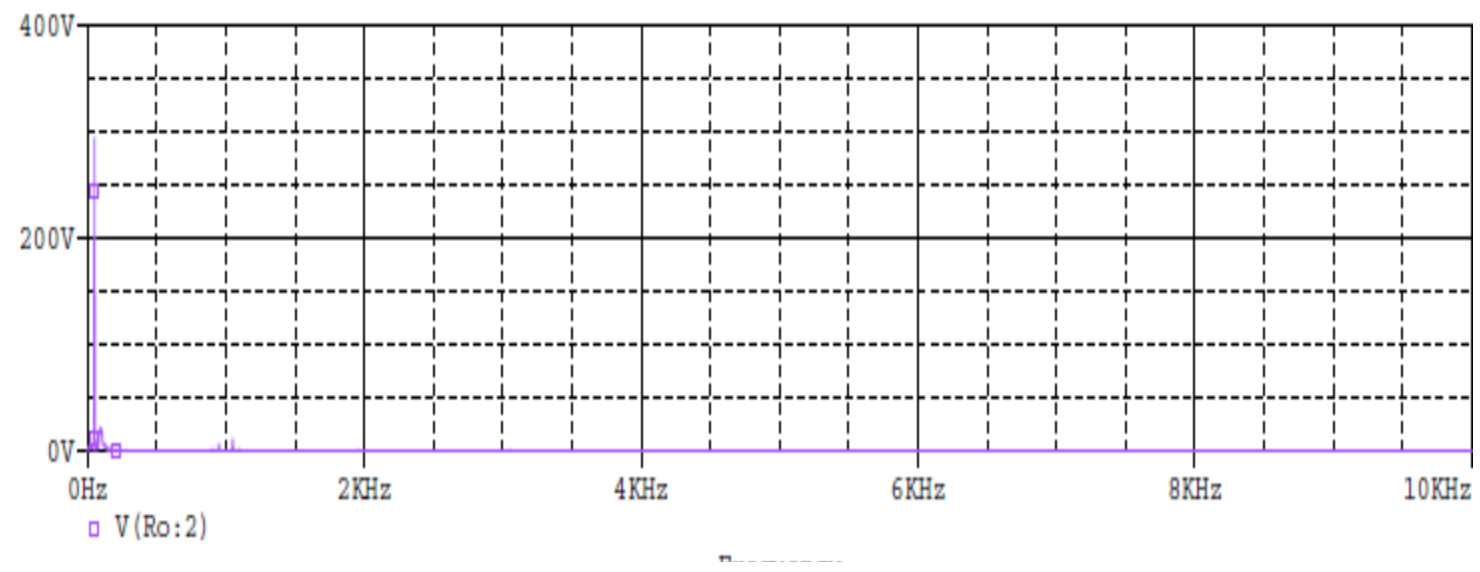

Fig-4.32: Spectrums of input current, output current and output voltage according to figure 4.31 


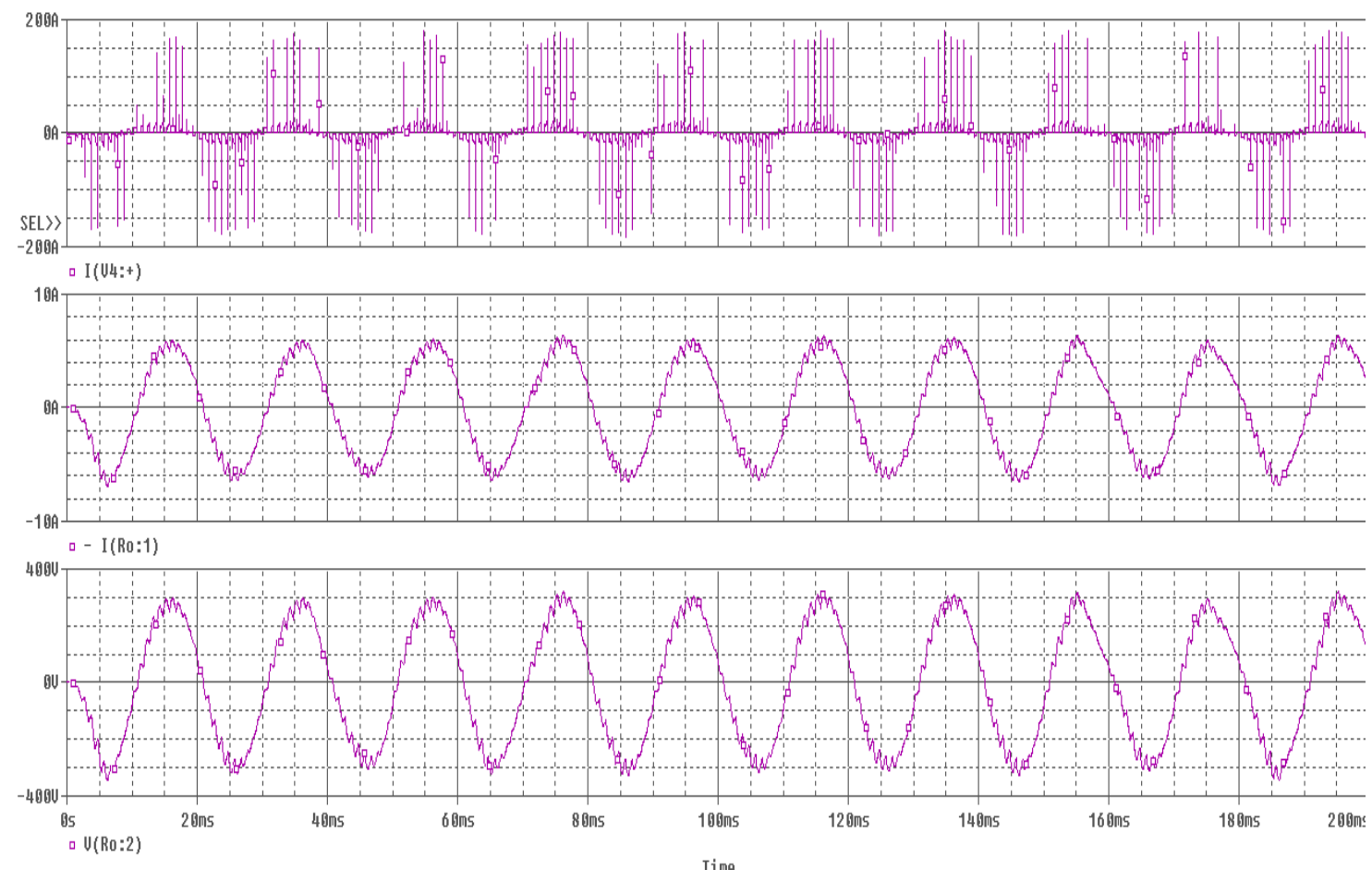

Fig-4.33: Input current, output current and output voltage waveforms when input voltage $325 \mathrm{~V}$
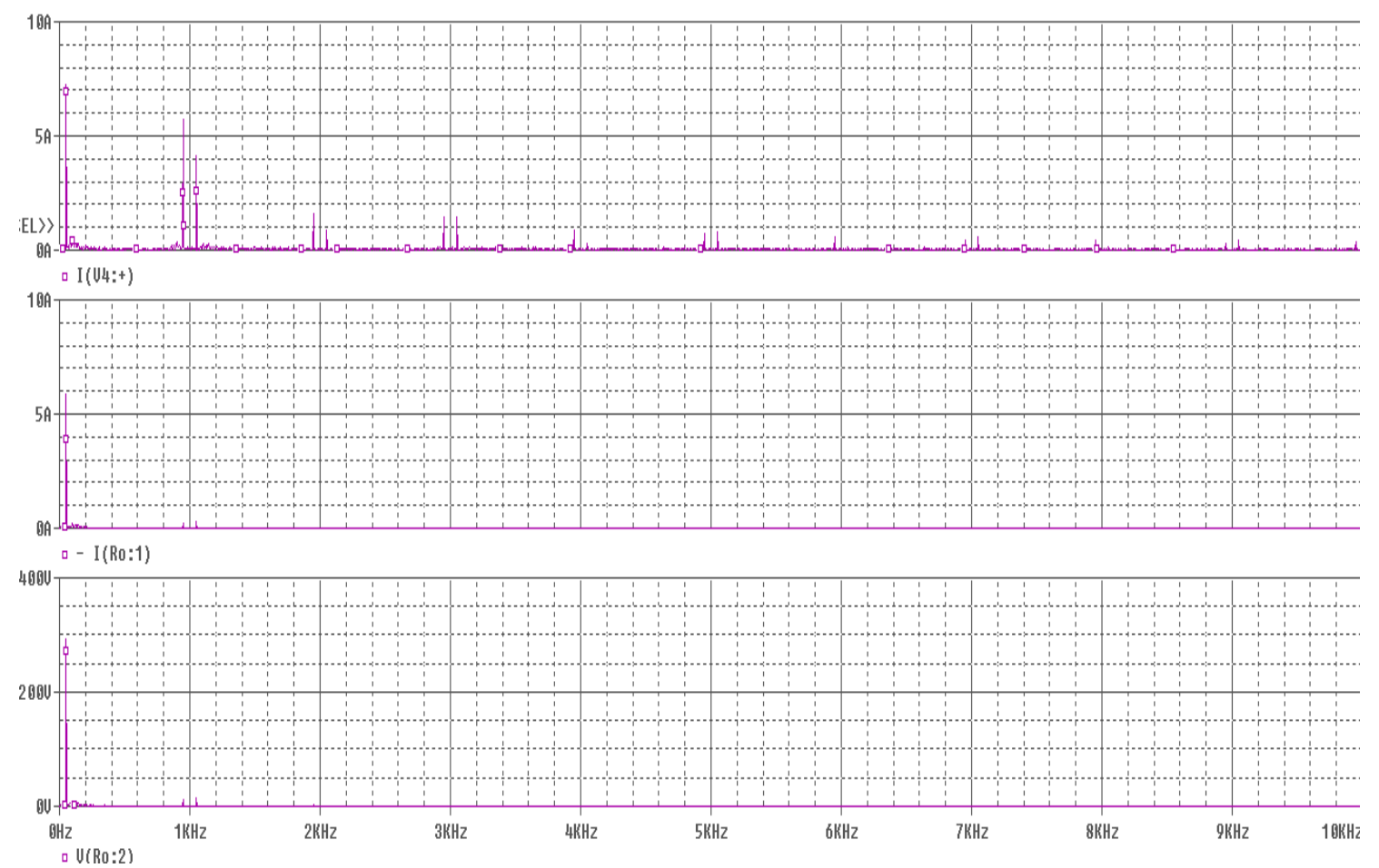

Fig-4.34: Spectrums of input current, output current and output voltage according to figure 4.33 


\subsection{COMPARISON OF RESULTS: PROPOSED AC CûK WITH REVIEWED BUCK-BOOST REGULATOR}

\section{(A) Comparison based on input-output waveforms as input voltage varies from its rated supply voltage $(250 \mathrm{~V}$ to $350 \mathrm{~V})$ :}

The all circuits have been simulated by OrCAD (version 16.1). By comparing figures 2.9, 2.11 and 2.12 for manually controlled AC Buck-Boost regulator with corresponding figures 4.14, 4.15 and 4.16 (for manually controlled AC CûK regulator), it is evident that output remains constant (300V-peak), with no significant ripple, by using PWM technique in both arrangements.

On the other hand, by comparing figures $2.15,2.16$ and 2.17 ( for automatic controlled AC Buck-Boost regulator) with corresponding figures 4.23, 4.24 and 4.26 (for automatic controlled AC CûK regulator ), it is apparent that output always remains constant (300Vpeak) in both cases. However, the proposed AC Cûk regulator output has better, ripplefree waveforms than the output of the AC Buck-Boost regulator.

\section{(B) Comparison based on harmonics analysis:}

Comparing the waveform of figure 4.27 with corresponding figure 4.31 , it is observed that the input current contains fewer harmonics (spikes) and the output current and output voltage waveforms are all most ripple fee sinusoidal in the proposed automatically controlled AC Cûk configuration, rather than the similarly controlled AC Buck-Boost regulator reviewed earlier.

Furthermore, based on spectrum analysis, according to figure 4.28 with corresponding figure 4.32, it is also observed that input current contains fewer harmonics (spikes) and output current and output voltage waveforms contain almost no harmonic components with the proposed automatic controlled AC Cûk regulator. 
Finally, for both regulators total harmonic distortion (THD) have been calculated based on spectrum analysis, according to figure 4.28 and figure 4.32 (for input $250 \mathrm{~V}$ in both cases) by using the formula in equation (4.1).

The calculated THD values are:

$\operatorname{THD} \%=\frac{\sqrt{\left([4.10) \Sigma^{2}+\left([2.12) \Sigma^{2}+(1.06)^{2}+(0.567)^{2}\right.\right.}}{4.80} * 100=103.64 \%$

(For AC Buck-Boost Regulator)

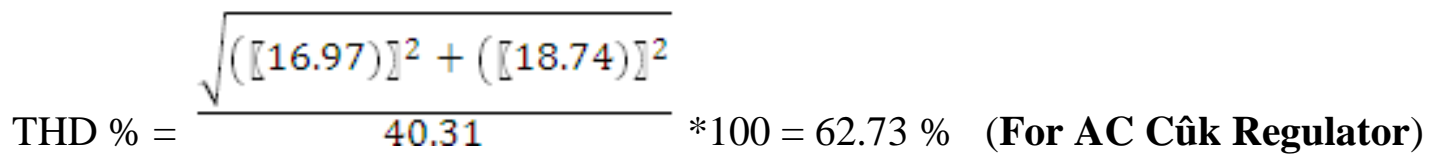

So, according to input-output waveforms, harmonics as well as THD values, it can be concluded that the performance of the proposed AC Cûk regulator is superior to the reported AC Buck-Boost regulator [8]. 


\section{CHAPTER-5}

\section{CONCLUSION AND RECOMMENDATION}

\subsection{CONCLUSION}

The quality of voltage and current of power system is one of the most important considerations in domestic, industrial and commercial applications today. Voltage sags are one of the chief power quality problems affecting domestic, industrial and commercial customers. Voltage sag is the momentary decrease or increase in the voltage magnitude, usually caused by faults or sudden loading within the power system. As the complexity of equipment used in modern industrial plants increases, that equipment is increasingly sensitivity to voltage fluctuations. If the output voltage remains constant equipment life increases while outages and maintenance are reduced. Advances in power semiconductor devices are making it possible for utilities to use a variety of power control equipment to raise power quality levels to meet the requirements.

An essential feature of efficient electronic power processing is the use of semiconductor devices in a power supply, in switch mode, to control the transfer of energy from source to load through the use of pulse width modulated (PWM) techniques. Inductive and capacitive energy storage elements are used to smooth the flow of energy while keeping losses at a minimum. As the frequency of the switching increases, the size of the capacitive and inductive elements decreases in a direct proportion. Because of their superior performance the SMPS are replacing conventional linear power supplies. This work has proposed a switch mode AC voltage regulator for AC power application. The function of the proposed AC-AC Cûk regulator is to maintain constant output voltage given fluctuations of input voltage, within certain limits. First, a manually controlled AC Cûk regulator is developed and its performance analyzed. After that, an automatically controlled AC Cûk voltage regulator circuit is developed, and its performance undergoes a detailed analysis. Finally, the performance of AC Cûk regulator is compared with Buck-Boost regulator that had been reviewed. In the controlled AC Cûk regulator when 
input voltage is varied from $250 \mathrm{~V}$ to $350 \mathrm{~V}$ then output voltage is always maintained at $300 \mathrm{~V}$ (peak value). To maintain constant output voltage PWM control is used. By varying the duty cycle through automatically electronic control circuit, we have achieved the goal of maintaining the constant output voltage across load.

The simulation results reported in this project shows that the AC-AC switching voltage regulator to correct voltage sag by using Cûk converter topology achieves better performance. The output voltage and output current of the proposed AC Cûk regulator are smooth sinusoidal waveforms. It gives more ripple - free output compared to existing components [8]. The input current waveforms are also sinusoidal as well compare to reported work. The total harmonic distortion (THD) values of input current are also reduced comparatively from $103.64 \%$ to $62.73 \%$.

The proposed AC Cûk regulator circuit shows promising aspects in moving towards a practical, lightweight, efficient and reliable AC voltage regulator. It is hoped that the presented work will provide useful guidelines and reference point for future researchers and Engineers to construct a "high performance" AC voltage regulator.

\subsection{RECOMMENDATION FOR FUTURE WORK}

The reported simulation results provided in this paper show feasibility of AC-AC switching voltage converter to correct voltage sag by using Cûk regulator topology. To obtain better output and performance further investigation and more research and development are needed concerning this arrangement. The input current of proposed AC Cûk regulator is very high and needs to be reduced by further research. In addition to this, some essential future areas are also recommended: proper selection of switching frequency to minimize losses, developing formulas (procedure) for considering the right choice of passive elements and developing proper feedback control circuit as per output requirements.

In addition, researchers should examine replacing the control circuit by commercially available SMPS chip and compare the results. Other aspects include efficiency 
calculations to achieve the goal, proper design of output and input filter to minimize ripple and harmonics and more attention to total harmonics distortion (THD) to meet standards, such as IEEE-519 and IEC 1000-3. 


\section{REFERENCES}

1. N. Kutkut, R. Schneider, T. Grant, and D. Divan, "AC Voltage Regulation Technologies," Power Quality Assurance, July-Aug.1997, pp. 92-97.

2. D. Divan, P. Sutherland, and T. Grant, "Dynamic Sag Corrector: A New Concept in Power Conditioning," Power Quality Assurance, Sept.-Oct. 1998, pp 42-48.

3. G. Venkataramanan, B. K. Johnson, and A. Sundaram, "An AC-AC Power Converter for Custom Power Applications," IEEE Trans. Power Delivery, vol. 11, July 1996, pp. 1666-1671.

4. S. M. Hietpas and R. Pecan, "Simulation of a Three-Phase Boost Converter to Compensate for Voltage Sags," in Proc. IEEE 1998 Rural Electric Power Conf, April 1998, pp. B4-1-B4-7.

5. S. M. Hietpas and M. Naden, "Automatic Voltage Regulator Using an AC Voltage - Voltage Converter," IEEE Transactions on Industry Applications, Vol. 36, No. 1. January/February 2000, pp.33-38.

6. M. E. Balci, M. H. Hocaoglu "Effects of Source Voltage Harmonic Distortion on Power Factor Compensation in Triac Controlled AC Chopper Circuits," International conference on PEDS, Vol. 2, Nov., 2005, pp. 1199 - 1204.

7. C. Chen and D. M. Divan, "Simple Topologies for Single Phase AC Line Conditioning," IEEE Transactions on Industry Applications, Vol.30, No.2, March/April 1994, pp. 406-412.

8. P. K. Banerjee, M. A. Choudhury and G. T. Rasul, "AC Voltage Regulation by Switch Mode BUCK-Boost Voltage Controller," Journal of Electrical Engineering, IEB, Vol. EE 31, No. I and II. December 2004, pp.27-31.

9. S. Cûk, "Basics of Switched Mode Power Conversion Topologies, Magnetics, and Control," Modern Power Electronics: Evaluation, Technology, and applications, Edited by B.K. Bose, IEEE Press, 1992, pp.265-296.

10. M. H. Rashid, Power Electronics - Circuits, Devices, and Applications, Prentice Hall India, Second Edition, 2000. 
11. M. R. Ahmed and M. J. Alam, "Design of a Switch Mode AC Voltage Regulator with Improved Performance," The 2nd IEEE International Conference on Power Electronics, India, December 2006, pp. 203-207.

12. N. A. Ahmed, K. Amei and M. Sakui, "Improved Circuit of AC Choppers for Single-Phase System," Proceedings of the IEEE Conference PCCON, vol.2, 2010, pp. 907-912.

13. N. A. Ahmed, K. Amei and M. Sakui, "A New Configuration of Single Phase Symmetrical PWM AC Chopper Voltage Controller," IEEE Transactions on Industrial Electronics, vol. 46, no. 5, October 1999, pp. 942- 952.

14. S. M. Cûk , "Modelling, Analysis and Design of Switching Converter," Ph.D Thesis, California Institute of Technology, Pasadena, California, 1977 (November $29,1976)$.

15. S. Cûk, "Survey of Switched Mode Power Supplies," IEEE International Conference on Power Electronics and Variable Speed Drives, London, 1985, pp. 83-94.

16. B. H. Li, S. S. Choi and D. M. Vilathgamuwa, "Design considerations on the line-side filter used in the dynamic voltage restorer," IEE Proceedings Generation, Transmission, and Distribution, 2001, pp. 1-7.

17. J. Wang, A. Xu, and Y. Shen, "A Survey on Control Strategies of Dynamic Voltage Restorer," 13th International Conference on Harmonics and Quality of Power (ICHQP), September 28 - October 01, 2008, pp. 1-5.

18. J. G. Nielsen and F. Blaabjerg, "A Detailed Comparison of System Topologies for Dynamic Voltage Restorers", IEEE Transactions on Industry Applications, vol, 41, no. 5, 2005, pp. 1272-1280.

19. Z. Ling, and L. Lei, "Isolated Cûk Three-Level AC-AC Converter", The 5th IEEE Conference on Industrial Electronics and Applications, ICIEA, 2010, pp.10121017.

20. J. Hoyo, H. Calleja, and J. Alcala, "High-quality output PWM AC voltage regulator based on Cûk converter," International Journal of Electronics, Vol.92, No.4, April 2005, pp. 231-242. 
21. V. Nazquez, A. Velazquez, C. Hernandez, E. Rodríguez and R. Orosco, "A Fast AC Voltage Regulator," (CIEP 2008). IEEE 11th International Power Electronics Congress, August 2008, pp.162-166.

22. J. Nan, T. Hou-jun, L. Wei and Y. Peng-sheng, "Analysis and control of BuckBoost Chopper type AC voltage regulator," IPEMC'09. IEEE 6th International Power Electronics and Motion Control Conference, May 2009, pp. 1019-1023.

23. A. V. Nazquez and C. Hernandez, "AC Voltage Regulator Based on the AC-AC Buck-Boost Converter," ISIE 2007. IEEE International Symposium on Industrial Electronics, June 2007, pp. 533-537.

24. Jose-Maria Flores-Arias, A. Moreno-Muñoz, F. Domingo-Perez, V. PallaresLopez, D. Gutierrez, "Voltage Regulator System Based on a PWM AC Chopper Converter," ISIE 2011. IEEE International Symposium on Industrial Electronics, June 2011, pp. 468-473.

25. R. Ithaya and V. Ponselvan, "Analysis and Simulation of PWM Controlled BuckBoost AC Voltage Regulator," International Journal for Research and Development in Engineering (IJRDE), Vol.1, No.2, October-November 2012, pp. 28-36.

26. P.C. Sen, Power Electronics, Tata McGraw-Hill Publishing Company Ltd., India, 1987.

27. B. T. Lin and Y. S. Lee, "Power Factor Correction using Cúk Converters in discontinuous capacitor voltage mode operation," IEEE Trans. on Industrial Electronics, vol. 44, no. 5, October 1997, pp. 648-653.

28. M. R. Ahmed, Ruma and M. J. Alam, "Improvement of Input Side Currents of Three Phase Rectifier Using Cúk Converter in Discontinuous-CapacitorVoltage Mode Operation," IEEE International Conference on Power and Energy (PECon 08), Malaysia, December 2008, pp. 1152- 1155.

29 R. Thompson, "A Thyristor Alternating Voltage Regulator," IEEE Trans. on Ind. and Gen. Application, vol. IGA 4 (1968) 2, pp. 162-166.

30. N. Mohan, T. M. Undeland and W. P. Robbins, Power Electronics- Converters, Applications, and Design, John Wiley and Sons Inc., Second ed., 1995. 
31. T. M. Undeland, "Switching Stress Reduction in Power Transistor converters," IEEE Industrial Application Society Conference Proc., 1976, pp. 383-392.

32 . T. M. Undeland, F. Jenset, A. Steinbakk, T. Rogne, and M. Hernes, “ A Snubber Configuration for Both Power Transistors and GTO PWM Converters," Power Electronics Specialists Conference Proc., 1984, pp. 42-53.

33. OrCAD Software, Release 16.1, OrCAD, 2012, Inc., U.S.A. 